الكرب النفسي، والدعم الاجتماعي في ضوء بعض المتغيرات لدى مريضات لدعم سرطان النّي الثدي

\author{
إعداد \\ د/ عبدالله بن احمد الزهراني \\ أستاذ علم النفس المشارك- قسم علم النفس - كلية التربية - \\ جامعة الملك سعود علمد النمار
}




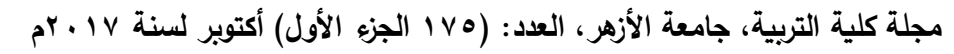

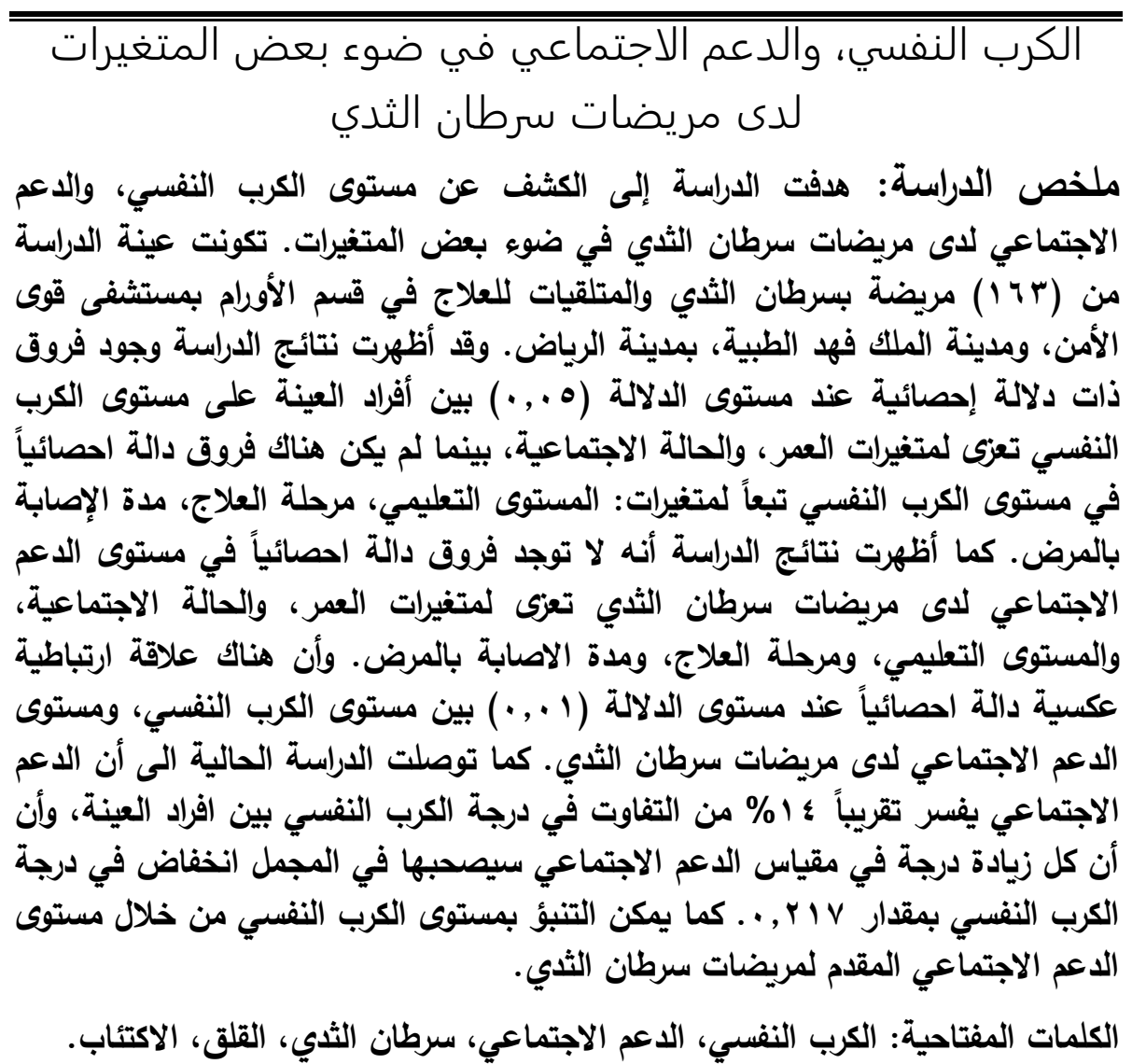

Psychological distress, Social support among Breast

Cancer patients according to some variables

Abstract: The study aimed to detect the level of psychological distress and social support in breast cancer patients in the light of some variables. The study sample consisted of $(\mathbf{1 6 3})$ breast cancer patients receiving treatment in the Oncology Department of the Security Forces Hospital and King Fahad Medical City in Riyadh. The results of the study showed that there were statistically significant differences at the level of significance $(0.05)$ among the sample members at the level of psychological stress due to the variables of age and social status. There were no statistically significant differences in the level of psychological distress according to the variables: educational level, Infection. The results of the study showed that there were no significant differences in the level of social support in breast cancer patients due to the variables of age, social status, educational level, stage of treatment, and duration of the disease. And that there is a statistically significant correlation between the level of 


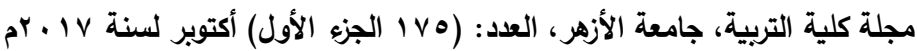

psychological stress and the level of social support in breast cancer patients. The study also found that social support accounts for approximately $14 \%$ of the psychosocial differences in the sample, and that each increase in the social support scale will be accompanied by a total decrease of psychological stress by 0.217 . The level of psychological distress can also be predicted from the level of social support provided to breast cancer patient.

Key words: psychological distress, social support, breast cancer, Anxiety, depression.

$$
\text { مفاهيم الاراسة النظرية: سرطان الثري: }
$$

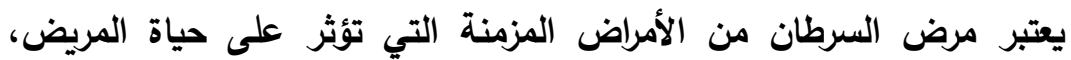

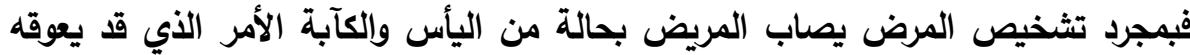

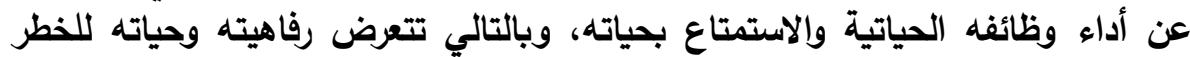

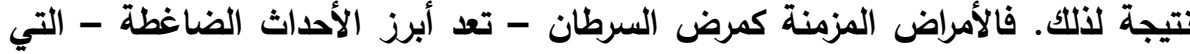

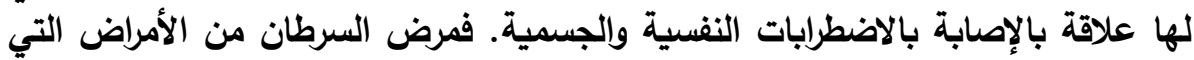
تشكل خطورة على حياة الإنسان ويصيب هذا المرض أي جزي الإنه من أجزاء الجسم، ويحدث

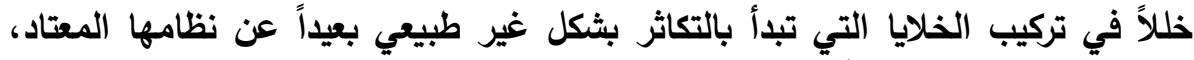

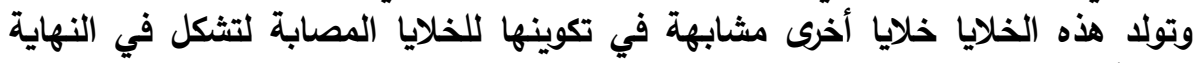

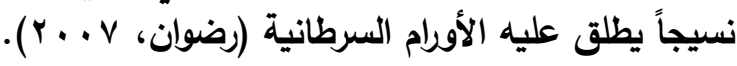

يصنف سرطان الثدي في مقدمة أمراض السرطان المتنوعة، التي تصيب النساء

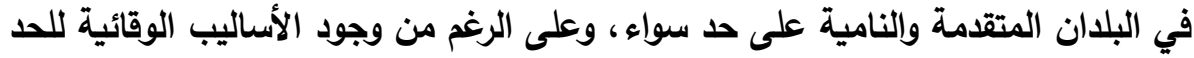

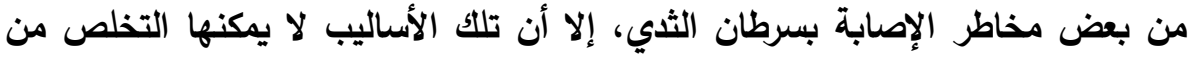
معظم الحالات. إذ توجد حالات لا يجري تثخيصها إلا في مراحل متأخرة (منظمة الصحة

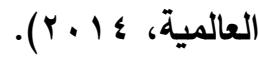

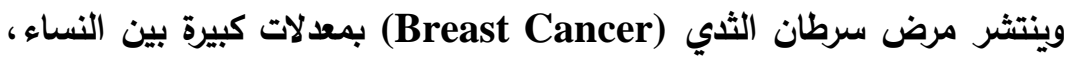

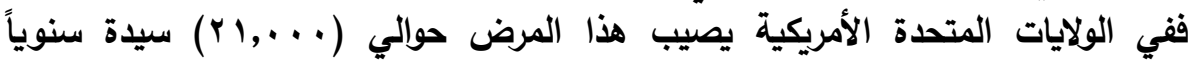
(Nelson et al., 2010)

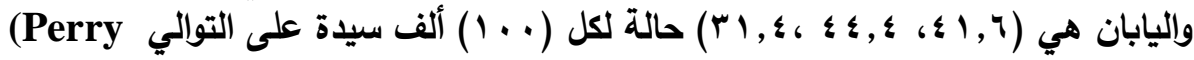
(et al., 2006)

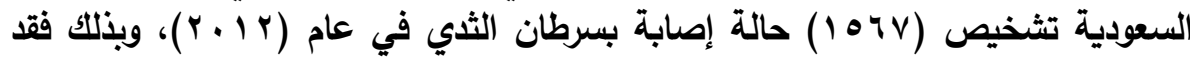

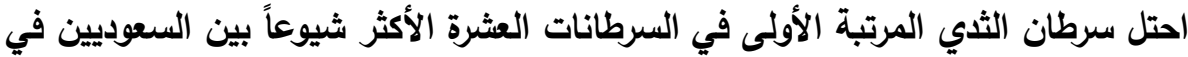

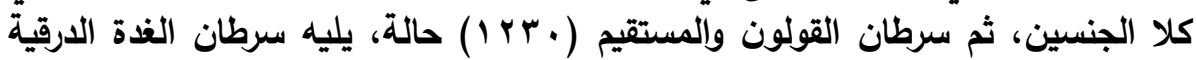




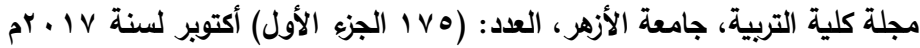

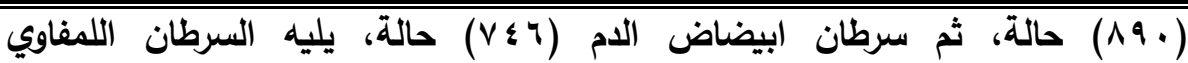

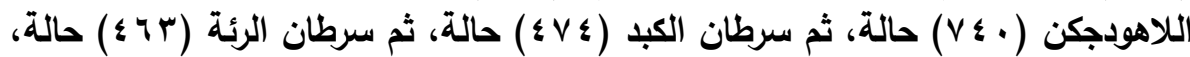

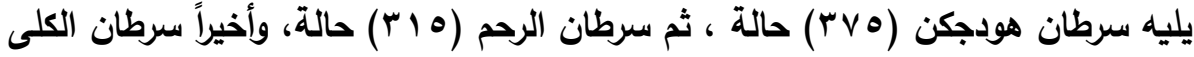

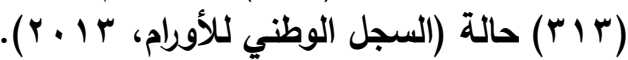

تعرف جمعية السرطان الأمريكية سرطان الثذي بأنها: ورم خبيث يسبب نمواً غير

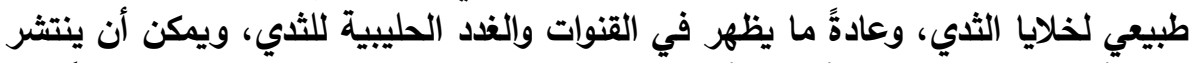

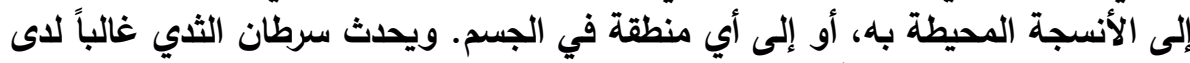
النساء، وقد يحدث أحياناً لاى الرجال (American Cancer Society, 2014).

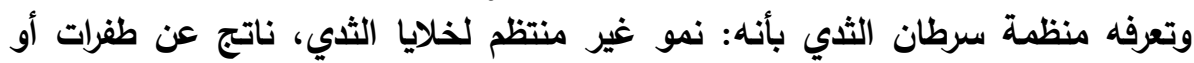
تغيرات غير طبيعية في الجينات المسؤولة عن تنظيم نمو الخلايا والحفاظ على صحته نئها

.(Breast Cancer Organization, 2013)

وللأسف فإنه رغم الجهود الصحية المبذولة لم يتم التوصل الى السبب الرئيسي

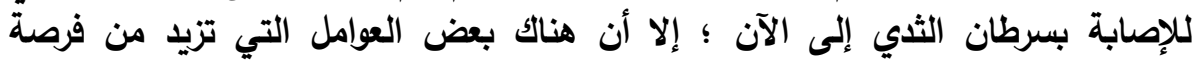

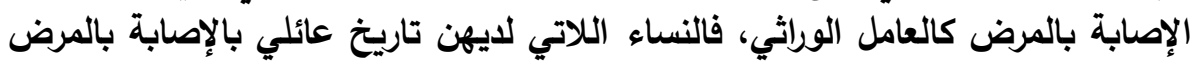

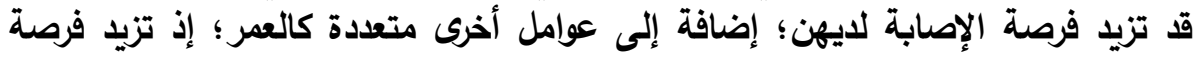

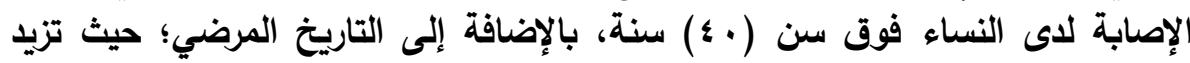

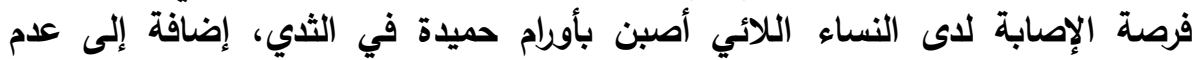

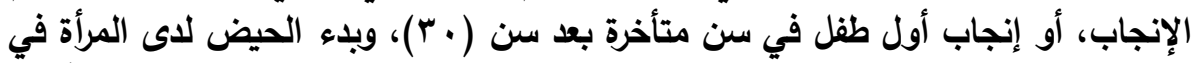

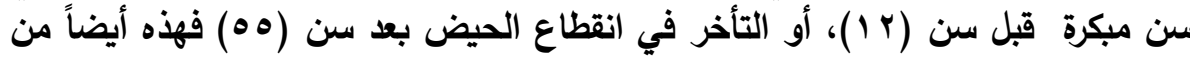

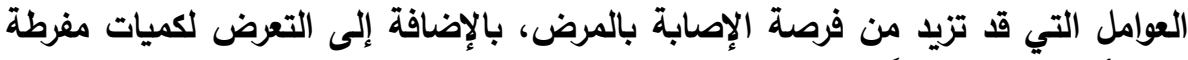

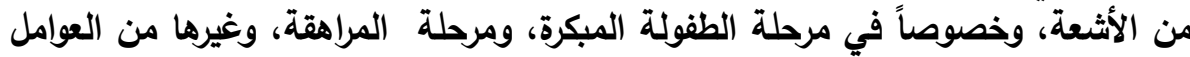

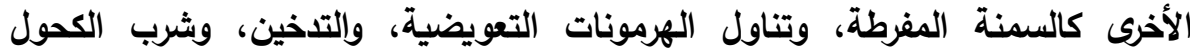

. (Smeltzer, Bare, Hinkle \& Cheever, 2008)

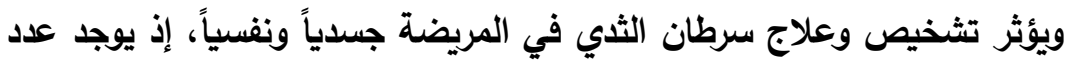

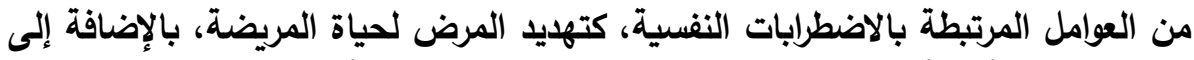

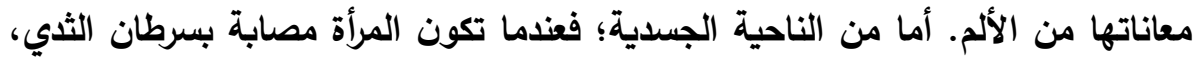

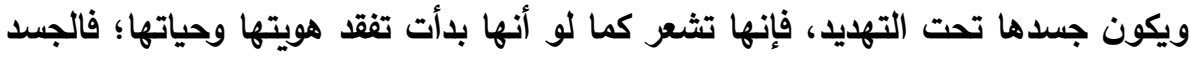

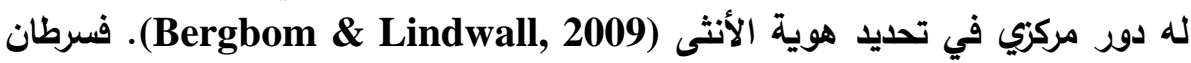

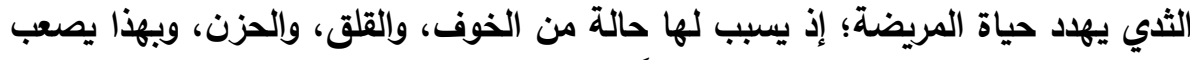

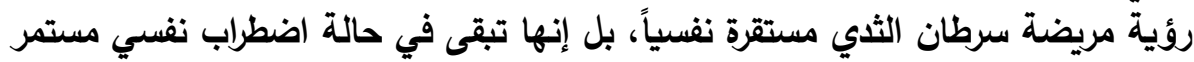

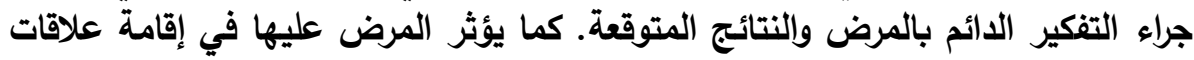

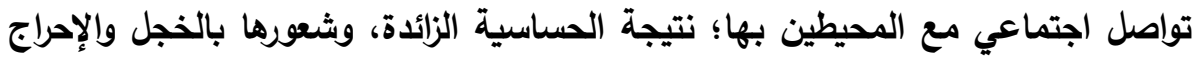




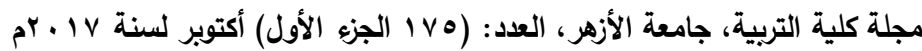

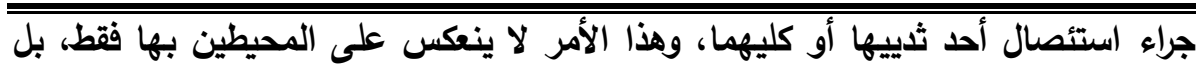

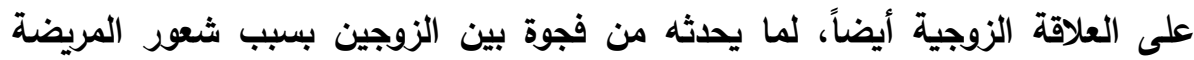

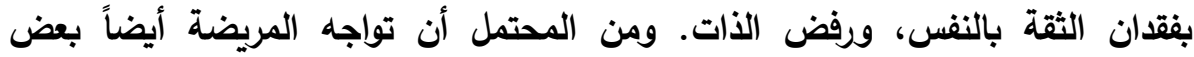

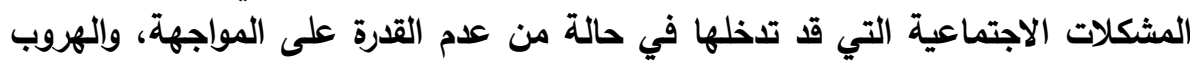

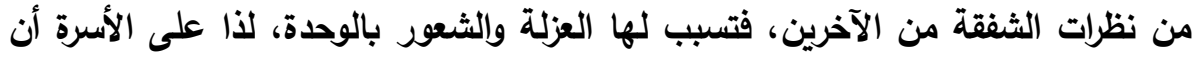

تظهر الاعم والمساندة للمريضة (Kleponis, 2006).

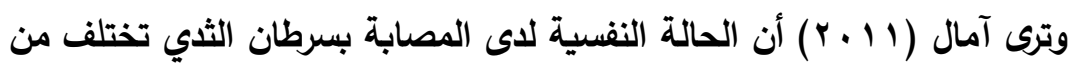

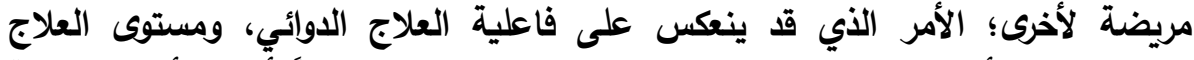

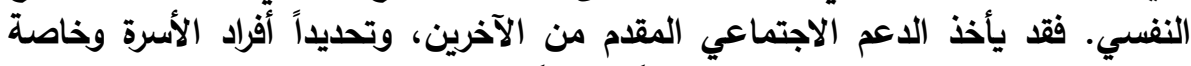

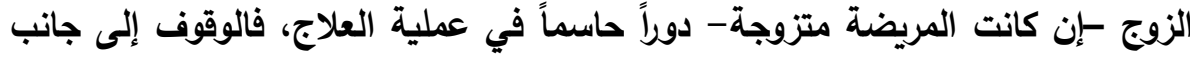

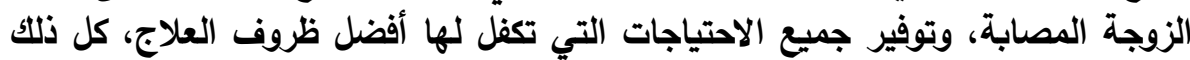
ينعكس بثكل إيجابي على الحالة النفسية للمصابة.

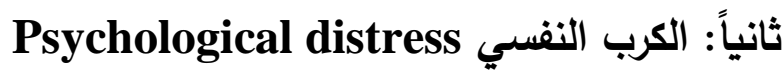

العيش مع الأمراض المزمنة عادة ما يرتبط إلى حد كبير ببعض الاض الاضطرابات

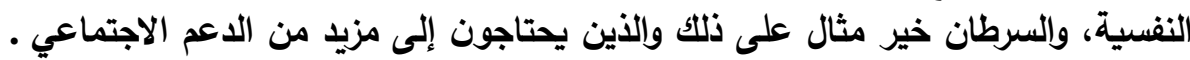
عرفي (Yang et al., 2013; Van't, Trijsburg \& Duivenvoorden, 1997)

مصطلح الكرب من قبل الثبكة الوطنية الأمريكية للسرطان (NCCN) كخبرة وجدانية

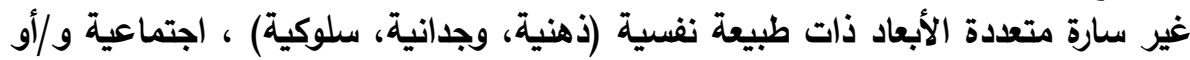

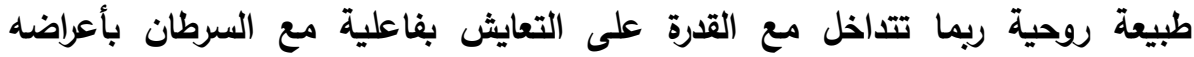

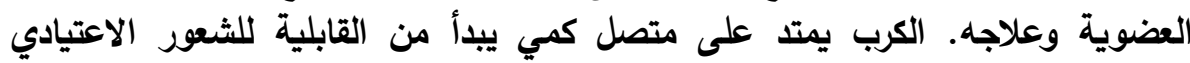

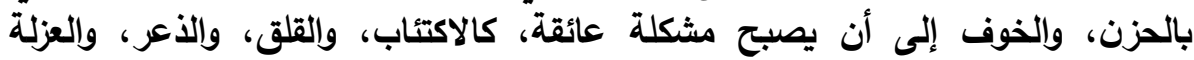
الاجتماعية، والأزمة الروحية (NCCN, 2015).

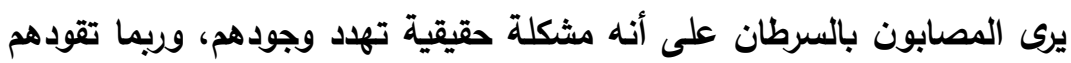

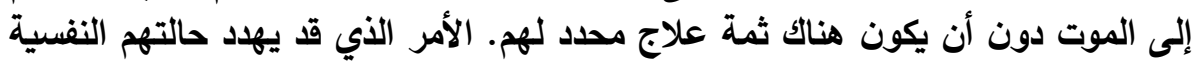

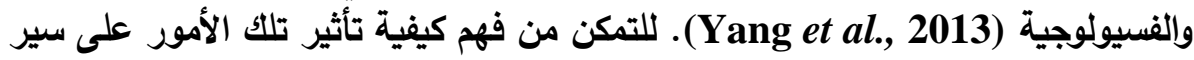

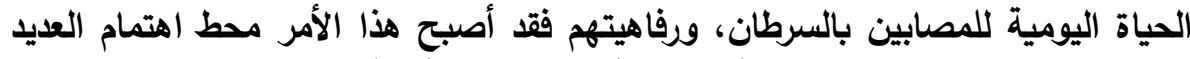

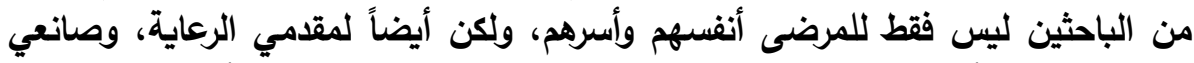

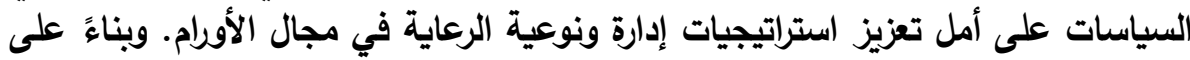

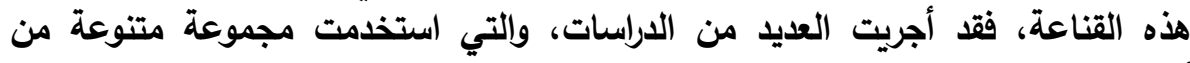

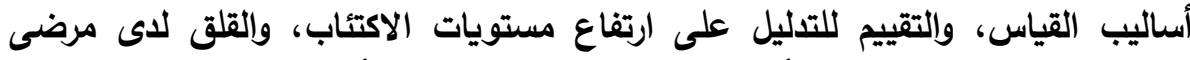

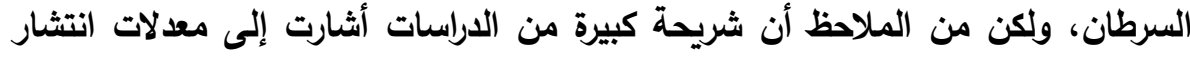

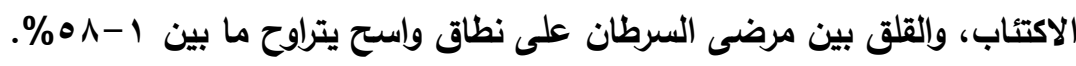




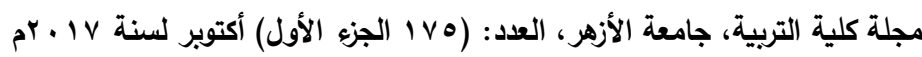

(Hotopf, Chidgey \& Addington, 2002; Mitchell et al., 2011).

ففي العقود الأخيرة من الزمن، فإن مرضى سرطان الثدي قد ارتفعت فرص بقان فيائهم

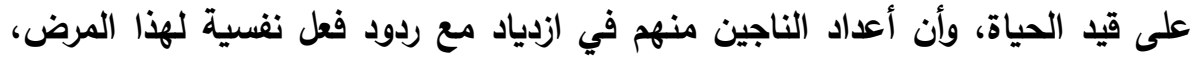

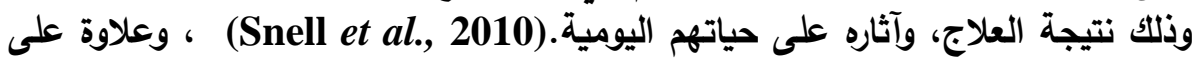

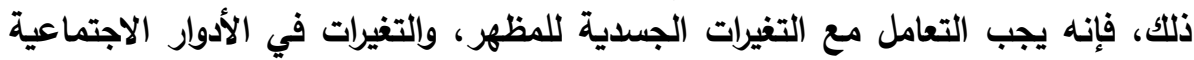

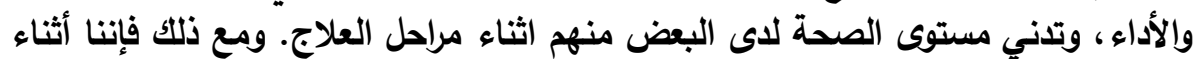

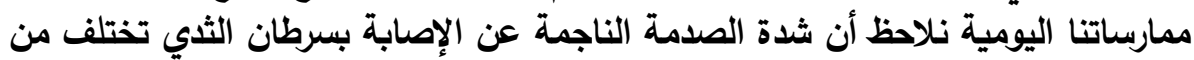

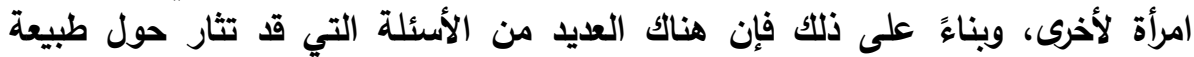

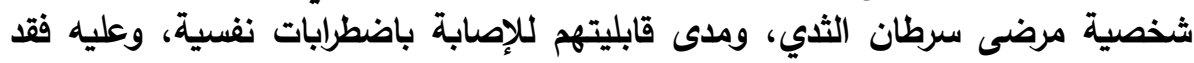

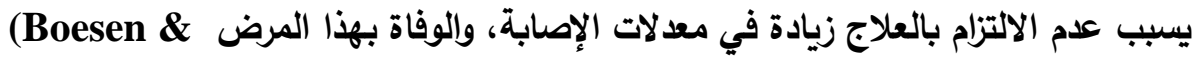

.Johansen, 2008; Coyne, Hanisch \& Palmer, 2007)

اشارت بعض الدراسات إلى أن دول شرق آسيا ذات الاخل المنخفض توجه

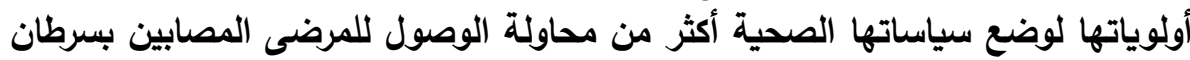

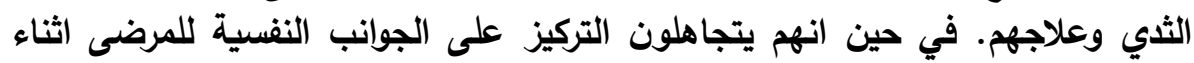

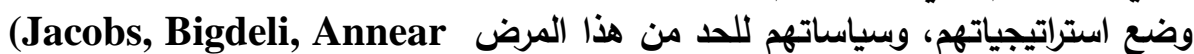

\& Van Damme, 2012)

قد يواجه مرضى سرطان الثدي مجموعة واسعة من الأعراض الجسدية، والنفس التفاء

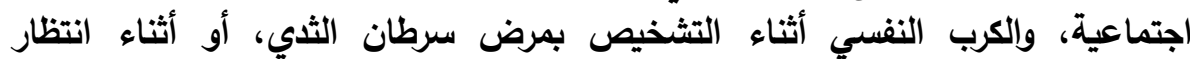
التشخيص، أو اثناء العلاج. ففي هذا السياق أجرى ليو وآخرون (Liao et al., 2015)

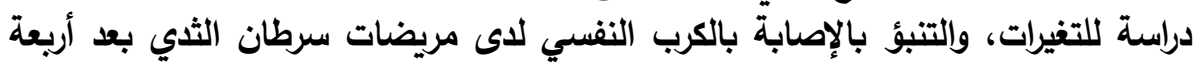

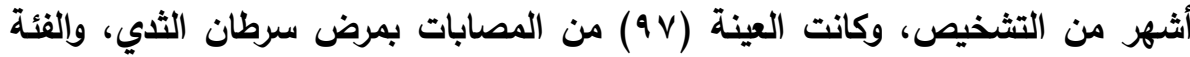

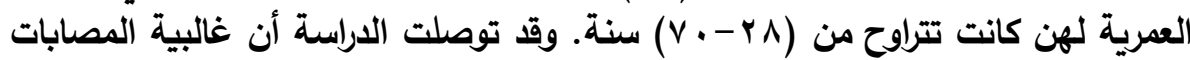

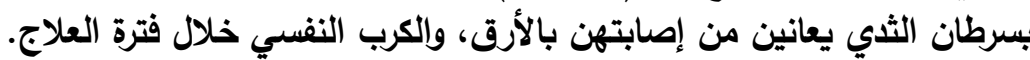
وفي دراسة أخرى قام بها مفيل (Mphil et al,. 2015) هدفت الى دراسة مدى الثى

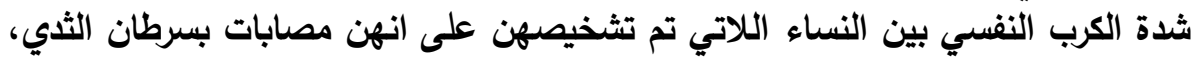

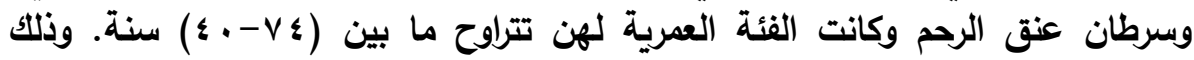

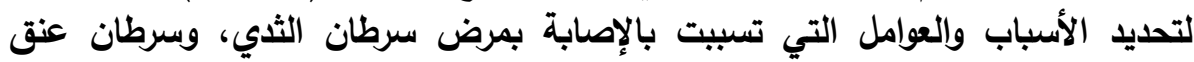

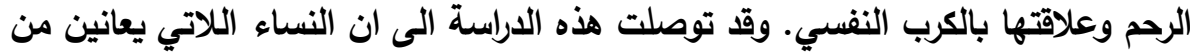

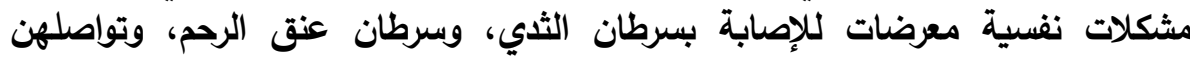

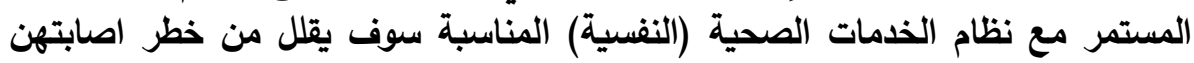
بهذا النوع من الأمراض. 


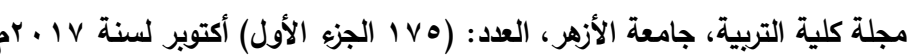

كما م هدفت دراسة

(Jorgensen, Garne, Sogaard \& Laursen, 2015)

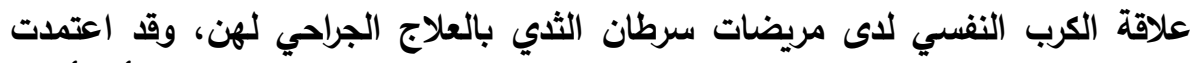

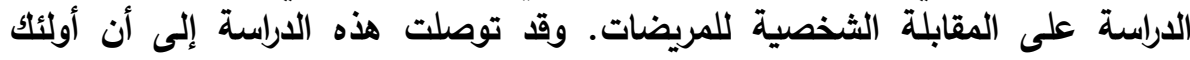

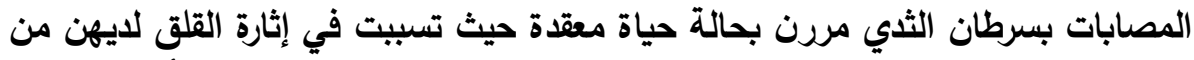

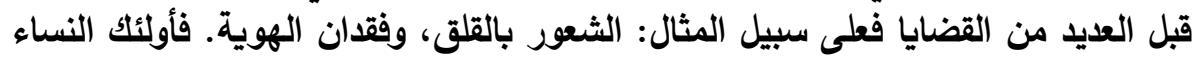

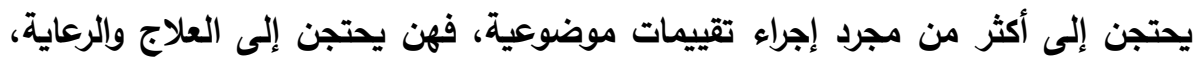
واللذان يسهمان في تحسن حالتهن الصحية.

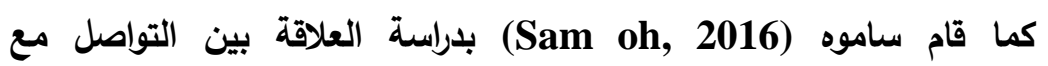

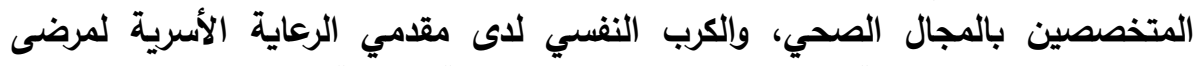

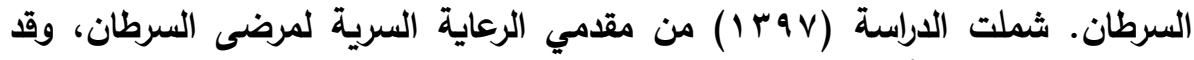

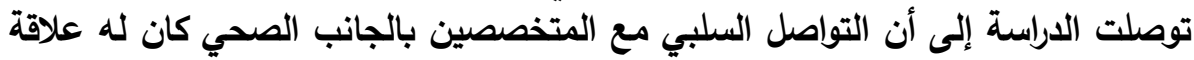

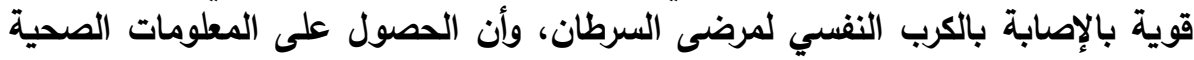

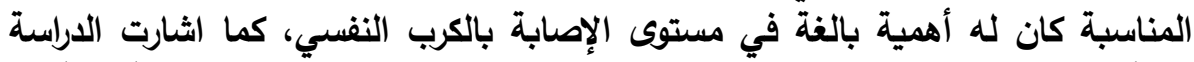

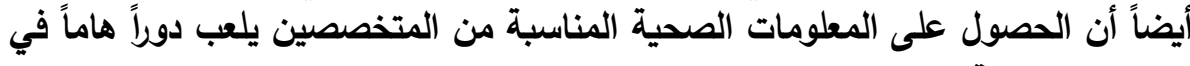

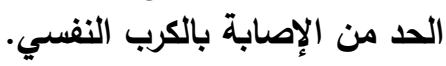

أجرى كاسولز قروا، فيفز، فونتا، وأوشوا Casellas-Grau, Vives, Fonta) \& Ochoa, 2016)

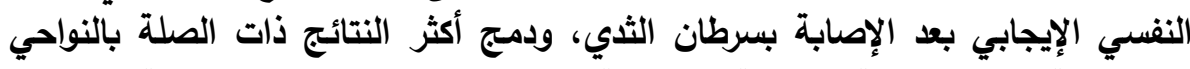

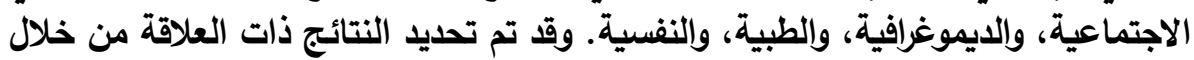

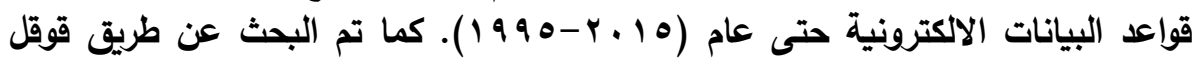

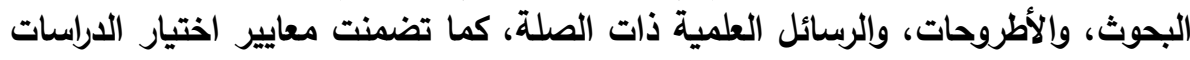

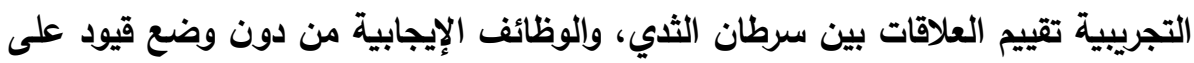

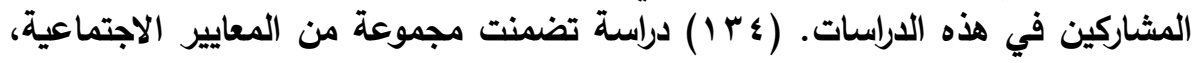

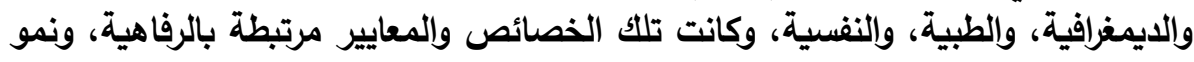

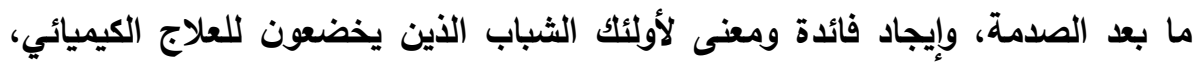

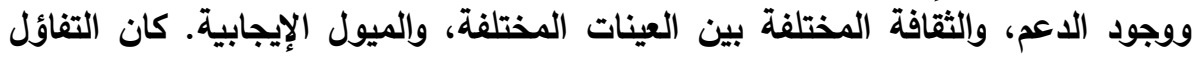

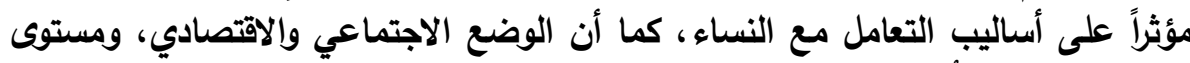

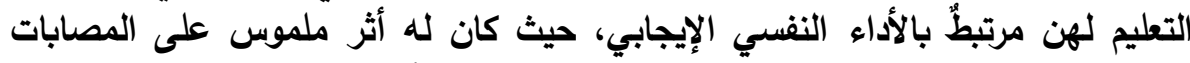

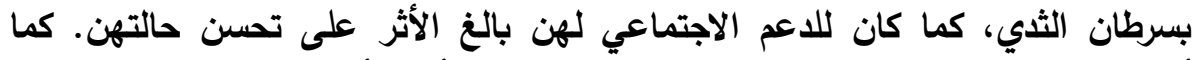

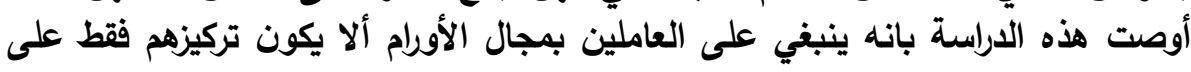

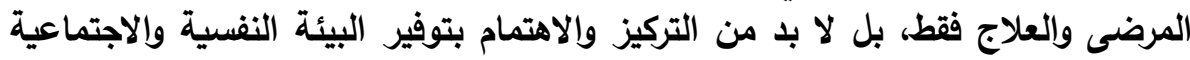

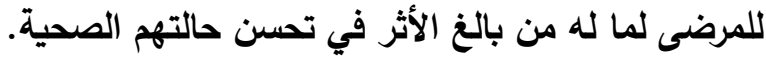
- rrq - 


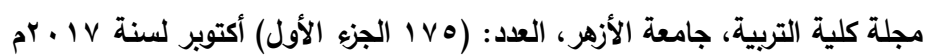

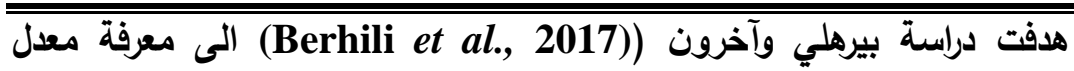

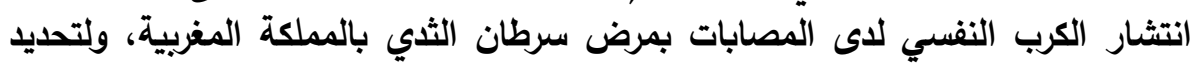

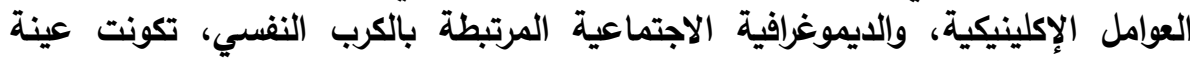

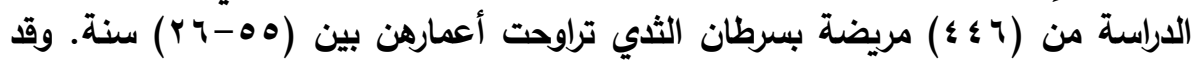

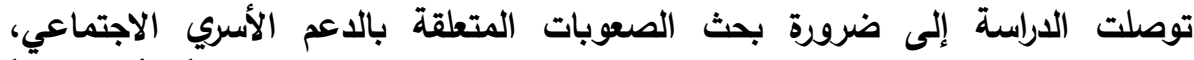

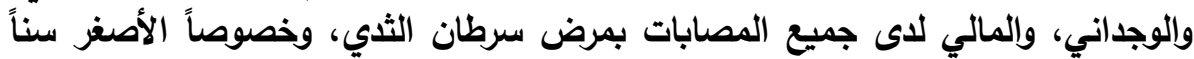

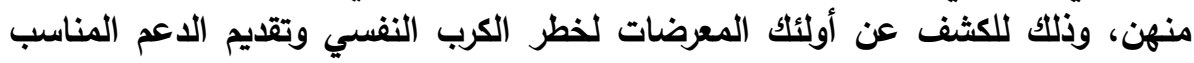
لـن

ومما سبق يتضح لنا أن معظم الدراسات السابقة التي تناولت موضوع سرطان

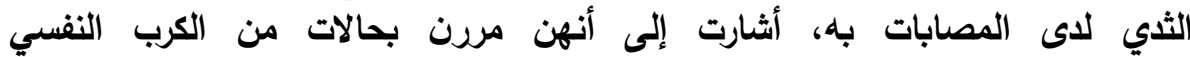
(Jorgensen, Garne, Sogaard \& Laursen, 2015; Mplil, 2015; Sam كما أن بعض المصابات بمرض سرطان الثدي يعانين oh, 2016; Liao et al., 2015) ثالثاً:

من القلق النفسي، والاكتئاب (Yang,et al., 2013). Social Support الاعم الاجتماعي الاعيكي

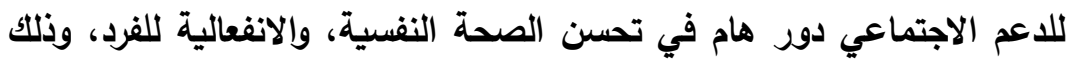

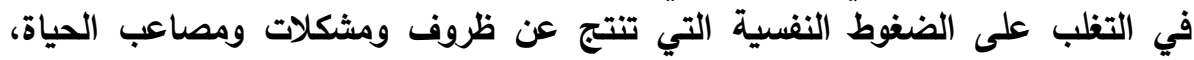
وكذلك يحقق الاستقرار النفسي والرضا عن الحياة شعور بالسعادة يؤثر تأثيرا إيجابيا كبيراً

في الفرد (Buunkm, Vanyperen, Taylor \& Collins, 1991).

ففي الآونة الأخيرة اتخذ الارشاد النفسي منحى آخر في دراسة البيئة

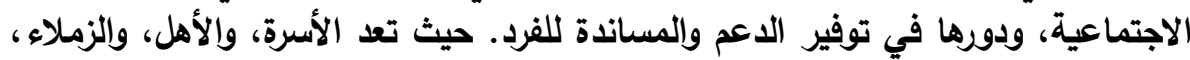

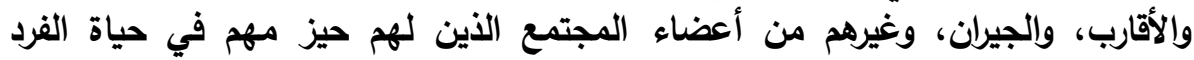

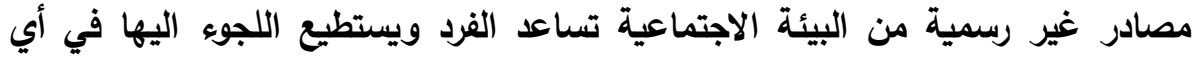

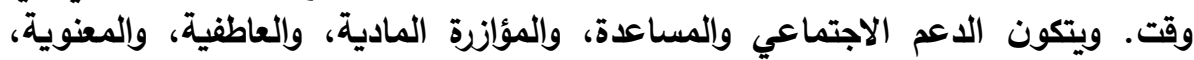

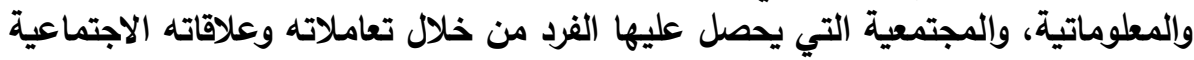

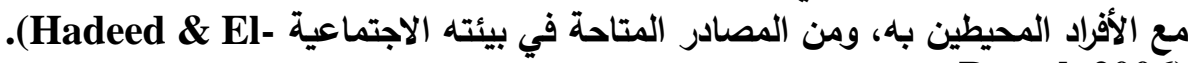

Bassel, 2006)

تناول عدد من الباحثين والعلماء مفهوم الدعم الاجتماعي من حيث تعريفه،

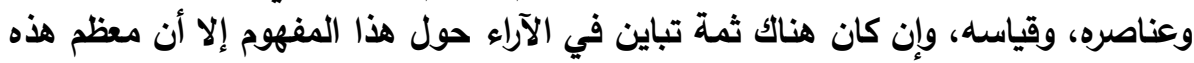

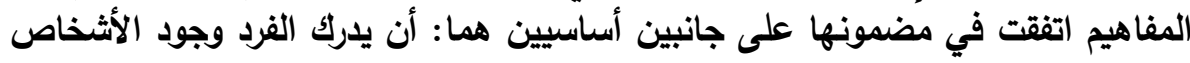

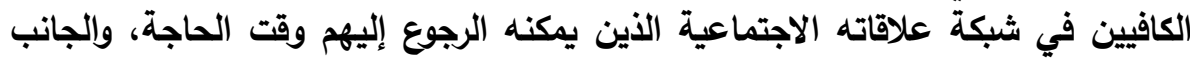

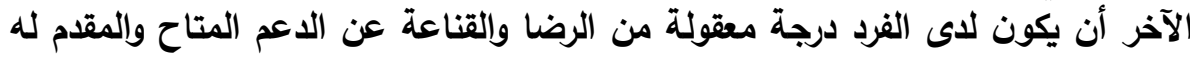

.(Sarason, Levine, Basham \& sarason, 1983) 


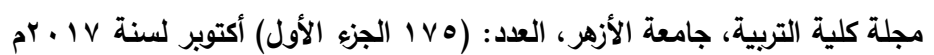

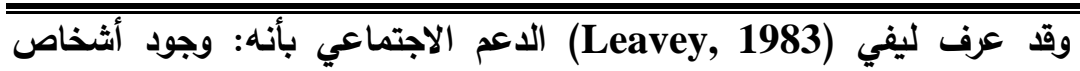

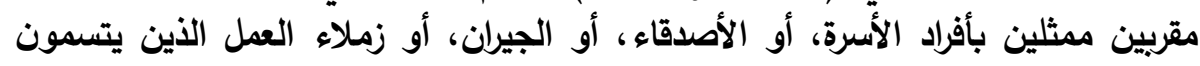

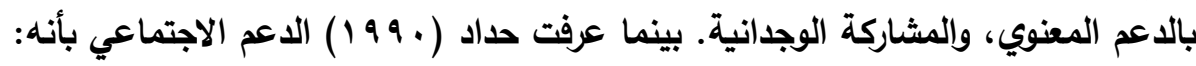

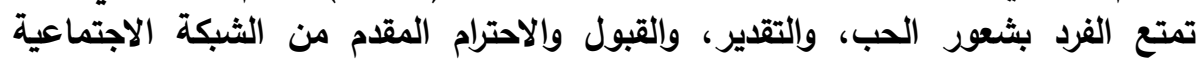

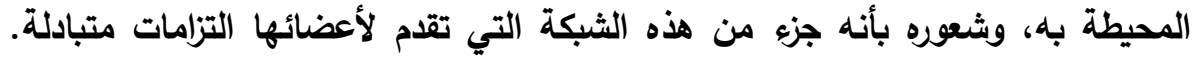

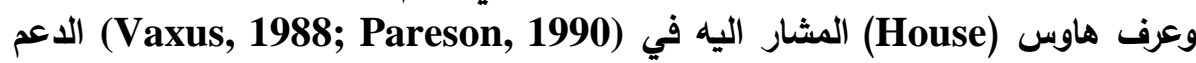

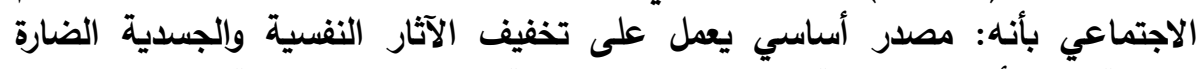

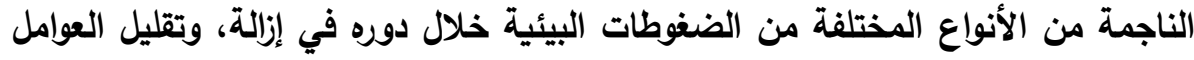

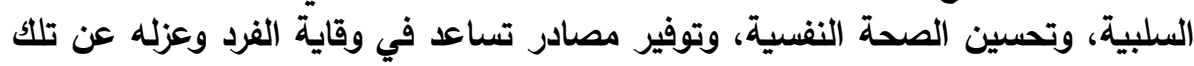

التأثيرات السلبية.

كما عرف كوهن و ول الدعم الاجتماعي (Cohen \& Will, 1985)

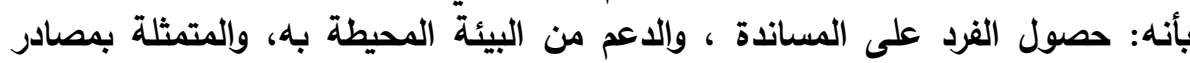

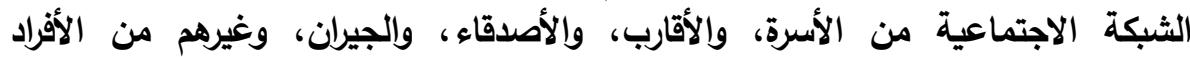
المحيطين بالفرد لمواجهة أحداث الحياة الضاغطة، والألة التكيف معها.

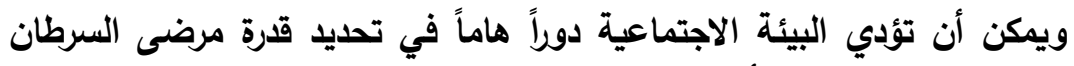

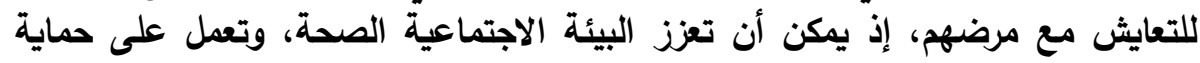

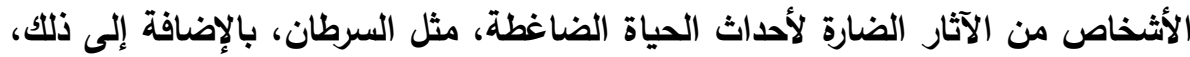

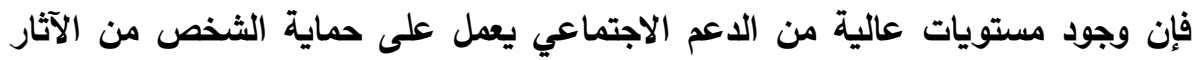

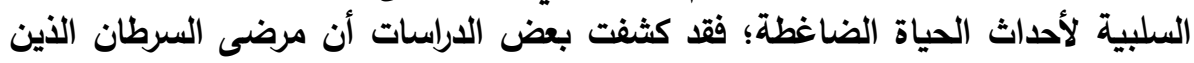

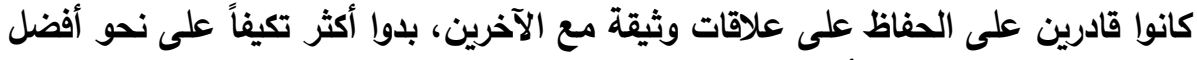

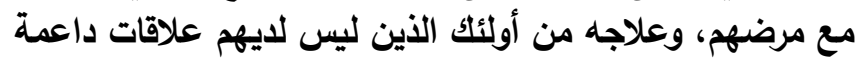

(Cutrona, Russel \& Rose, 1986; Helgeson \& Cohens, 1996).

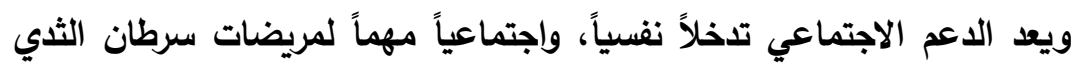

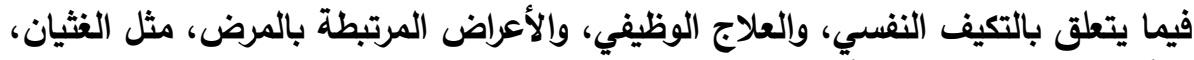

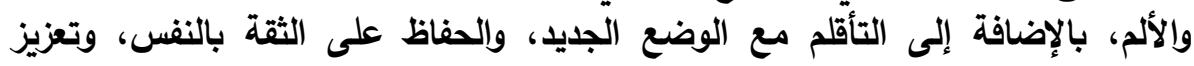

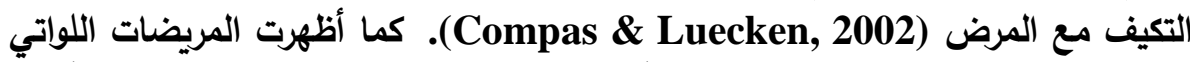

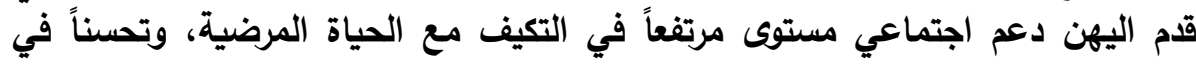
حالتهن الصحية (Savetina \& Nastran, 2012).

ويوفز الأدب النظري أدلة قوية على أن الدعم المقدم من العلاقات الاجتماعية

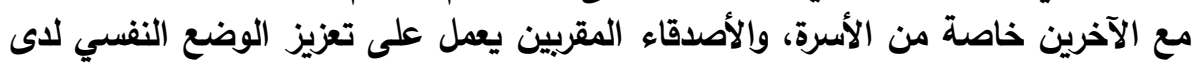

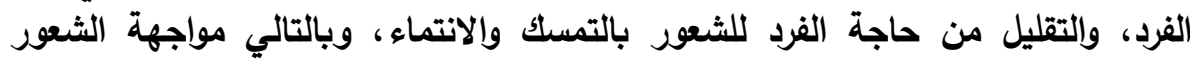

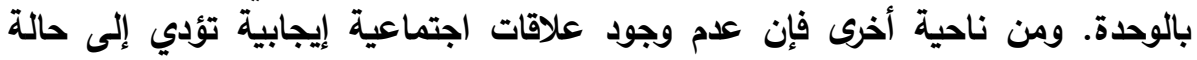




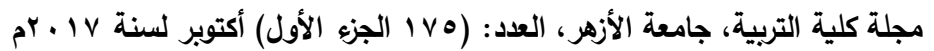

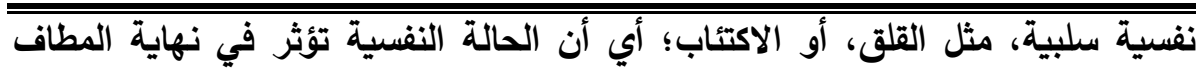

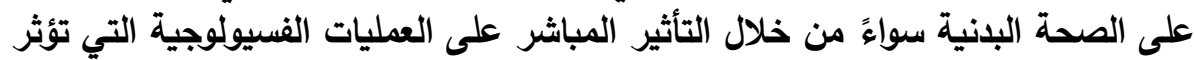

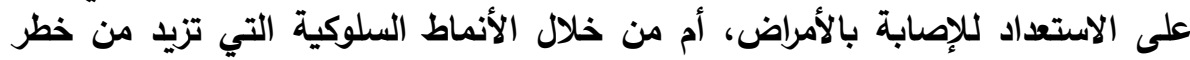

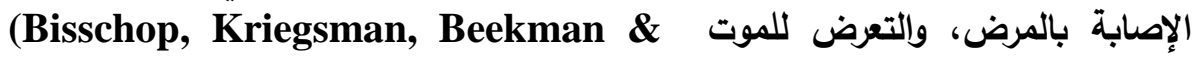
وقد أكلت النتائج التي توصل اليها سيك ايوم وآخرون (r Deeg, 2004).

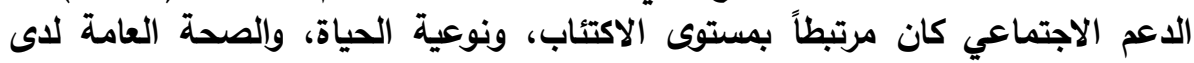
عينة من مريضات سرطان الثي كان (Sick-Eom et al., 2013).

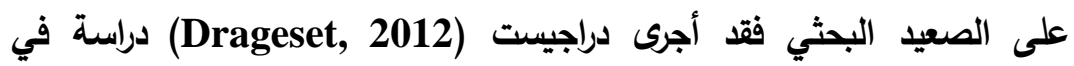
النرويج بعنوان" الكرب النفسي، والتكيف والدعم الاجتماعي في مرحلة التشخيص، وراجئ وقبل

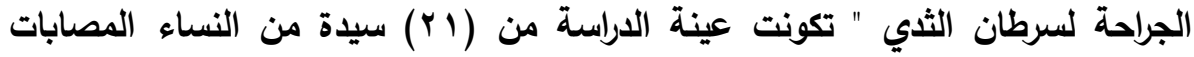

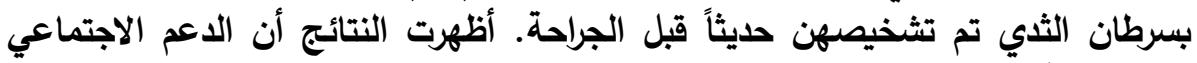

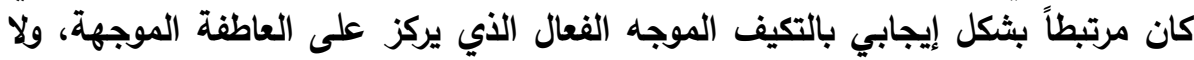

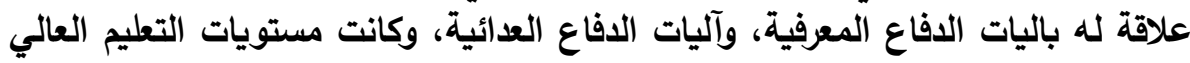

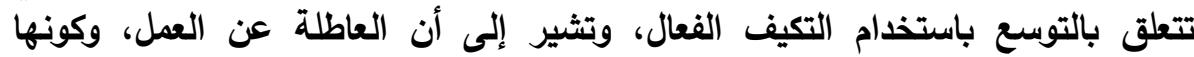

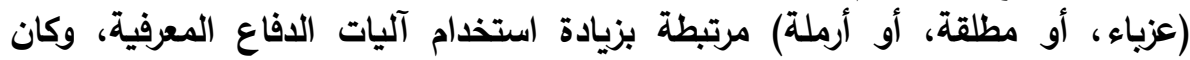

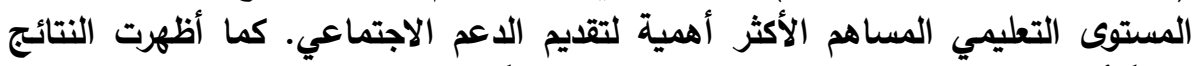

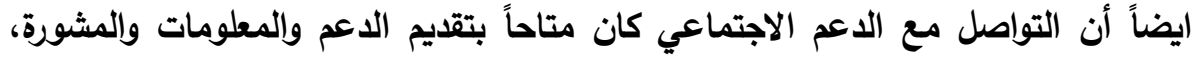

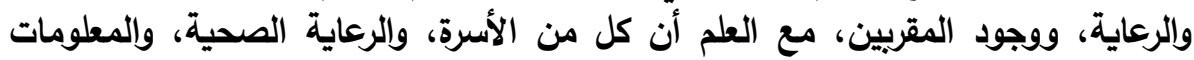

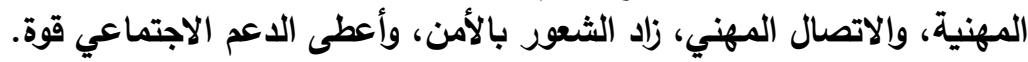

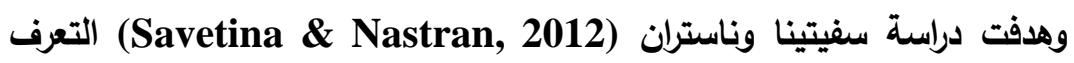

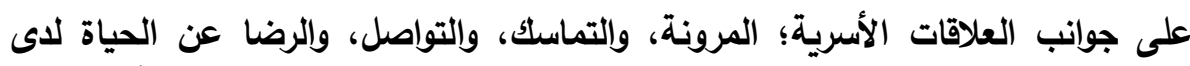

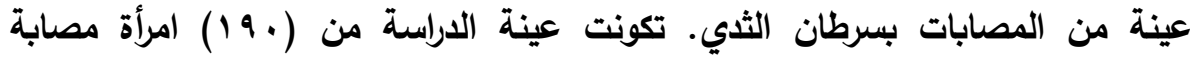

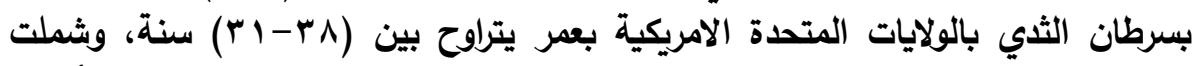

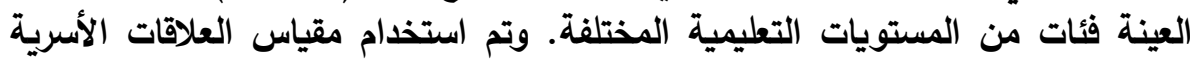

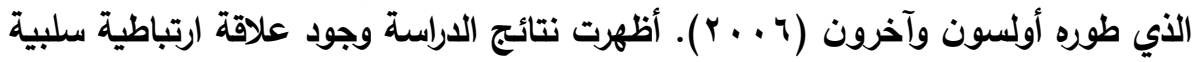

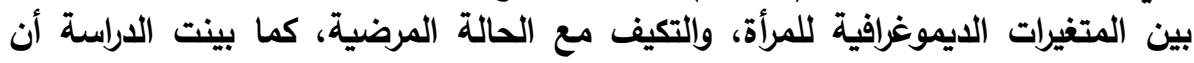

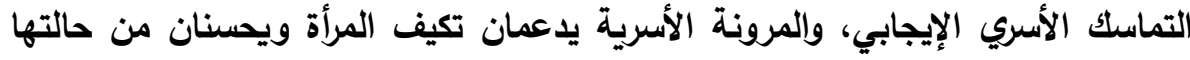

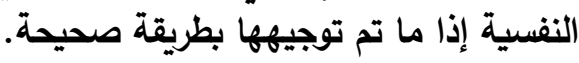

قام يلدريم ، وباتماز (Yildirim \& Batmaz, 2013) بدراسة بتركيا للحالة

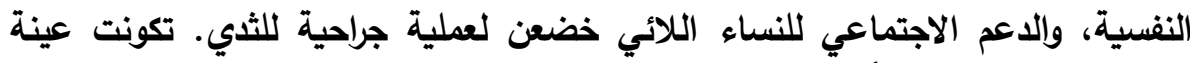

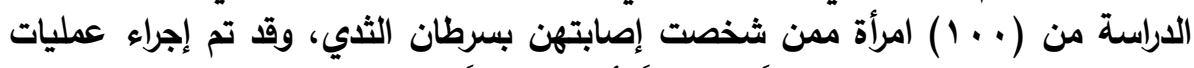

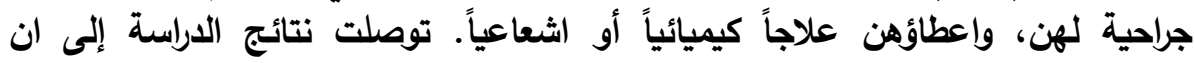


مجلة كلية التربية، جامعة الأزهر ، العدد: (V V الجزء الأول) أكتوبر لسنة V V + Yم

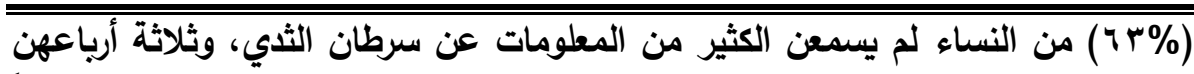

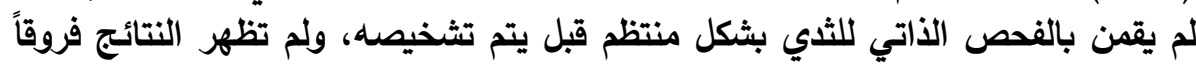

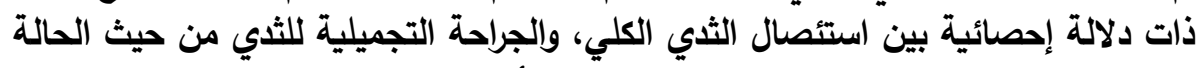

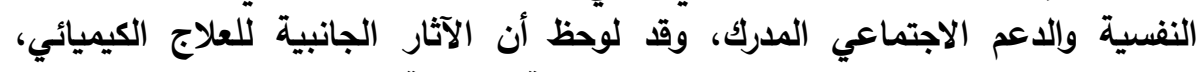

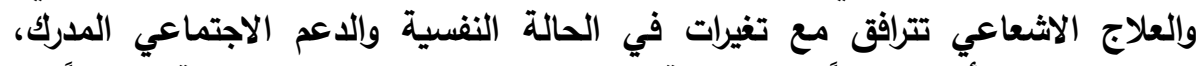

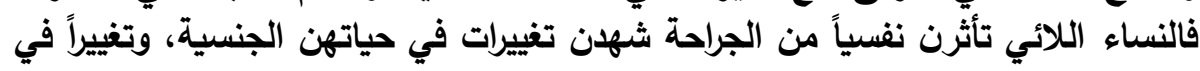

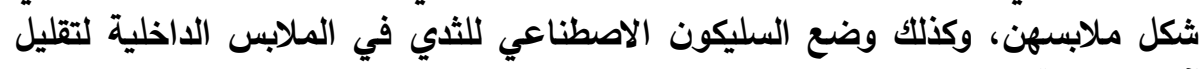
آثار الجراحة على مظهرهن.

ومن جانب آخر أجرى تل، وساري، وآيدن (Tel, Sari \& Aydin, 2013)

دراسة هدفت إلى تحديد مدى الاعم الاجتماعي وارتباطه بمستوى الاكتئاب لآى مريضات

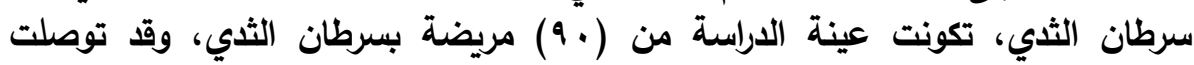

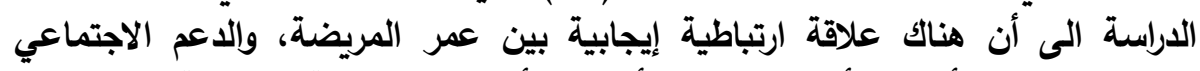

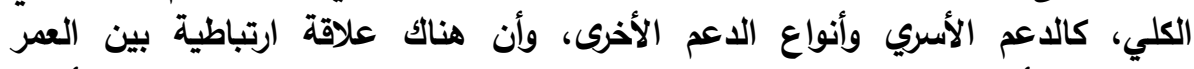

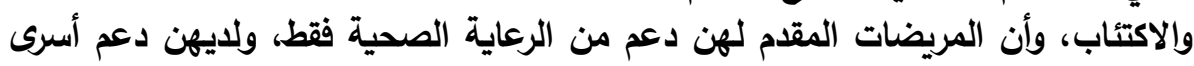

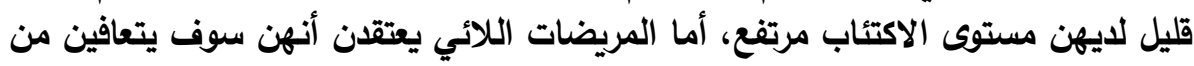

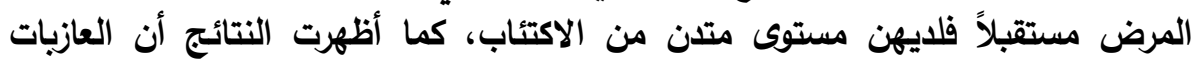

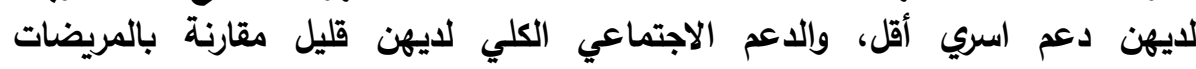

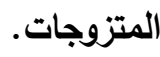

وأجرى سيك إيوم وآخرون (Sick-Eom et al., 2013) دراسة في كوريا

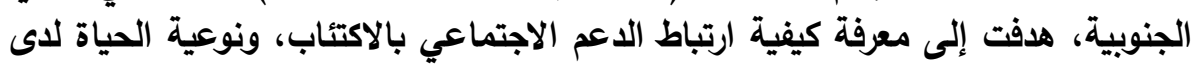

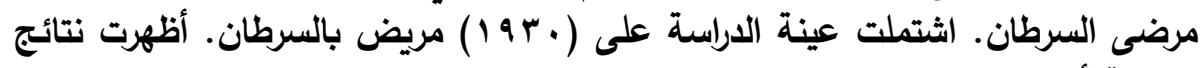

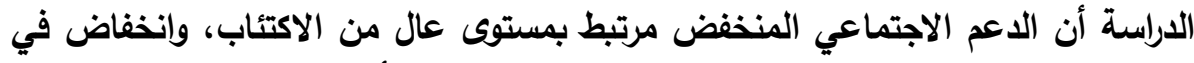

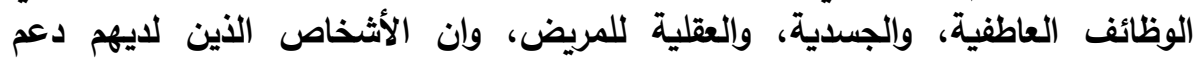

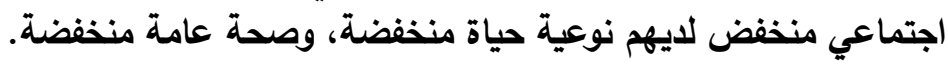

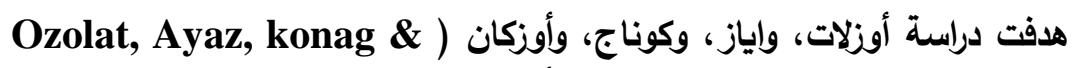

(ozkan, 2014

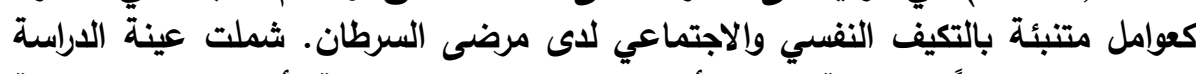

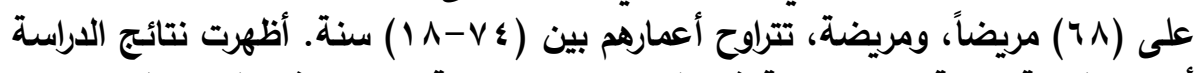

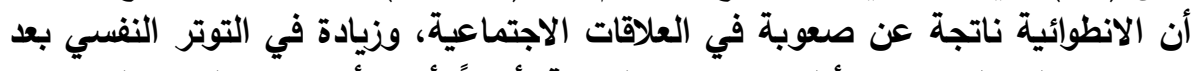

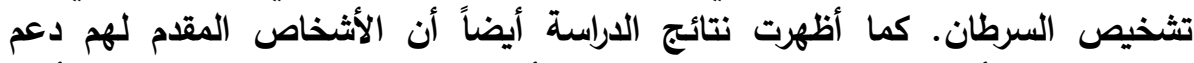

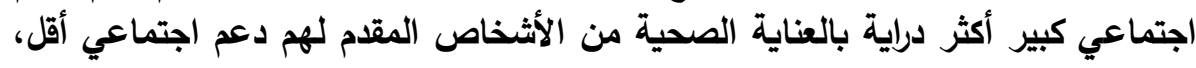




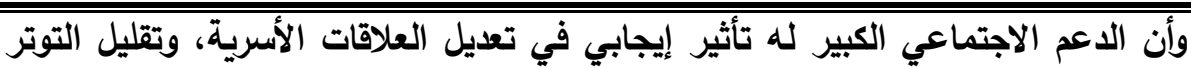
النفسي لمرضى السرطان مقارنة بالأثخاص التمقدم لهم دعم اجتماعي أقل.

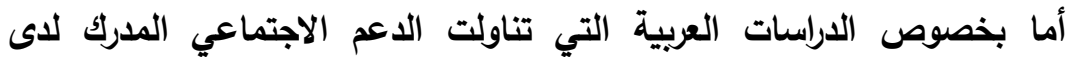

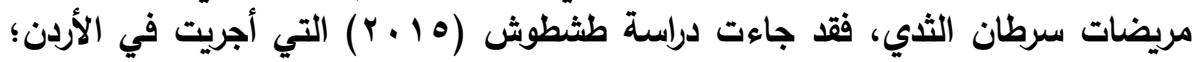

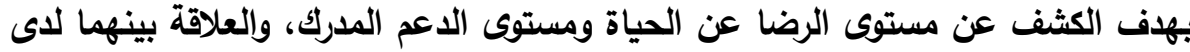

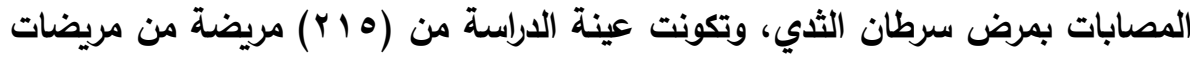

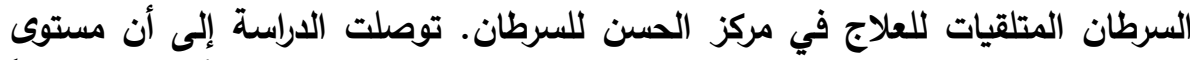

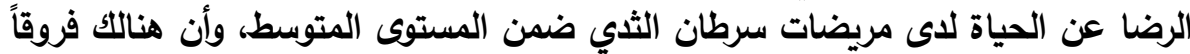

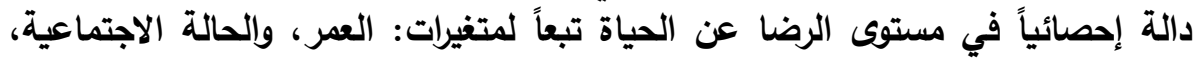

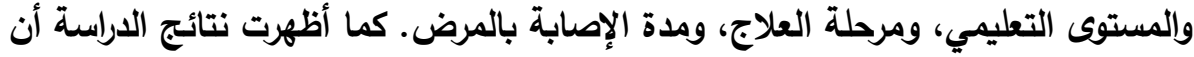

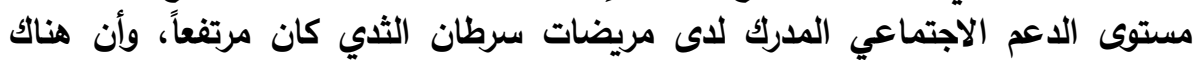

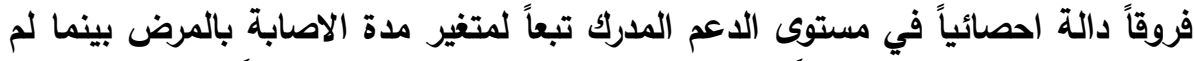

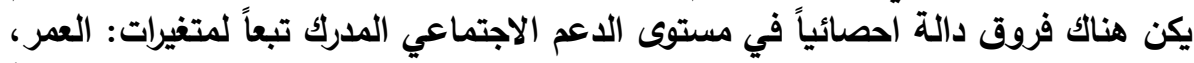

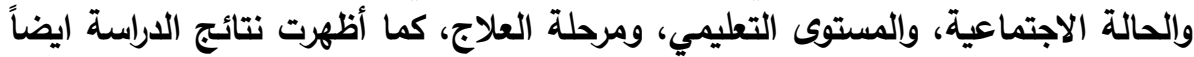

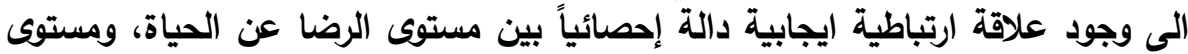

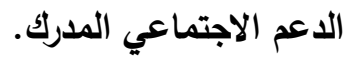

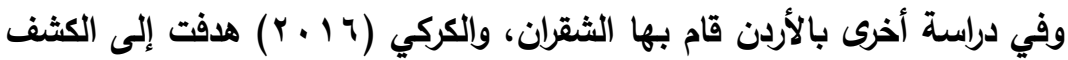

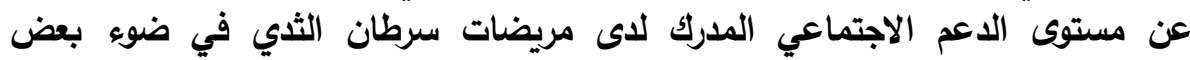

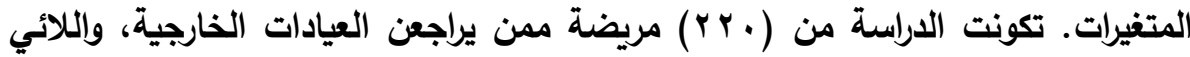

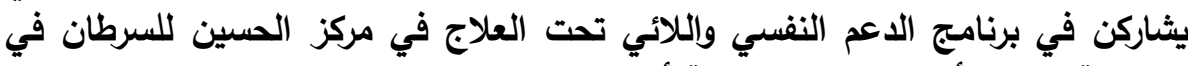

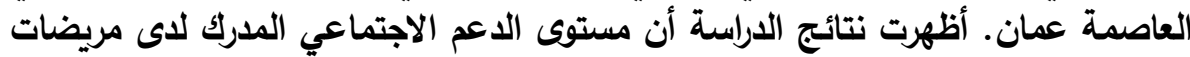

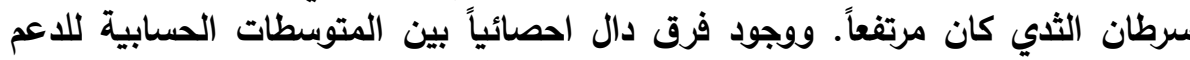

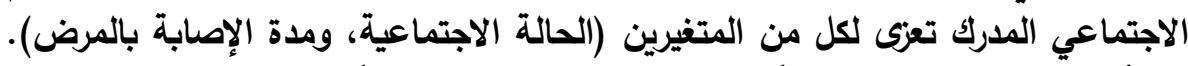

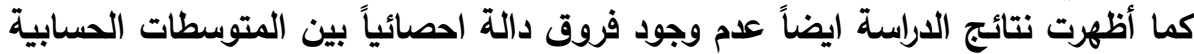
للاعم الاجتماعي المدرك تعزى لمتغيرات (العمر ، والمستوى التطليمي، ومرحلة العلاج).

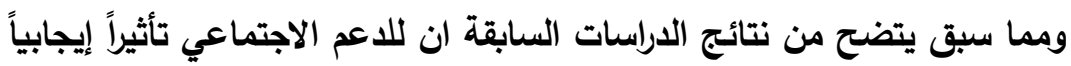

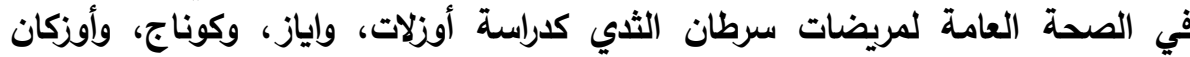

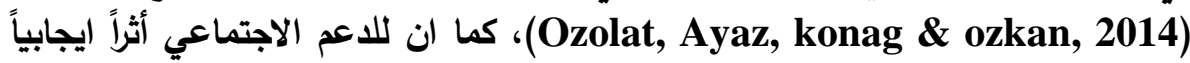

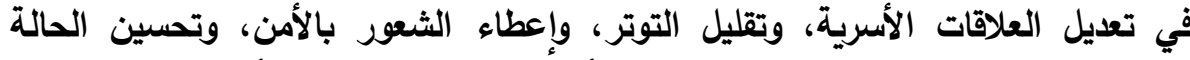

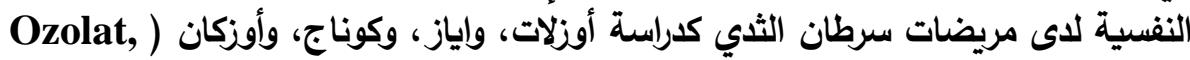

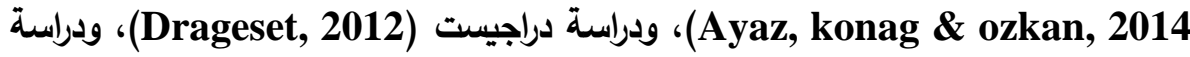

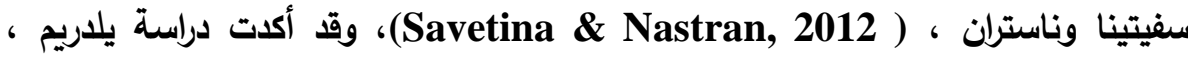


مجلة كلية التربية، جامعة الأزهر ، العدد: (V0 V الجزء الأول) أكتوبر لسنة V V ب rم

وباتماز (Yildirim \& Batmaz, 2013) ، أن الآثار الجانبية للعلاج الكيميائي،

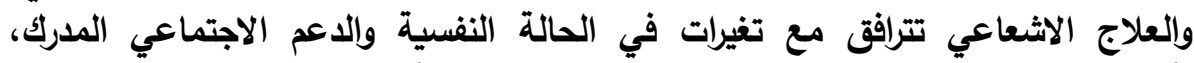

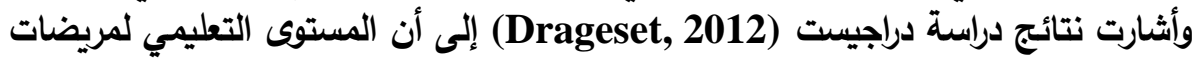
سرطان الثدي هو المساهم الأكبر لتقديم الدعم الاجتماعي لمرضى السرطان.

من خلال استعراض الاراسات السابقة فإن الدراسة الحالية تتناول متغيراً جليداً

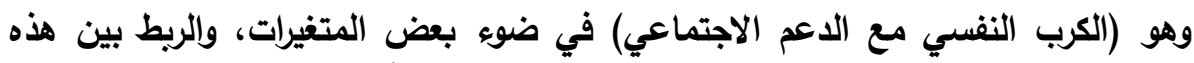

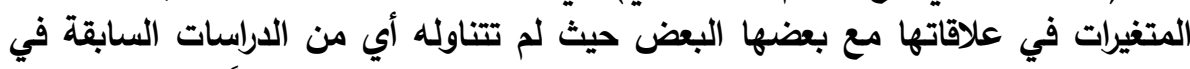

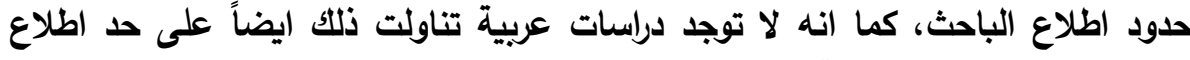

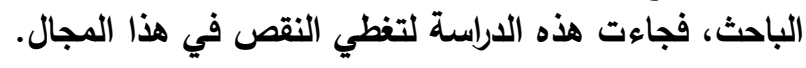

مشكلة الاراسة:

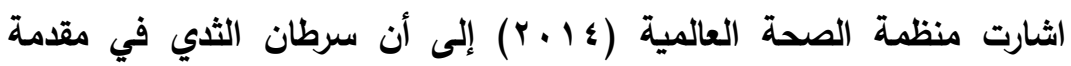

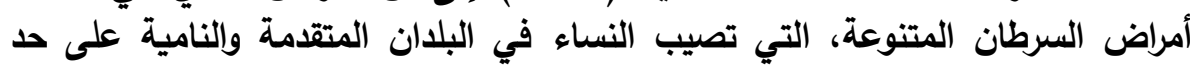

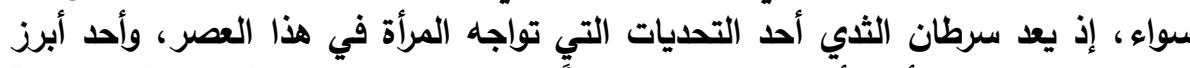

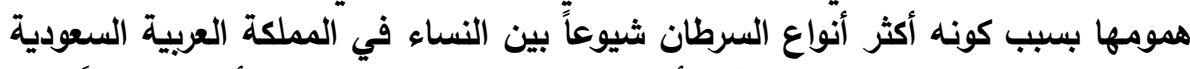

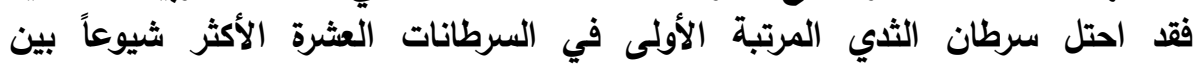

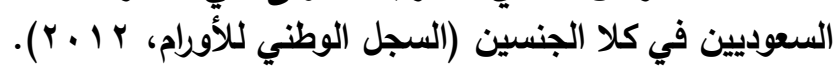

ويثكل مرض سرطان الثدي مثكلة كبرى في جميع المجالات الصحية،

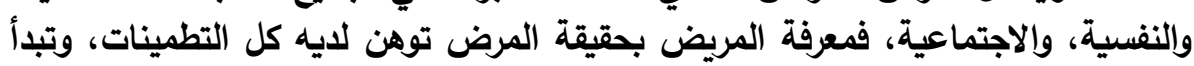

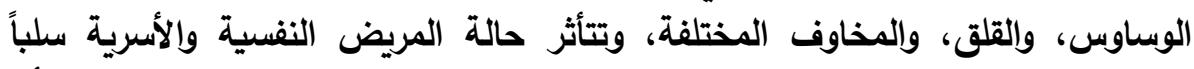

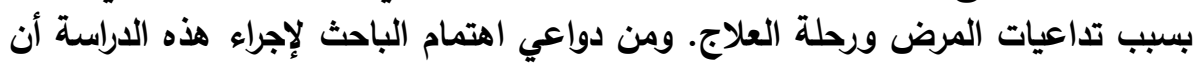

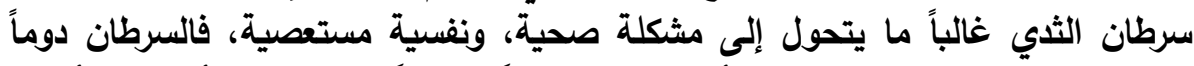

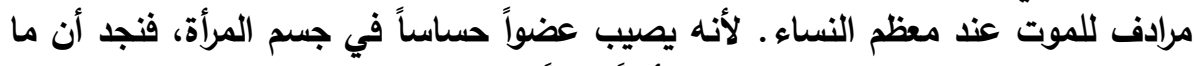

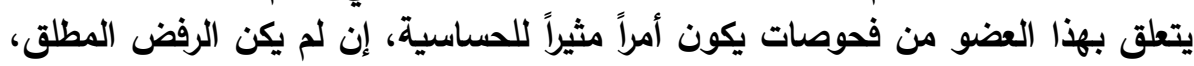

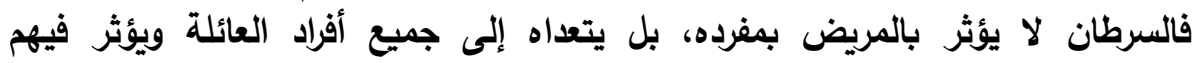

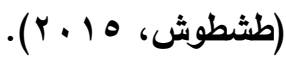

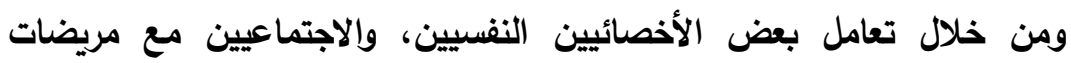

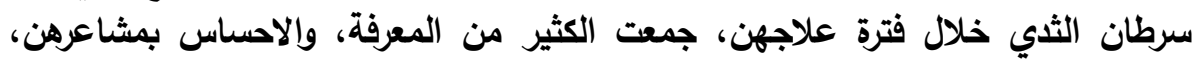

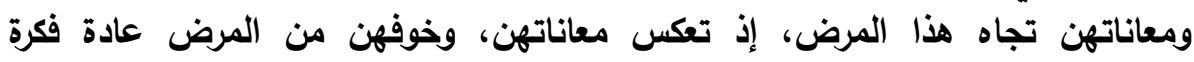

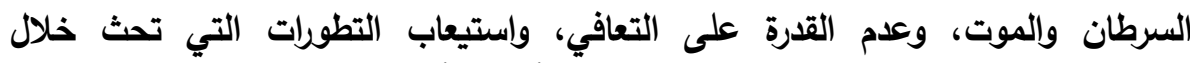
مسيرتهن العلاجية، وكذلك خوفهن من مواجهة الأهل والأصدقاء، والتواب والزوج، والثبيئة المحيطة

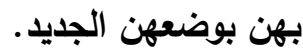




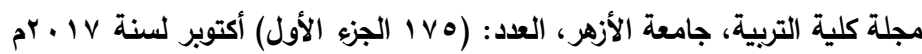

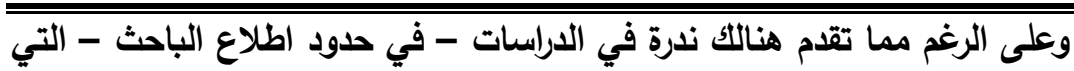

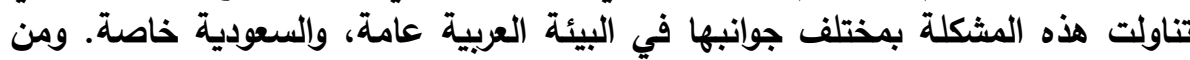

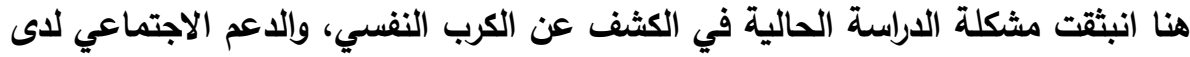

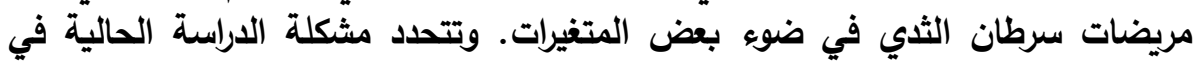

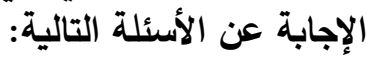

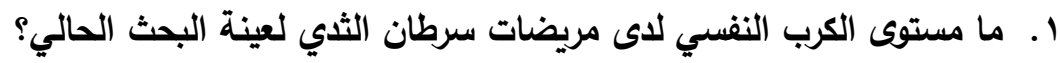

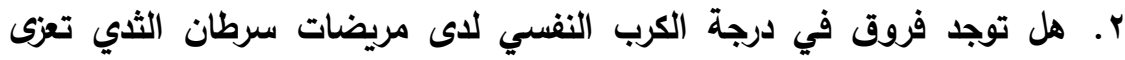

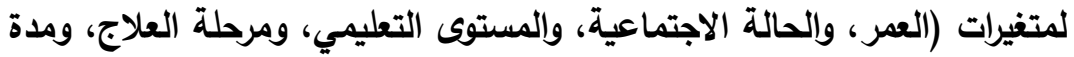

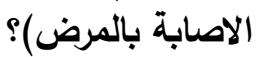

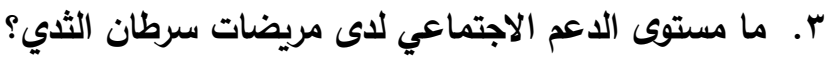

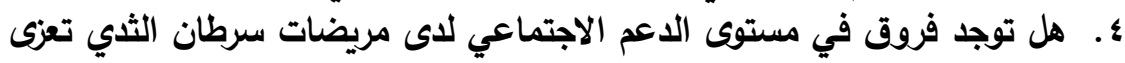

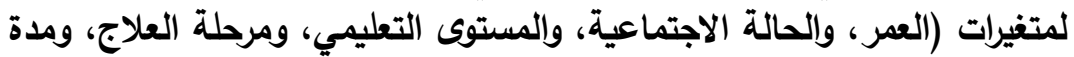

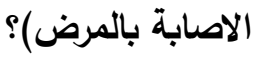

ه. هل توجد علاقة ارتباطية بين مستوى الكرب النفسي، ومستوى الدعم الاجتماعي

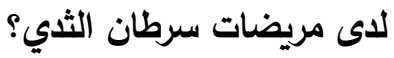

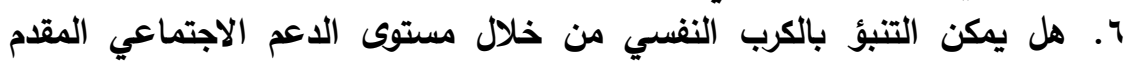

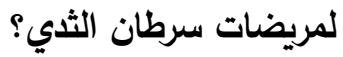

أهمية الدراسة:

تنبثق أهمية الدراسة الحالية في جانبين: الأهمية النظرية، والأهمية العملية.

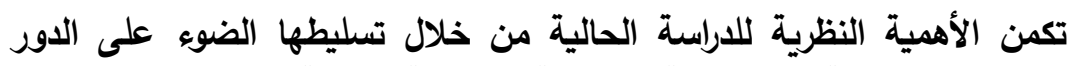

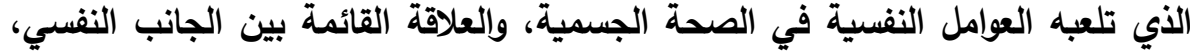

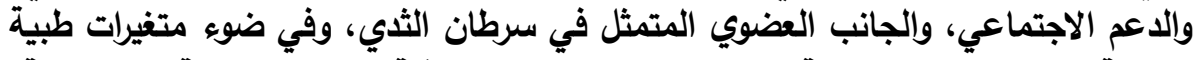

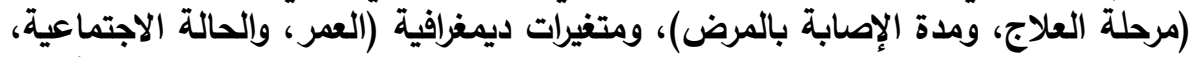

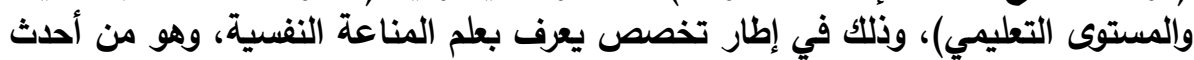

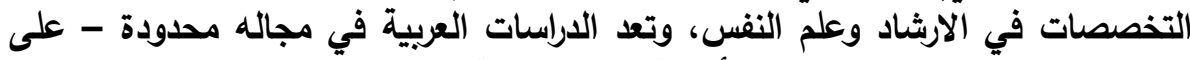

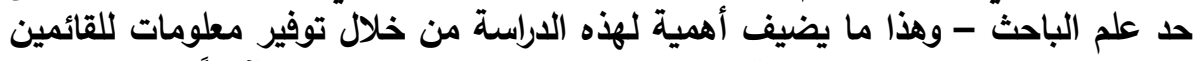

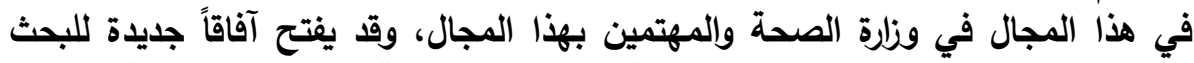
فيلة، ووضع خطط، وبرامج، وطرق ارشادية لمساعدة المريضة تجاوز هذه المنال فئة. 


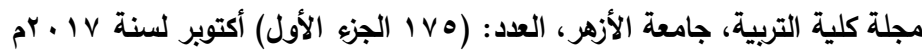

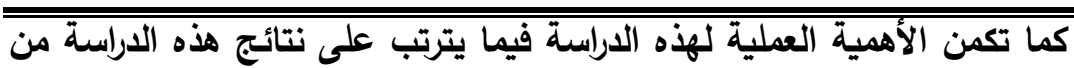

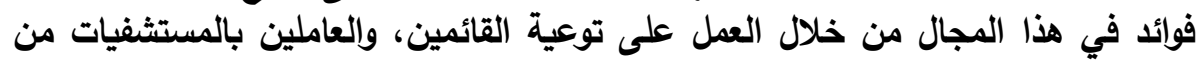

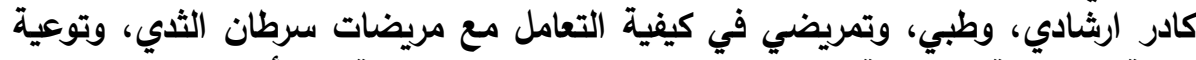

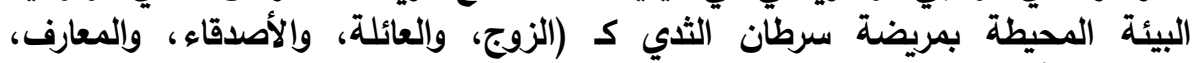
والمجتمع بأكمله) بمدى معاناة المصابة بسرطان الثدي وحاجتها للاعم والمساندة.

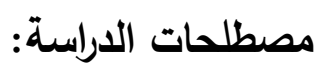

الكرب النفسي: خبرة وجدانية غير سارة متعددة الأبعاد ذات طبيعة نفسية

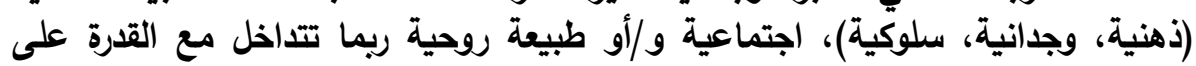

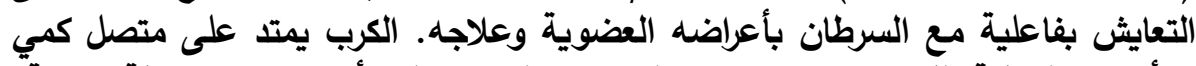

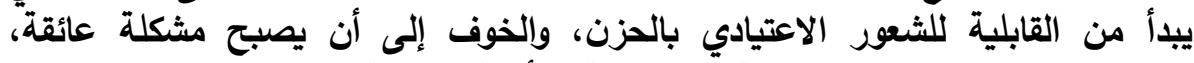

كالاكتئاب، والقلق، والذعر، والعزلة الاجتماعية، الأزمة الروحية (NCCN, 2015).

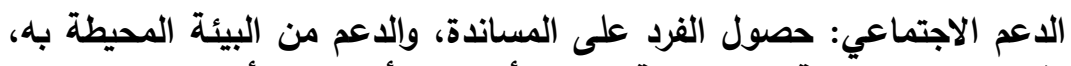

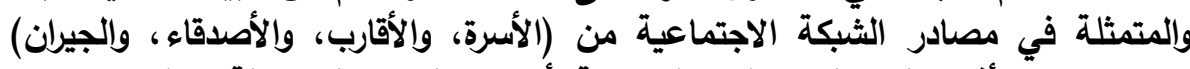
وغيرهم من الأفراد المحيطين بالفرد لمواجهة أحداث الحئمة الحياة الضاغطة، والتكيف معها

(Cohen \& Will, 1985).

$$
\text { محددات الاراسة: }
$$

1. تتحدد نتائج الداسة الحالية بأداتي الداسة وهما الكرب النفسي، والدعم

$$
\text { الاجتماعي وخصائصهما السيكومترية. الحية. }
$$

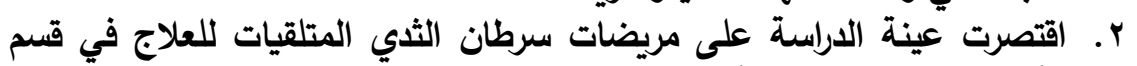

الأورام بمستشفى قوى الأمن، ومدينة الملك مرلك فهر الطبية بمدينة الرياض.

الطريقة وإجراء ات الدراسة:

عينة الاراسة:

تكونت عينة الدراسة من (بr آ ) مريضة من مريضات سرطان الثاي بالطريقة

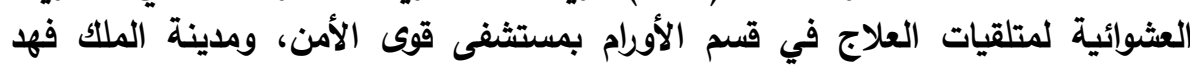

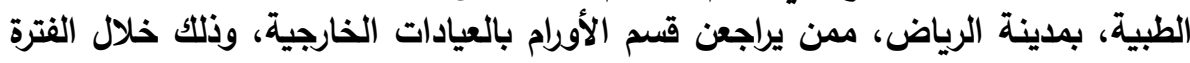

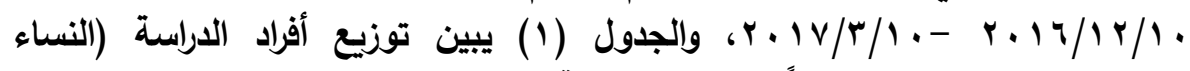

\begin{tabular}{|c|c|c|c|}
\hline النسبة المئوية & العدد & فئة المتغير & المتغير \\
\hline rY,I & rq & 9 19-0 سنة & العمر \\
\hline rq, \& & $\varepsilon \wedge$ & צب -0 ؛ سنة & \\
\hline
\end{tabular}

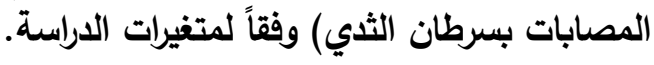

جدول (1) : توزيع أفراد العينة حسب متغيرات الدراسة

$-\mu r V-$ 


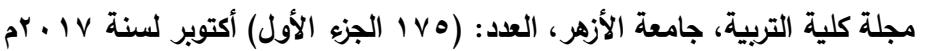

\begin{tabular}{|c|c|c|c|}
\hline$\varepsilon \wedge, 0$ & 79 & ج צ - فأكثر & \\
\hline $1 \leqslant, 1$ & $r r$ & عزباء & الحالة الاجتماعية \\
\hline $00, r$ & 9. & متزوجة & \\
\hline $11, v$ & 19 & مطلقة & \\
\hline $1 \wedge, \varepsilon$ & $r$. & أرملة & \\
\hline., 7 & 1 & مفقود & \\
\hline$r \cdot, r$ & $r r$ & ابتدائي & المستوى التعليمي \\
\hline $1 \leqslant, V$ & $r \leq$ & متوسط" & \\
\hline$r \cdot, v$ & o. & ثانوي & \\
\hline$r r, r$ & rs & جامعي & \\
\hline$\wedge, \cdot$ & ir & دراسات عليا & \\
\hline$r, 1$ & 0 & مفقود & \\
\hline $19, \cdot$ & $\varepsilon$ & جراحي & "مرحلة العلاج \\
\hline$r \cdot, \cdot$ & rי & كيميائي" & \\
\hline$r \bullet, r$ & or & اشعاعي & \\
\hline$r \bullet, v$ & $0 \leq$ & هرموني" & \\
\hline$r V, \cdot$ & $\varepsilon \leqslant$ & سنة فأقل & مدة الاصابة \\
\hline$r r, v$ & $\Delta 0$ & من سنة إلى ثلاث & \\
\hline$r v, \xi$ & 11 & سنوات & \\
\hline 1,1 & $r$ & ثلاث سنوات فأكثر & \\
\hline $1 \ldots$ & 194 & & المجموع \\
\hline
\end{tabular}

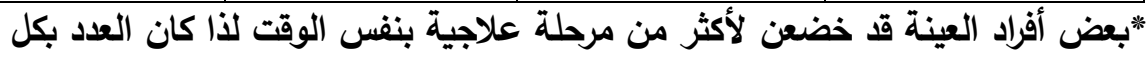

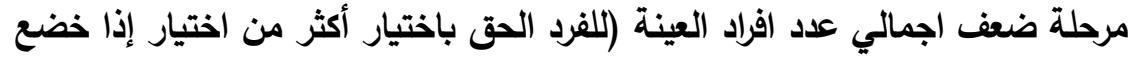
لأكثر من مرحلة علاجية). أدوات الدراسةة: - أد من مراته

(Hospital Anxiety and Depression أولاً - مقياس المستشفى للقلق والاكتئاب ) scale)

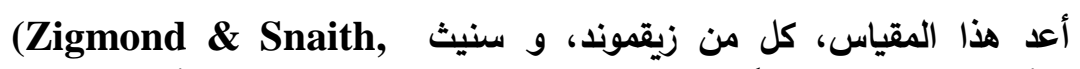

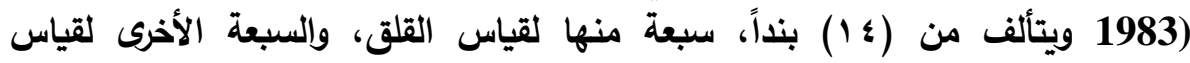

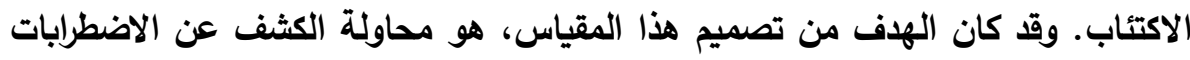

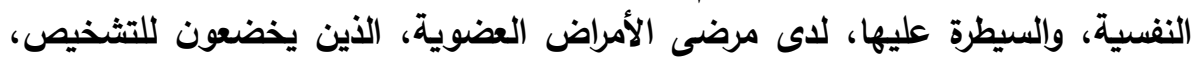

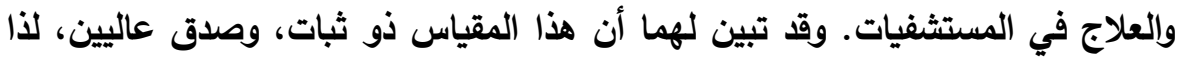

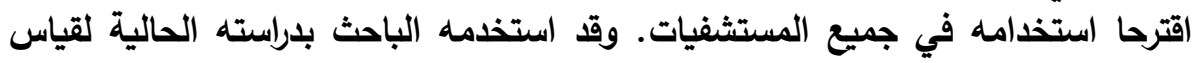




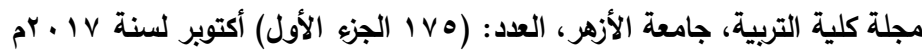

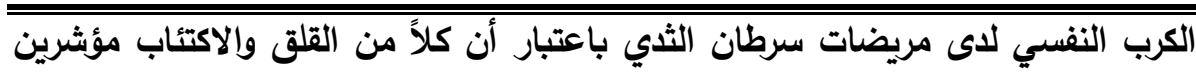

على مستوى الكرب النفسي. (NCCN, 2015)

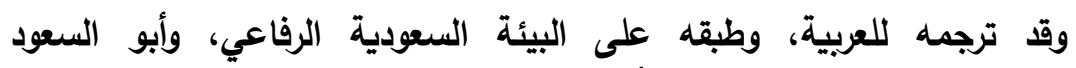

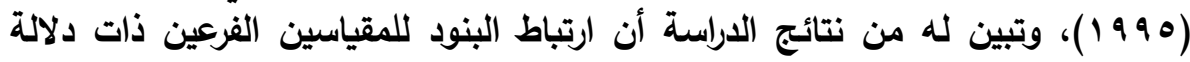

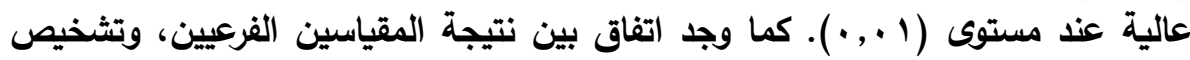

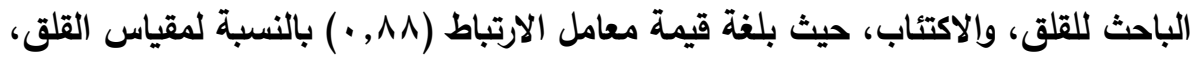

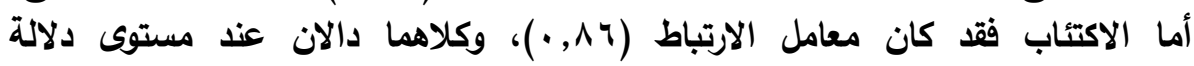

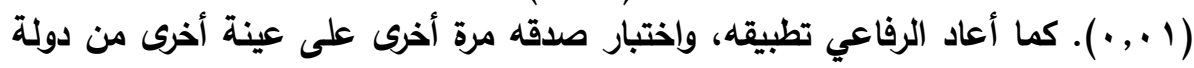

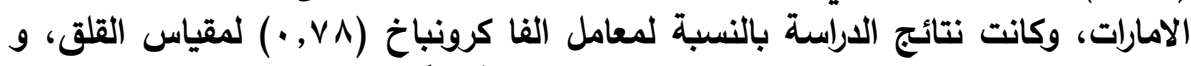

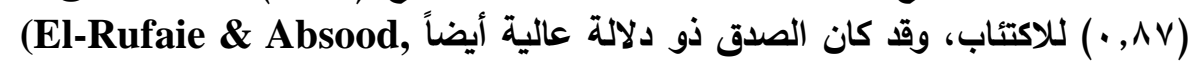

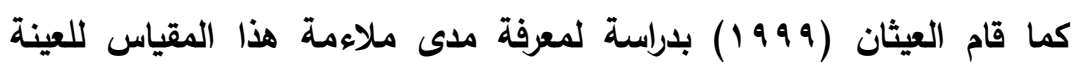

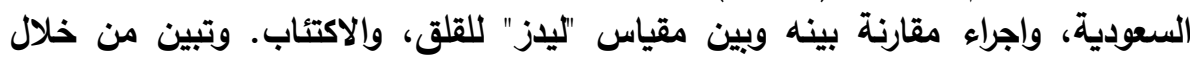

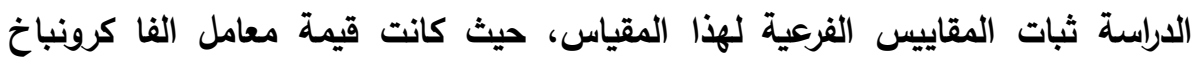

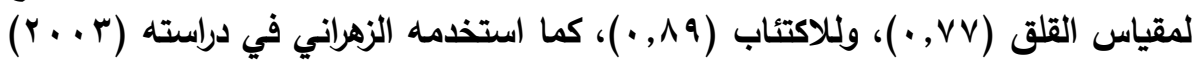

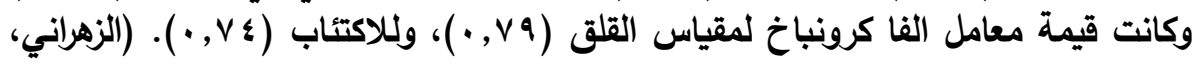

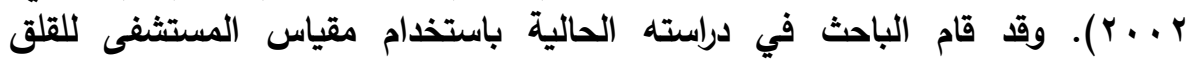

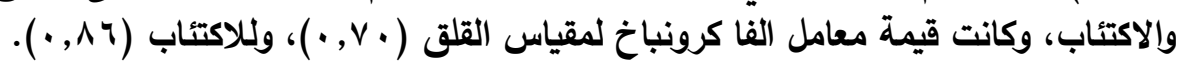

ثانياً - مقياس الدعم الاجتماعي (Social Support Scale)

للتعرف على مستوى الاعم الاجتماعي لاى مريضات سرطان الثاي، قام الباحث

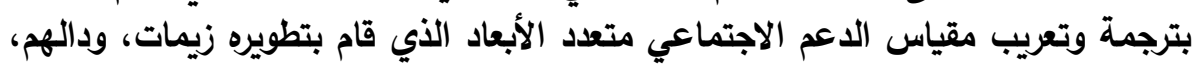

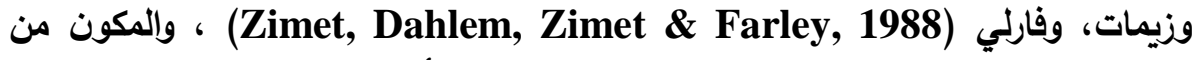

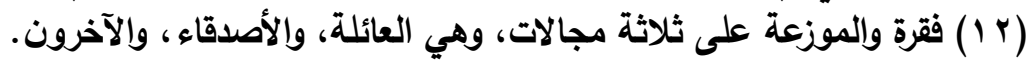
دلالات الصدق والثبات للمقياس:

1. صدق المحتوى: قام الباحث بترجمة فقرات المقياس بصورته الأصلية إلى اللغة

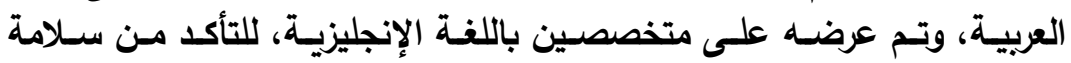

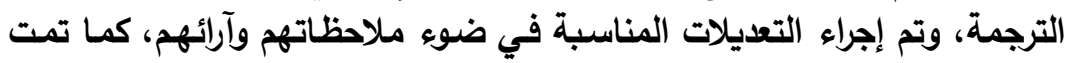

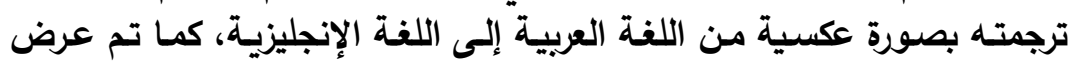

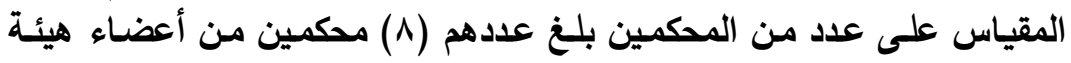

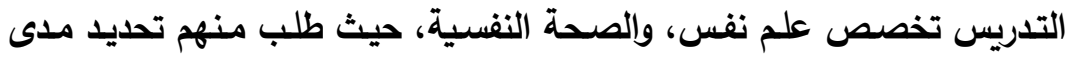

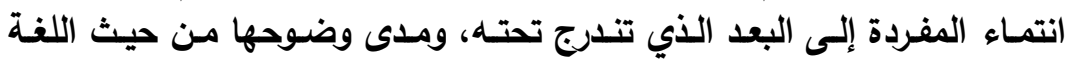




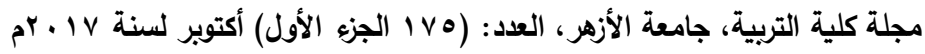

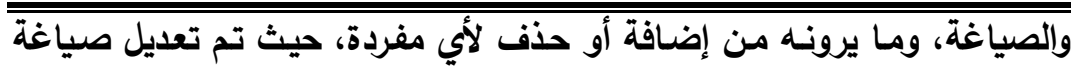

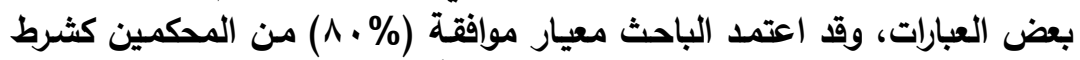
للإبقاء على الفقرة ، وبذلك اعتبر المقياس صادقاً.

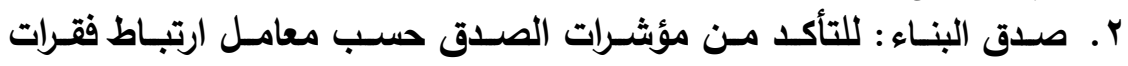

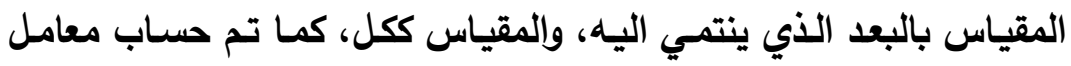

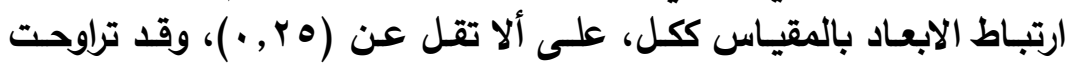

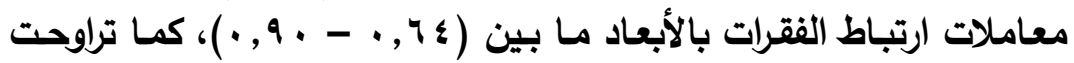

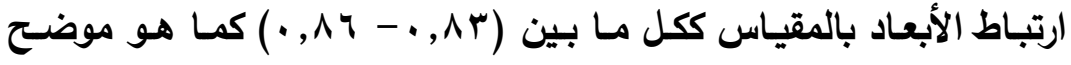

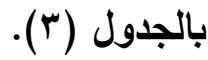

الجدول (ץ): يوضح معاملات ارتباط فقرات مقياس الدعم الاجتماعي مع الأبعاد بعد التصحيح

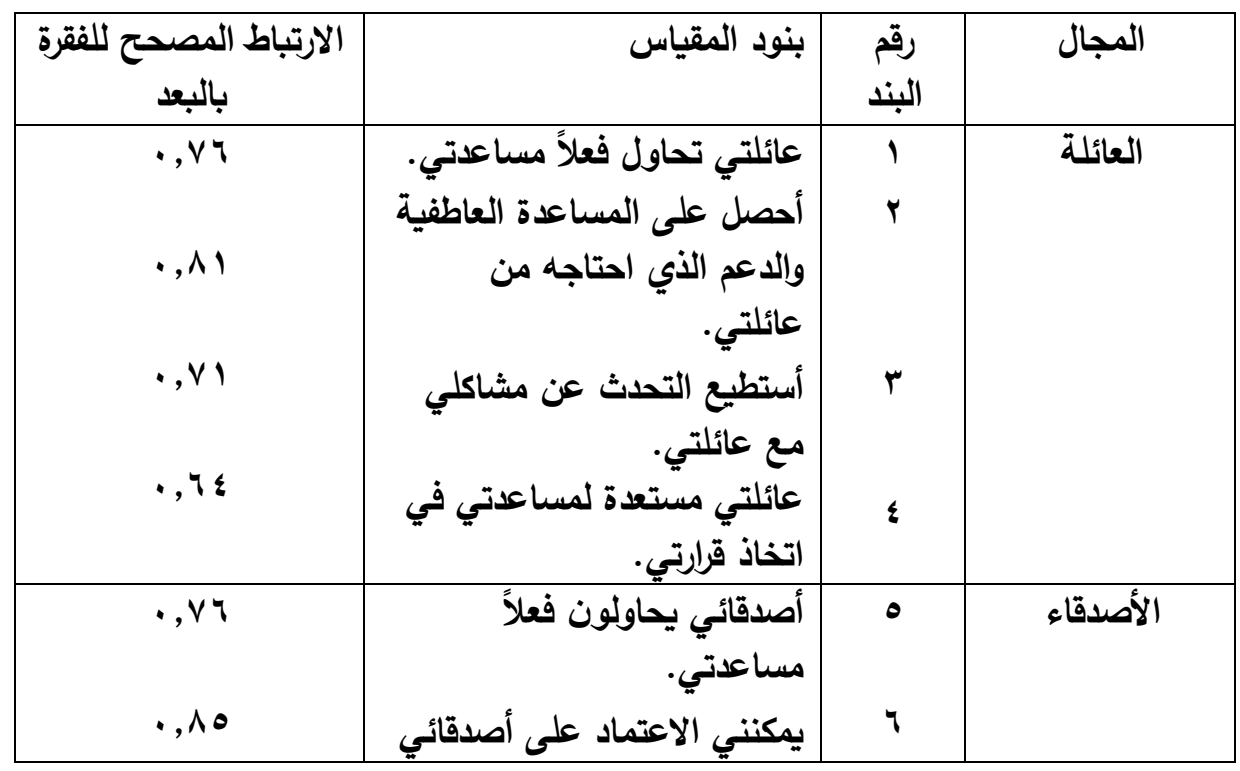

$-\mu \varepsilon$. 


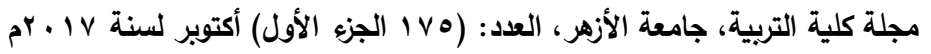

\begin{tabular}{|c|c|c|c|}
\hline الارتباط المصحح للفقرة & بنود المقياس & رقبم & المجال \\
\hline$\cdot, 9$. & لدئ أصدقائي يمكني الأمور. & V & \\
\hline$\cdot, \wedge \varepsilon$ & أستطيع التحدث عن مشاكلي & $\wedge$ & \\
\hline$\cdot, \vee \wedge$ & هناك شخص منديز بقربي عندما & 9 & الآخرين \\
\hline$\cdot, \wedge \varepsilon$ & هشاركته أفراحص مميز يمكنتي & 1. & \\
\hline$\cdot, \wedge \varepsilon$ & لاي شخص لي. مميز يعتبر مصدر & 11 & \\
\hline$\cdot, \wedge 0$ & لاي شختم لمشاعري. مميز في حياتي & Ir & \\
\hline
\end{tabular}

r. ثبات المقياس: للتأكد من ثبات المقياس تم تطبيق الأداة على (· ب) مريضـة

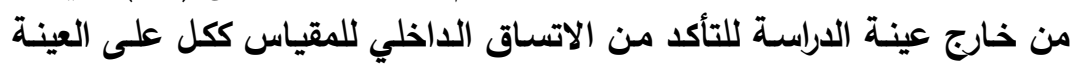

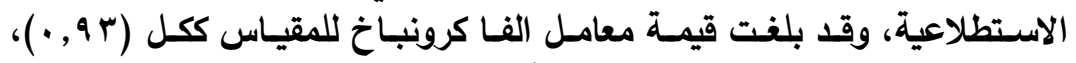

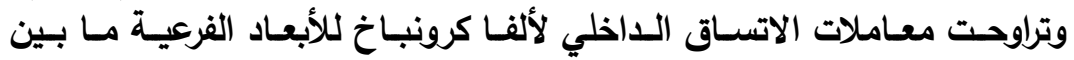

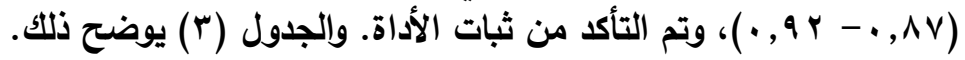

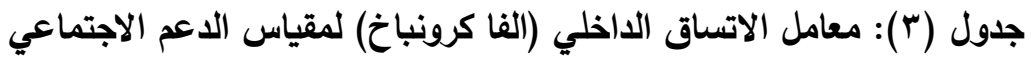

\begin{tabular}{|c|c|c|}
\hline ارتباط البعد بالمقياس ككل & معامل الفا كرونباخ & البعد \\
\hline$\cdot, \wedge \Gamma^{* * *}$ & $\cdot, \wedge V$ & العائلة \\
\hline •,,$\leqslant * * *$ &., 94 & الأصدقاء \\
\hline •, А५*** &., 94 & الآخرون \\
\hline
\end{tabular}

تصحيح مقياسي المستشفى للقلق والاكتئاب، والاعم الاجتماعي 


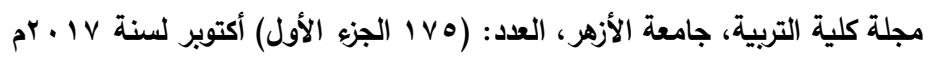

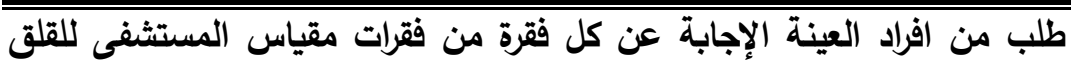

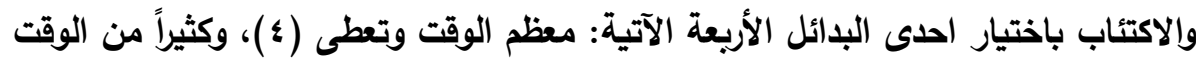

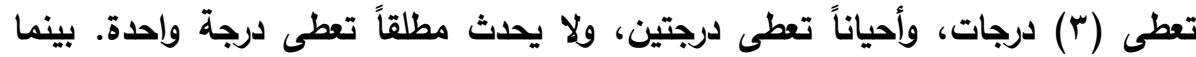

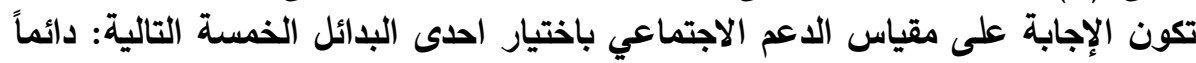

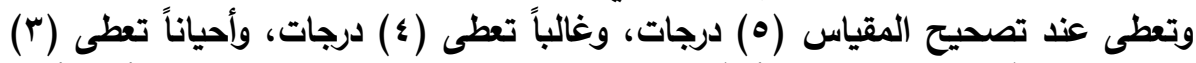

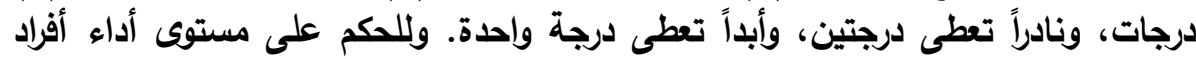

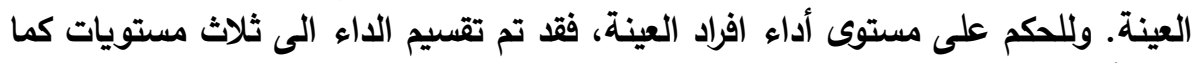

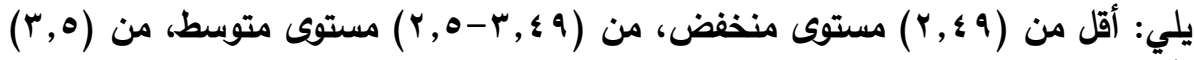

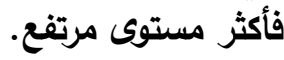

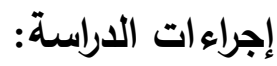

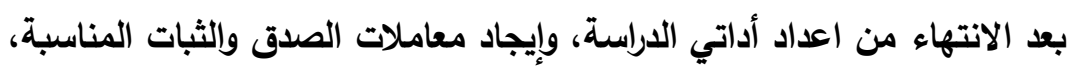

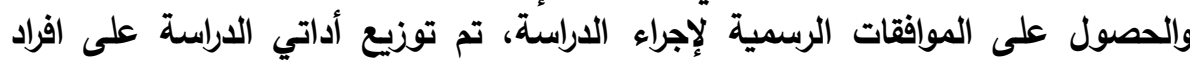

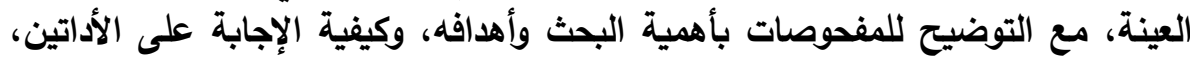

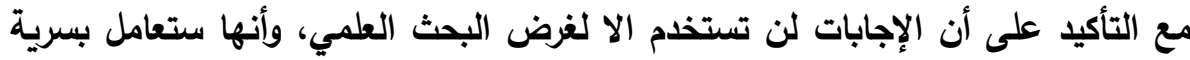

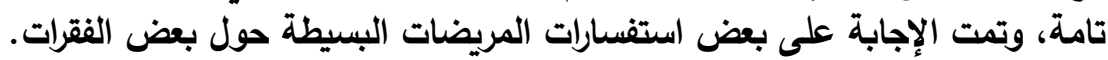

\section{منهج الاراسة:}

اقتضت طبيعة الدراسة استخدام المنهج الوصفي الارتباطي المقارن، وذلك لقدرته

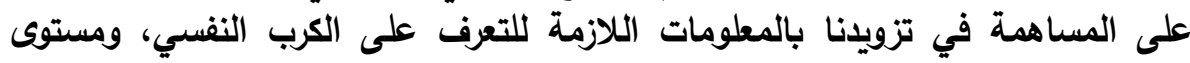

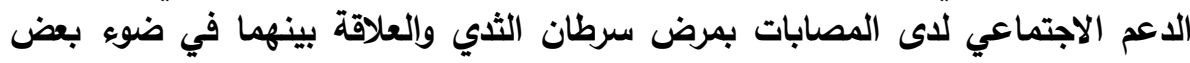

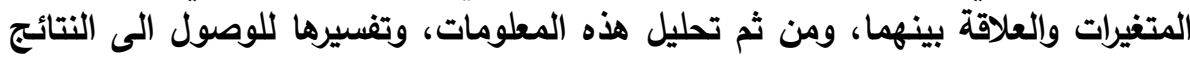

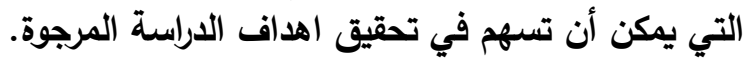

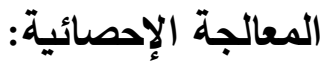

• لإجابة عن السؤالين الأول، والثالث استخدمت المتوسطات الحسابية،

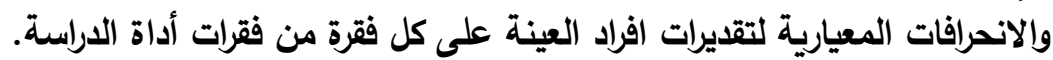

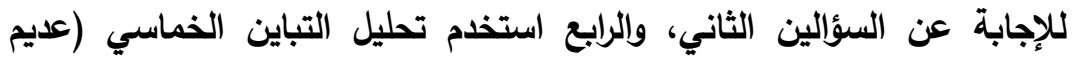

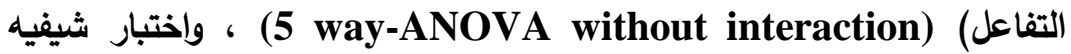

(Scheffe)

• لإجابة عن السؤال الخامس استخدم معامل الارتباط لبيرسون.

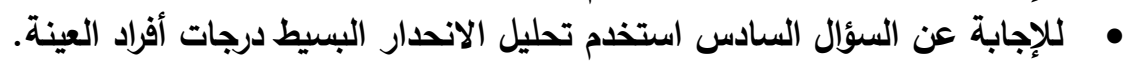




\section{نتائج الاراسة:}

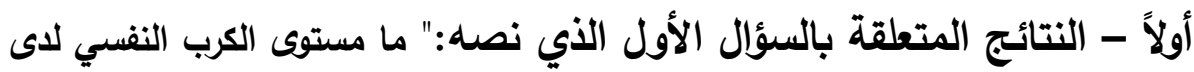

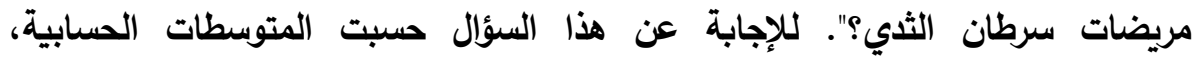

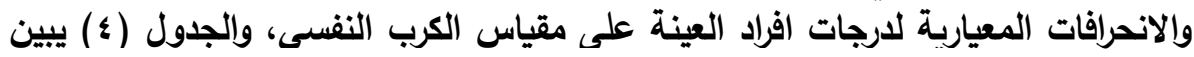

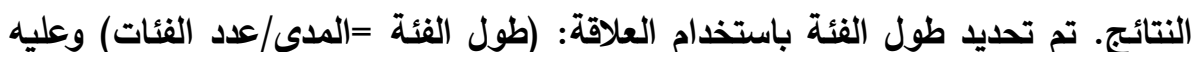

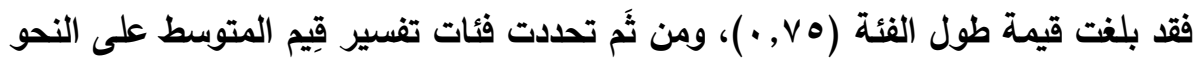

- - المتوسط المرجح من 0.00 إلى V0, · تغني التقييم بدرجة لا يحدث مطلقا.

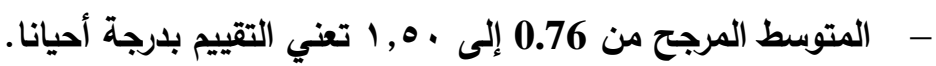

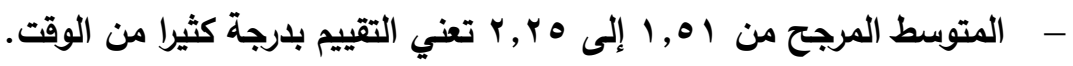

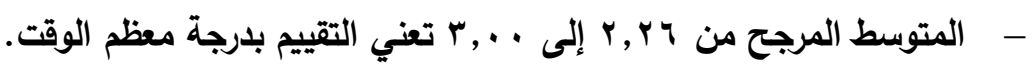

جدول (؛ ): المتوسطات الحسابية، والانحرافات المعيارية لارجات افراد العينة على مقياس

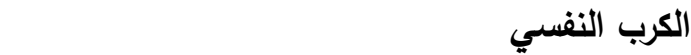

\begin{tabular}{|c|c|c|c|c|}
\hline الترتيب & التقيميم & ال الانحراف & المستوسط & مفردات المقياس \\
\hline $\mathrm{v}$ & كثيراً & 1.067 & 1.54 & 1. اشعر بحالة ضيق وتوتر \\
\hline$\varepsilon$ & كثيراً & 995. & 1.61 & 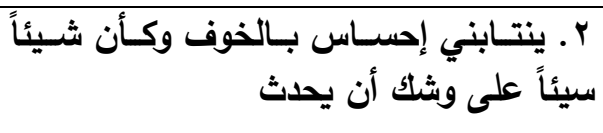 \\
\hline 7 & كثيراً & 1.017 & 1.55 & r. تـتابني نوبات من التفكير القلق المزعج \\
\hline 9 & أحياناً & .954 & 1.29 & بالاسترخاء ـ أستطع أن أجلس بهدوء وارتياح وأحس \\
\hline $1 \leqslant$ & أحياناً & .869 & .79 & 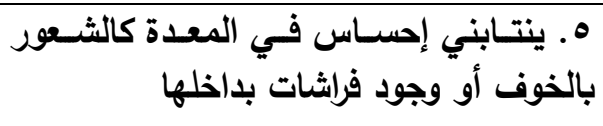 \\
\hline$\wedge$ & أحياناً & .989 & 1.36 & 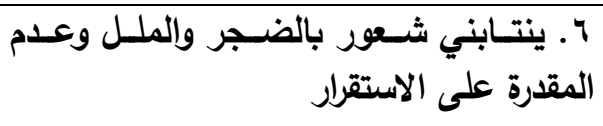 \\
\hline$r$ & كثيراً & 1.011 & 1.63 & V. تنتــابني نوبــات مفاجئــة مــن الخــوف \\
\hline
\end{tabular}




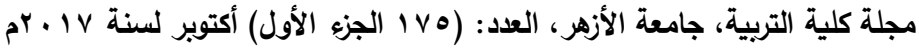

\begin{tabular}{|c|c|c|c|c|}
\hline الترتيب & التقيمة & المعياري & الحستوسط & مفردات المقياس \\
\hline & & & & والرعب والهلع \\
\hline 1. & أحياناً & .963 & 1.23 & ^ـ مـا زبلت استمتع بالأشياء التي استمتع \\
\hline 11 & أحياناً & .846 & 1.18 & المواقف أستطيع أن اضحك وأن أرى الفكاهة في \\
\hline 0 & كثيراً & .913 & 1.57 & • 1 ـ أحس بالفرح والانشراح \\
\hline 1 & كثيراً & .879 & 1.79 & في حركتي 11 ـ أشسعر وكـأنتي أصسبحت خـاملاً وبطيئاً \\
\hline$r$ & كثيراً & .984 & 1.72 & r ا ـ فقدت اهتمامي بمظهري \\
\hline IT & أحياناً & .928 & 1.04 & r ا ـ أتطلع للاستمتاع بالأشياء \\
\hline IT & أحياناً & 1.039 & .96 & 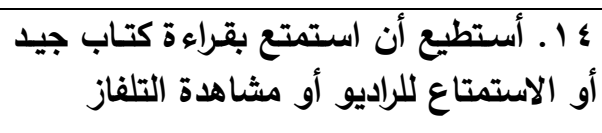 \\
\hline
\end{tabular}

يتضح من الجدول رقم (؛ ) أن عبارة " أشعر وكأنني أصبحت خاملاً وبطيئاً في

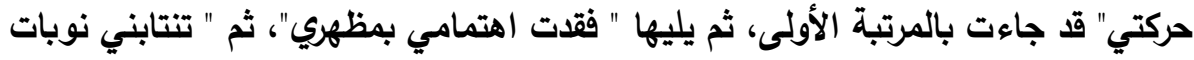

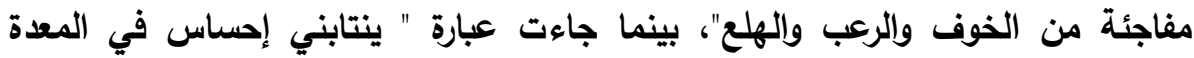

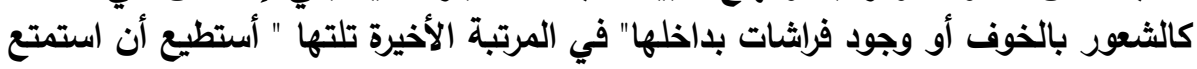

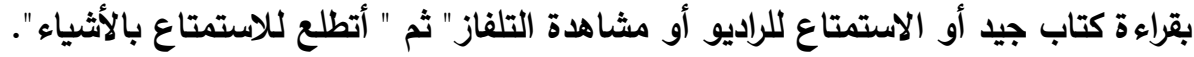
ثانياً - النتائج المتعلقة بالسؤال الثاني الأي نصه:" هل توجد فروق دالة احصائياً

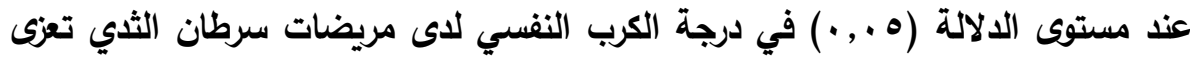

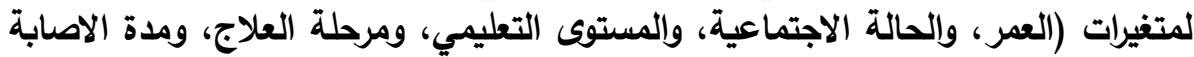

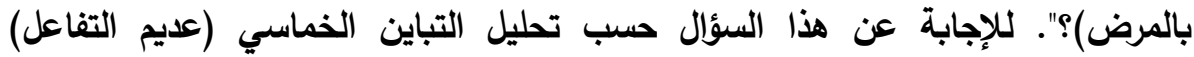

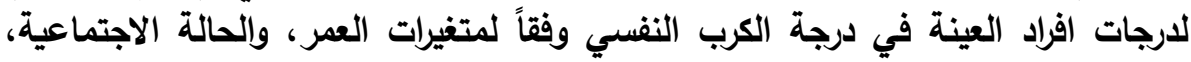

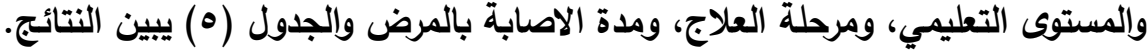
جدول (•) تحليل التباين الخماسي (عديم التفاعل) لدرجات افراد العينة في درجة الكرب النفسي وفقاً لمتغيرات الدراسة الاستة

\begin{tabular}{|c|c|c|c|c|c|}
\hline الدلالة & قيمة ف & متوسط & درجة & مجموع & مصدر \\
\hline
\end{tabular}




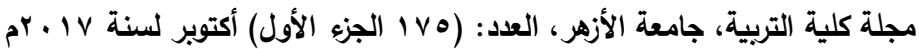

\begin{tabular}{|c|c|c|c|c|c|}
\hline الاحصائية & & المربعات & الحرية & المربعات & التباين \\
\hline ***, , I I & $r, \Delta \Delta r$ & $q \leq, r \cdot q$ & $r$ & $|\wedge \wedge, \&| \wedge$ & العمر \\
\hline ** •, , r & 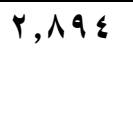 & V & $r$ & $r r \cdot, r \cdot V$ & الاجتماعية \\
\hline$\cdot, 7 \leq 0$ & צד & 17,091 & $\varepsilon$ & סדו, צד & التعليميتوى \\
\hline$\cdot, r \cdot r$ & 1,011 & $\varepsilon \cdot, \wedge$. & $\varepsilon$ & A $17, r \mid$ & مرحلة العلاج \\
\hline.,$\leqslant 17$ & $\cdot, \wedge \wedge r$ & $r r, r \wedge r$ & $\begin{array}{c}\text { r } \\
\text { irv } \\
\text { ior }\end{array}$ & 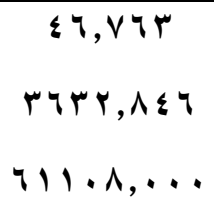 & مدة الإصابة \\
\hline
\end{tabular}

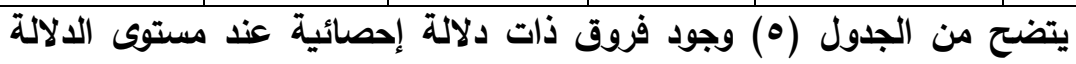

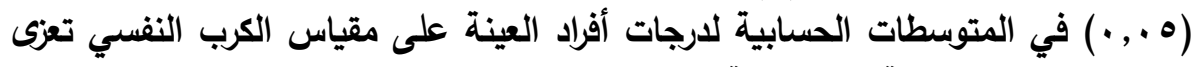

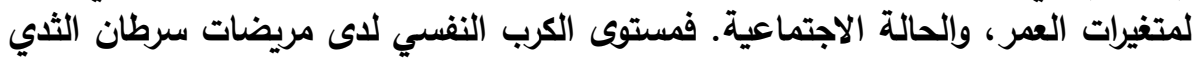

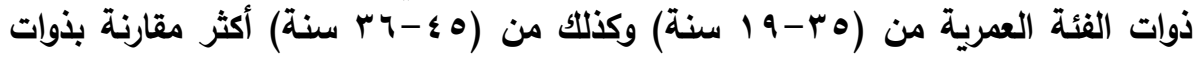

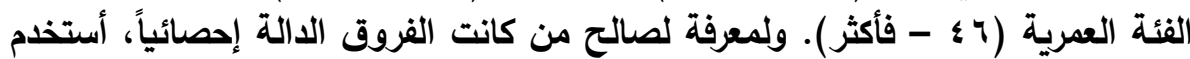
اختبار شيفيه (Scheffe) للمقارنات البعدية، والجدول (؟) يبين ذلك. جدول (†) نتائج اختبار شيفيه (Scheffe) للمقارنات البعدية لمتغيرات العمر

\begin{tabular}{|c|c|c|c|}
\hline الاحصائية & المتوسط الحسابي & فئة المتغير & المتغير \\
\hline $\begin{array}{l}., .11 \\
., .11\end{array}$ & $\begin{array}{l}\text { *Y, }, 00 \uparrow 0- \\
* Y, \Gamma \backslash \wedge \Lambda-\end{array}$ & 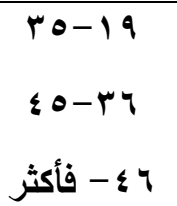 & العمر \\
\hline
\end{tabular}

يتضح من الجدول (7) وجود فروق ذات دلالة إحصائية عند مستوى الدلالة

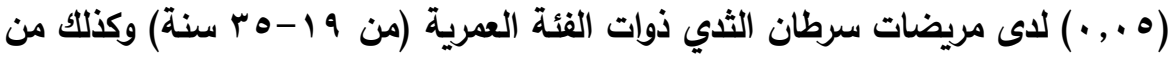

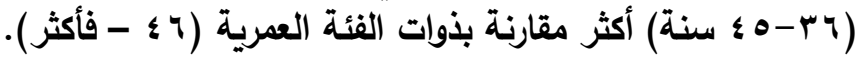

جدول (V) نتائج اختبار شيفيه (Scheffe) للمقارنات البعدية لمتغير الحالة الاجتماعية 


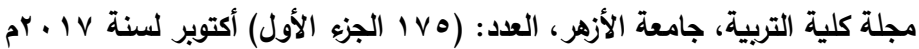

\begin{tabular}{|c|c|c|c|}
\hline الالالة الاحصائية & المتوسط الحسابي & فئة المتغير & المتغير \\
\hline $\begin{array}{l}\cdot, \cdot r \leq \\
\cdot, V \cdot r \\
\cdot, r r q\end{array}$ & 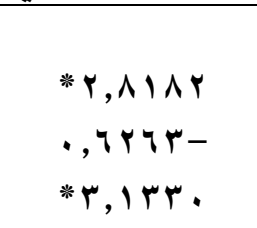 & متزوجة مطلة & عزباء الحالة الاجتماعية: \\
\hline $\begin{array}{l}\cdot, \cdot r \varepsilon \\
\cdot, \cdot 11 \\
\cdot, V \wedge r\end{array}$ & 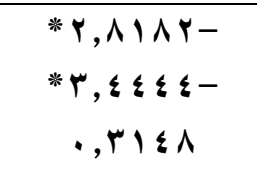 & مزباء & متزوجة \\
\hline $\begin{array}{l}\cdot, v \cdot r \\
\cdot,+11 \\
\cdot,+11\end{array}$ & 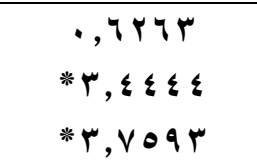 & متزوجة مزبة & مطلقة \\
\hline $\begin{array}{l}\cdot, \cdot r q \\
\cdot, \vee \wedge r \\
\cdot, \cdot 1 \wedge\end{array}$ & $\begin{array}{l}r, \mid r r \cdot- \\
\cdot, r \mid \leq \wedge- \\
* r, \vee \diamond q r-\end{array}$ & متزوجة & أرملة \\
\hline
\end{tabular}

يتضح من الجدول (V) وجود فروق ذات دلالة إحصائية عند مستوى الدلالة

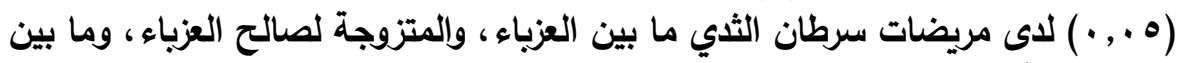

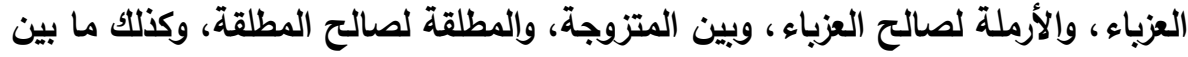

المطلقة والأرملة لصالح المطلقة.

ثالثاً - النتائج المتعلقة بالسؤال الثالث الذي نصه:" ما مستوى الدعم الاجتماعي لأى الداب

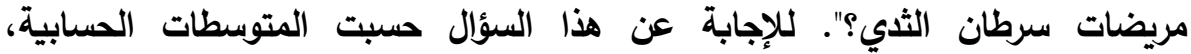

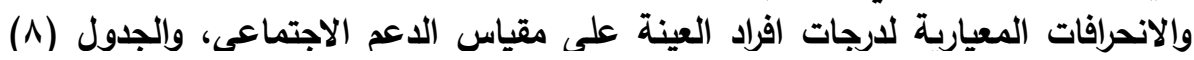

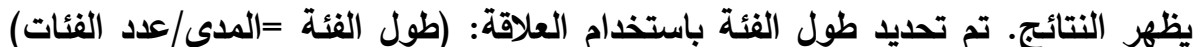

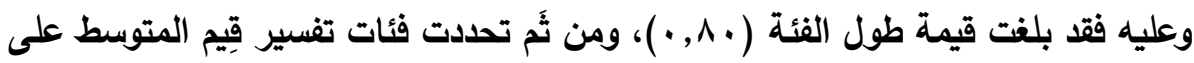
النحو الآتي: وعلي

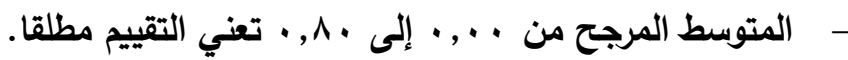
- - المتوسط المرجح من 1 1, • إلى • ؟ , 1 تعني التقييم نادرا.

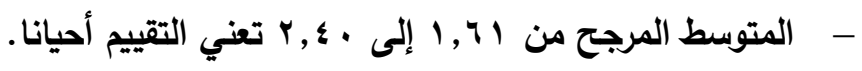

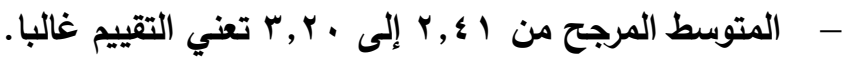

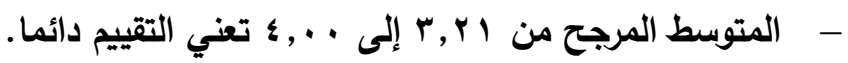




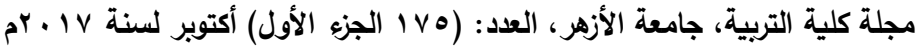

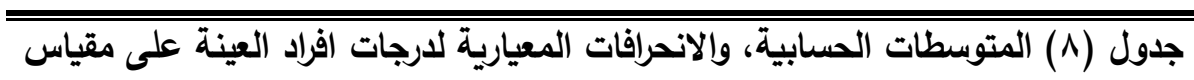

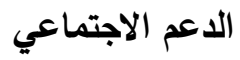

\begin{tabular}{|c|c|c|c|c|c|c|}
\hline التقييم & المستوى & الانحراف & الحسابي & المقياس & رقم & الرتبة \\
\hline دائماً & متوسط & $\cdot, V \varepsilon$ & $\Gamma, \mu \wedge$ & العائلة & 1 & 1 \\
\hline دائماً & متوسط & $\cdot, \wedge \wedge$ & r.r. & الآخرين & $r$ & r \\
\hline غالباً & متوسط & $1,1 r$ & $r, \ldots$ & الأصدقاء & $r$ & $r$ \\
\hline غالباُ & متوبط & $\cdot, \vee \wedge$ & 4,19 & الكلي & & \\
\hline
\end{tabular}

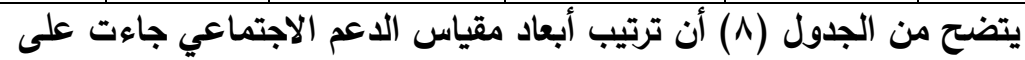

النحو التالي بعد العائلة، يليه الآخرين ثم الأصدقاء.

رابعاً - النتائج المتعلقة بالسؤال الرابع الأي نصه:" هل توجد فروق دالة احصائياً

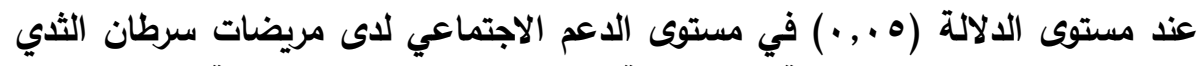

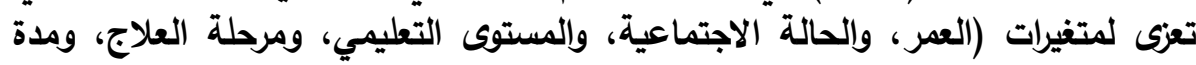

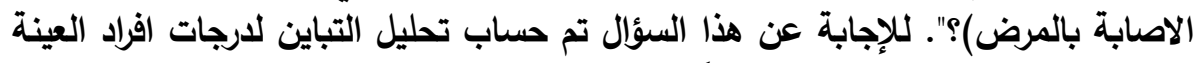

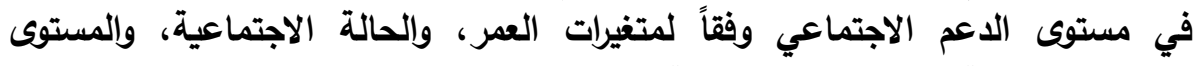
التعليمي، ومرحلة العلاج، ومدة الاصابة بالمرض وإئمات والجدول (9 ) يبين النتائج. جدول (9) تحليل التباين الخماسي (عديم التفاعل) لارجات افراد العينة في مستوى الدعم الاجتماعي وفقاً لمتغيرات الدراسة لاعة أفرات

\begin{tabular}{|c|c|c|c|c|c|}
\hline الاحصائية الالة & قيمة ف & المربعات & الحرية & مجموع المربعات & التباين مصدر \\
\hline$\cdot, V \cdot q$ & $\cdot, r \leqslant \Lambda$ & MI, & $r$ & $q Y, \& Y q$ & العمر \\
\hline$\cdot, \varepsilon \cdot r$ & $\cdot, 9 \wedge r$ & $\Lambda \Lambda, \cdot Y \theta$ & $r$ & YY\&,.VO & الاجتماعية \\
\hline$\cdot, \vee \wedge q$ & $\cdot, \leqslant Y q$ & $r \wedge, r \cdot \varepsilon$ & $\varepsilon$ & IOY,AIV & التعليمي المستوي \\
\hline.,$\leqslant 97$ & $\cdot, \wedge \bullet$. & Vq,1 r & $\varepsilon$ & r. $\leq, 70$. & مرحلة \\
\hline
\end{tabular}




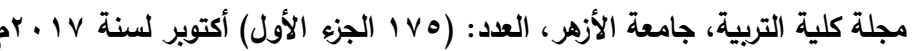

\begin{tabular}{|c|c|c|c|c|c|}
\hline., 09. & $\cdot, \Delta r$. & $\leqslant V, \leqslant V$. & $\begin{array}{l}\text { r } \\
\text { irt } \\
\text { IOr }\end{array}$ & $\begin{array}{c}q \leq, q \leq 1 \\
\text { Mrrvr, } 9 q \\
r r v q q \leq, \ldots\end{array}$ & مدة الإصابة \\
\hline
\end{tabular}

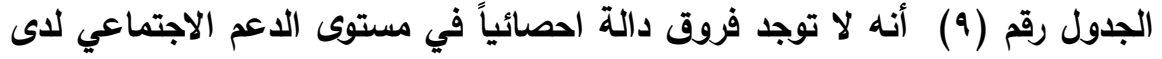
مريضات سرطان الثدي تعزى لمتغيرات العمر، والحالة الاجتماعية، والمستوى التهاتيات التعليمي،

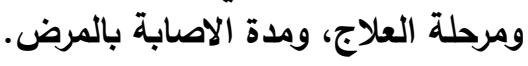

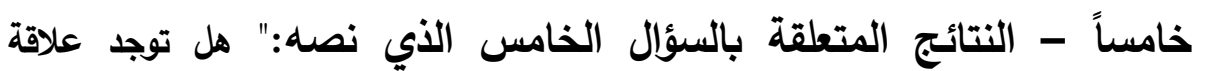

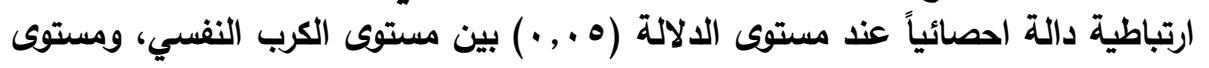

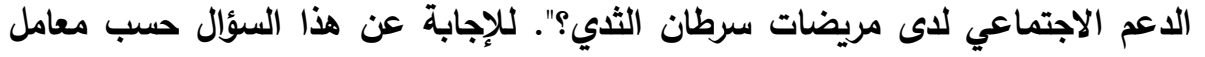

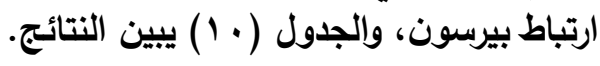

جدول رقم ( • 1) معامل الارتباط بين مستوى الكرب النفسي، والدعم الاجتماعي

\begin{tabular}{|c|c|}
\hline الاعم الاجتماعي & معامل ارتباط بيرسون \\
\hline$-.370^{* *}$ & الكرب النفسي Pearson Correlation \\
\hline .000 & Sig. (2-tailed) \\
\hline 171 & $\mathbf{N}$ \\
\hline
\end{tabular}

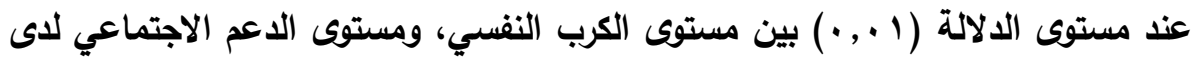
مريضات سرطان الثدي.

سادساً - النتائج المتعلقة بالسؤال السادس الذي نصه:" هل يمكن التنبؤ بالكرب

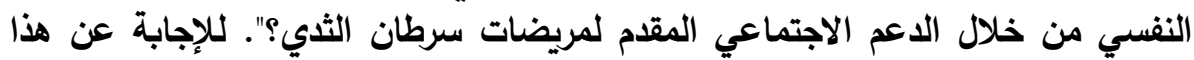
السؤال تم حساب قيم معامل الارتباط بين المتغيرين ومعامل التحديد وقيمة التئي التباين ودلالته

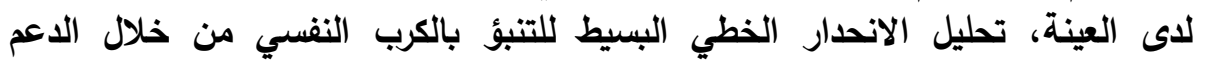
الاجتماعي، والجدول (1 (1)، (Y I ) يبين ذلك. 


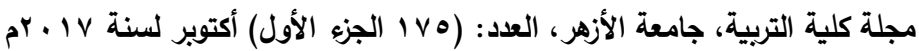

جدول (1 11) يبين قيم معامل الارتباط بين المتغيرين ومعامل التحديد وقيمة التباين ودلالته لاى العينة

\begin{tabular}{|c|c|c|c|c|}
\hline الاحصائية الالة & قيمة ( ف) & $\begin{array}{c}\text { مربع معامل الارتباط المتعدد } \\
\text { (R²) }\end{array}$ & $\begin{array}{c}\text { معامل الارتباط (R) } \\
\text { المتعدد }\end{array}$ & مصدر الانحدار \\
\hline$\ldots$ & $r \Delta, Y Y$ &.,$I r V$ & $\cdot, r V$ & الكرب النفسي \\
\hline
\end{tabular}

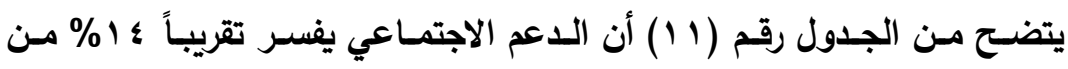

التفاوت في درجة الكرب النفسي بين افراد العينة.

حدول (Y I ) تحليل الانحدار الخطي البسط للتنئُ بالكرب النفسي من خلال الدعم الاجتماعي

\begin{tabular}{|c|c|c|c|c|}
\hline الاحصائية & قيمة (ت) & معامل الانحدار & $\begin{array}{c}\text { معامل الانحدار } \\
\text { B }\end{array}$ & المؤشرات الاحصائية \\
\hline .000 & & & $r V, £ V$ & ثابت الانحدار \\
\hline .000 & $0, \cdot r-$ & $\cdot, r v-$ & - , YIV- & الاعم الاجتماعي \\
\hline
\end{tabular}

يتضح من الجدول رقم (r I ) أن كل زيادة درجة في مقياس الدعم الاجتماعي

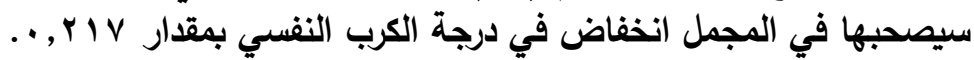

مناقشة نتائج الاراسة:

أولاً: مناقشة النتائج المتعلقة بالسؤال الأول " ما مستوى الكرب النفسي لاى

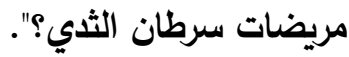

$-r \leqslant q-$ 


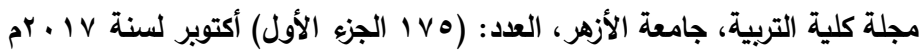

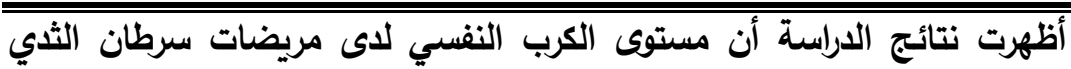

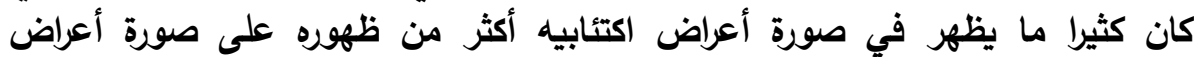

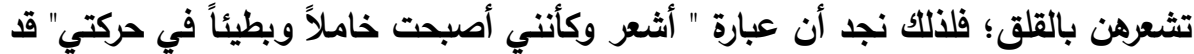

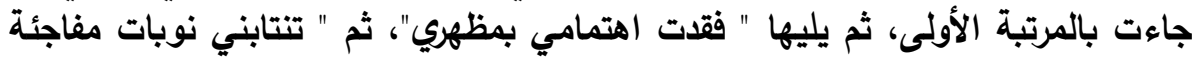

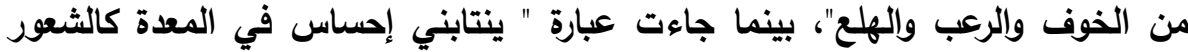

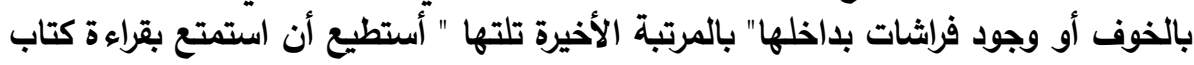

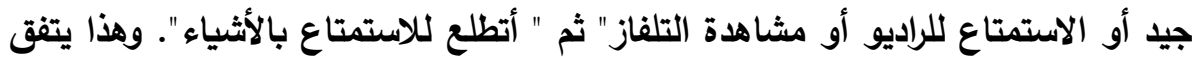

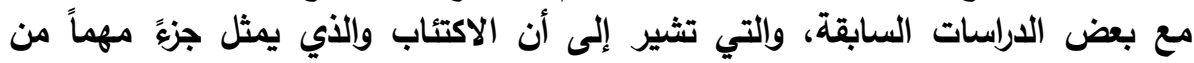

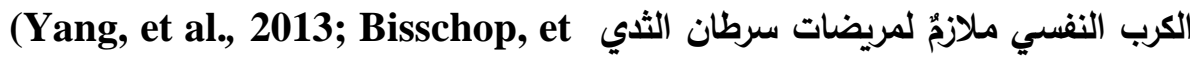
al., 2004; Sick-Eom et al., 2013; Tel, Sari \& Aydin, 2013)

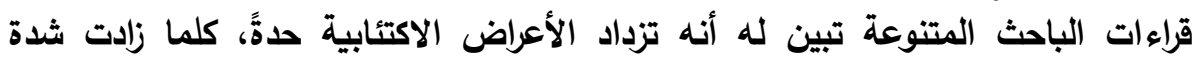

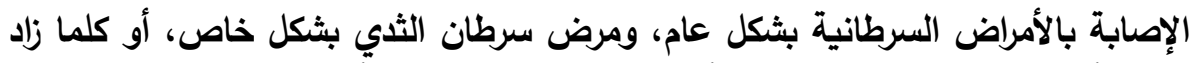

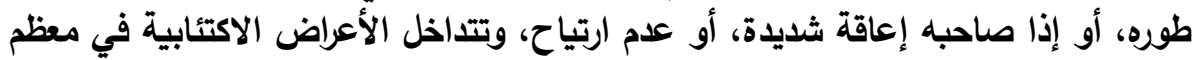

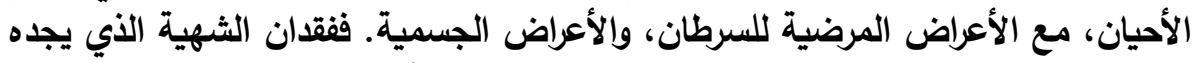

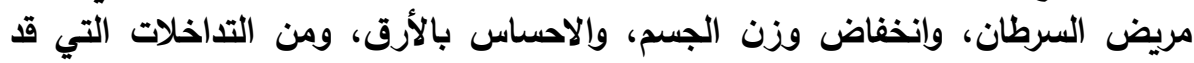

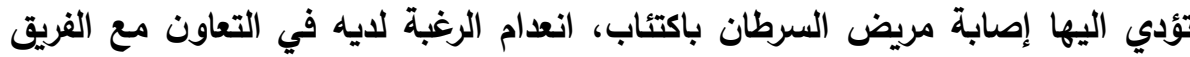

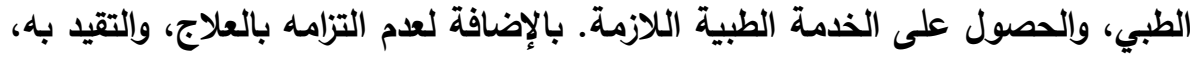

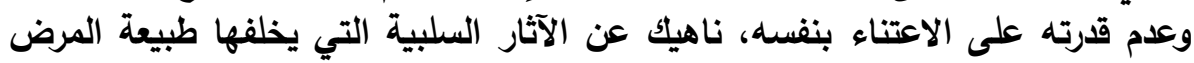
على نوعية حياة المريض بثكل عام.

ثانياً - مناقشة النتائج المتعلقة بالسؤال الثاني الذي نصه:" هل توجد فروق دالة

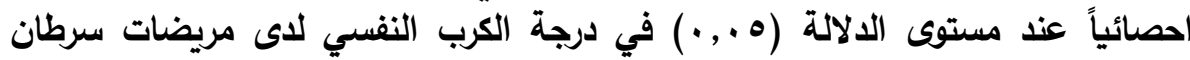

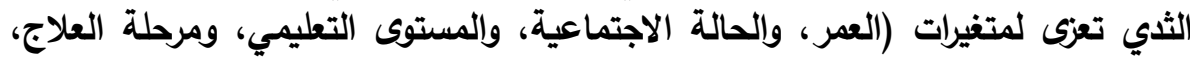

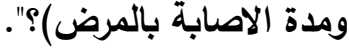

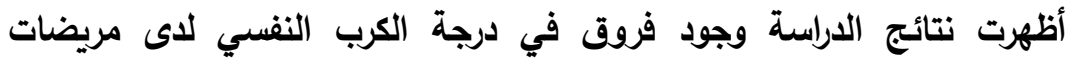

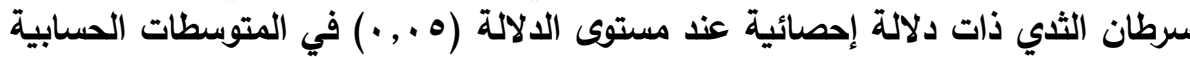

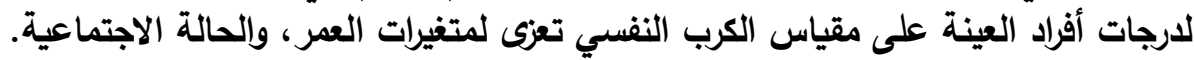

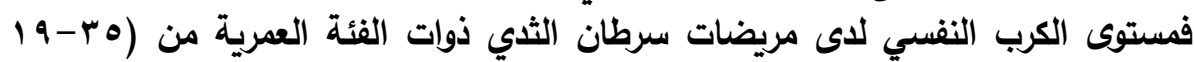

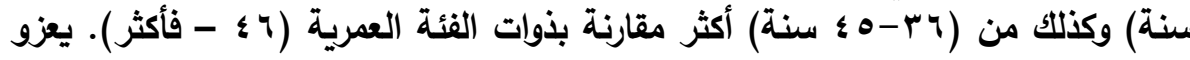

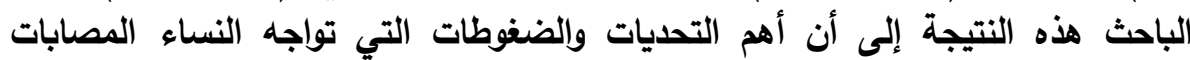

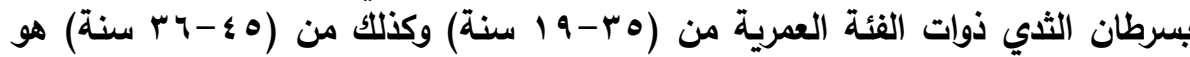

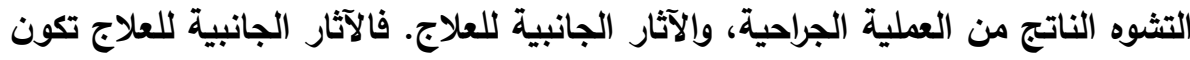

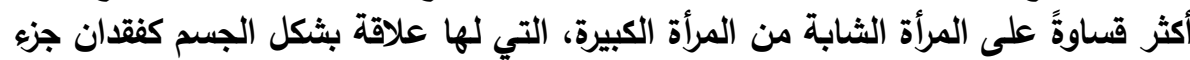




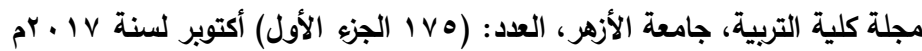

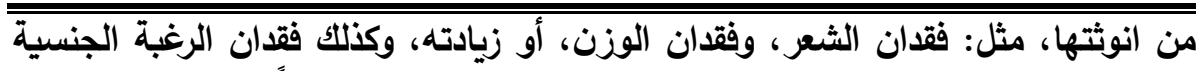

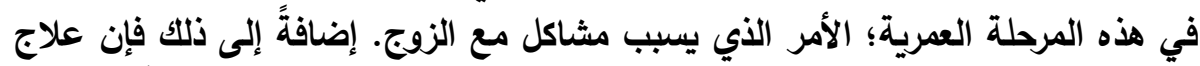

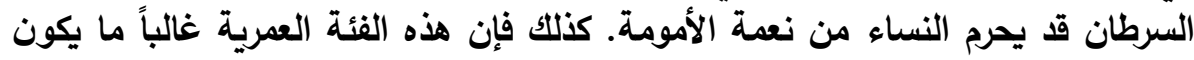

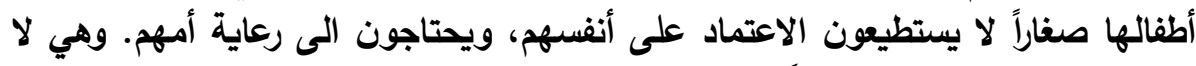

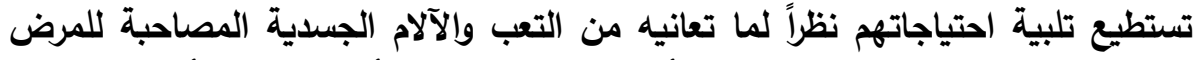

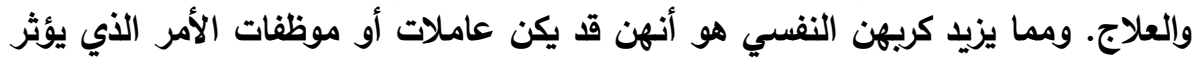
على مستوى دخلهن المادي والمستوى الاقتصادي للأسرة.

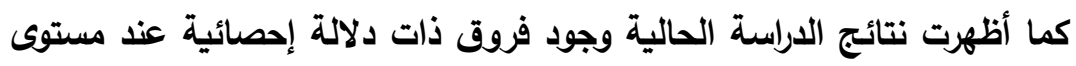

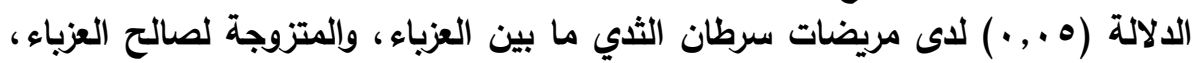

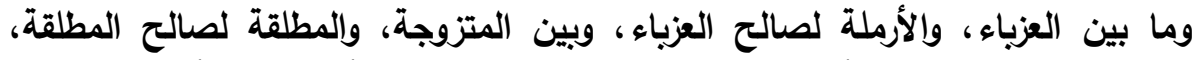

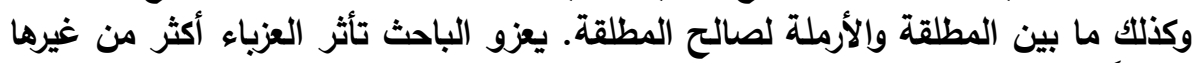

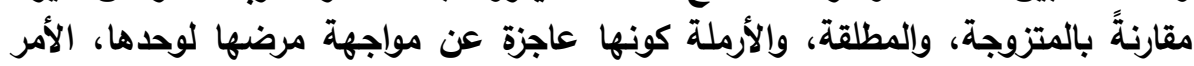

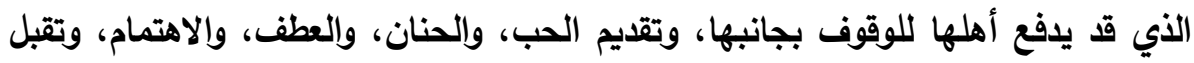

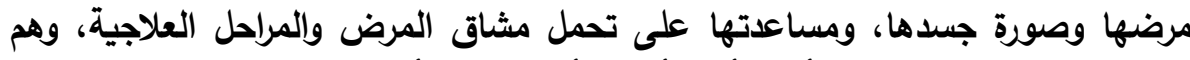

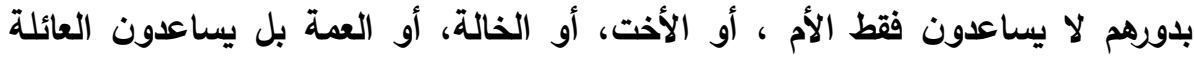

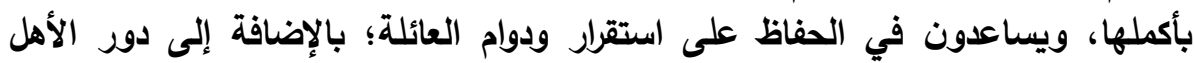

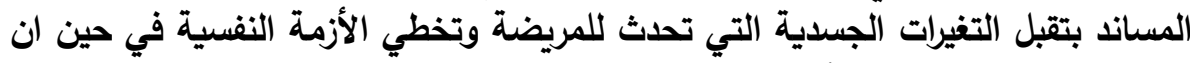

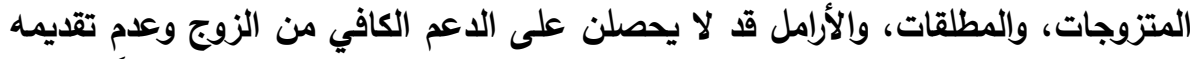

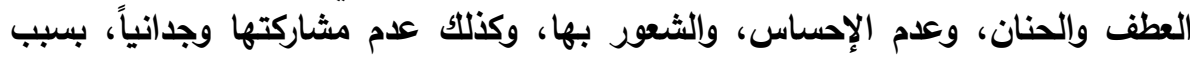

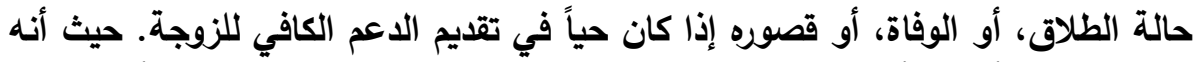

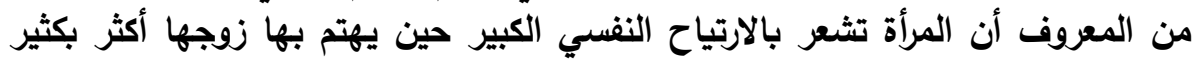

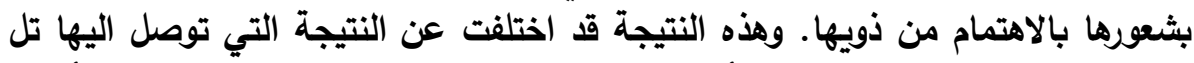

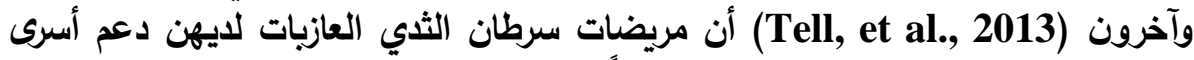

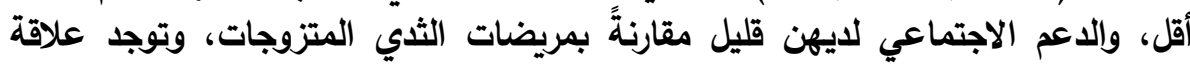
سلبية ذات دلالة إحصائية بين درجات الثعور بالوحدة، ودرجات الاعم الاجتماعي.

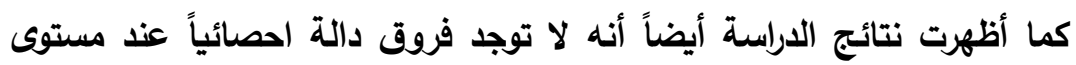

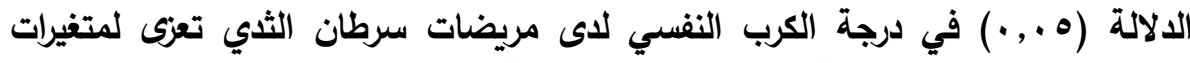

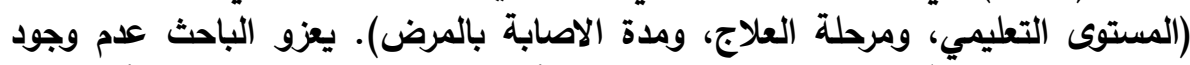

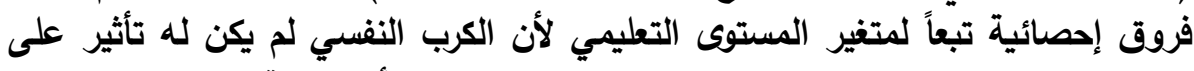

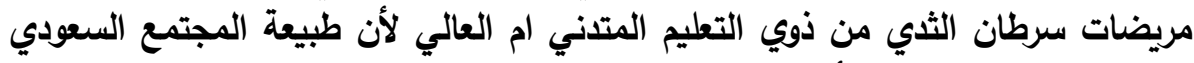

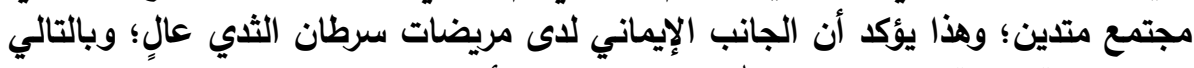

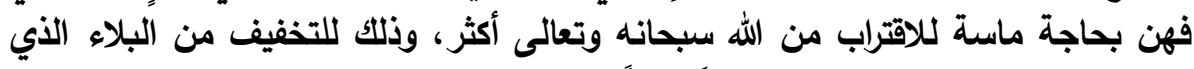

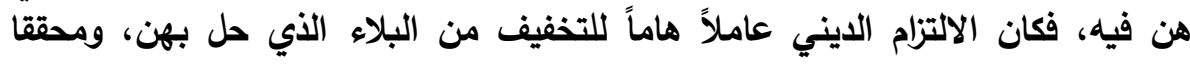


مجلة كلية التربية، جامعة الأزهر ، العلد : (V0 الجزء الأول) أكتوبر لسنة V V ب Yم

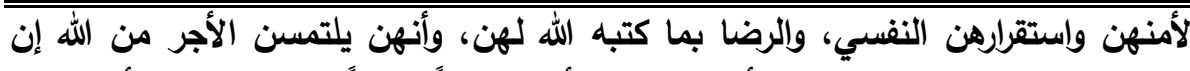

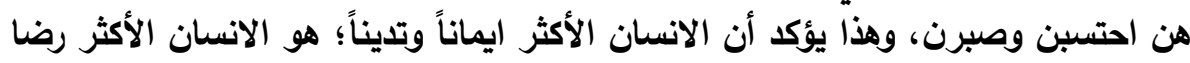

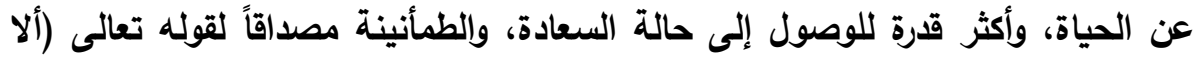

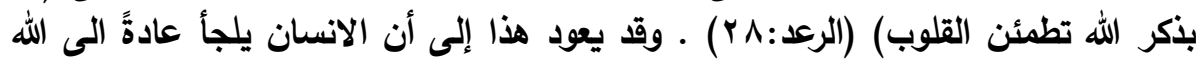

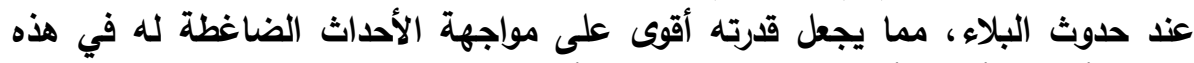

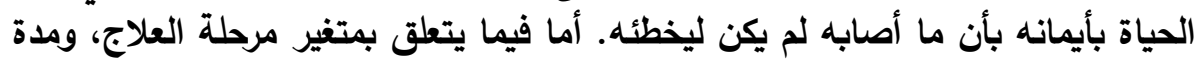

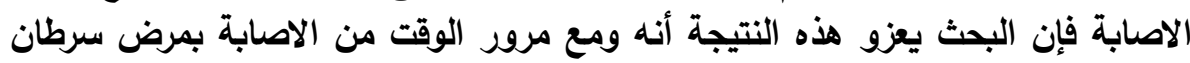

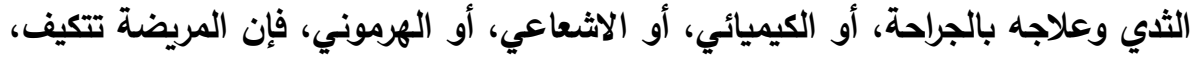

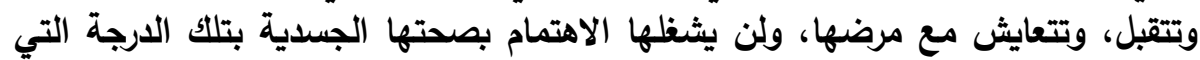

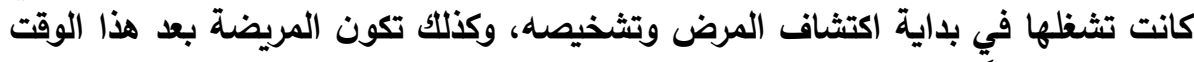

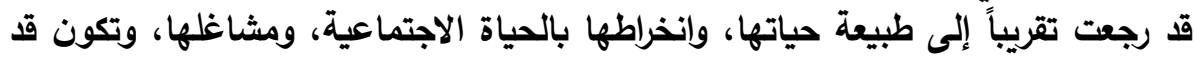

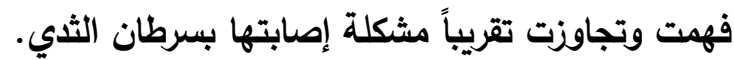
ثالثاً: مناقشة النتائج المتعلقة بالسؤال الثالث " ما مستوى الدعم الاجتماعي لدى إى لثان

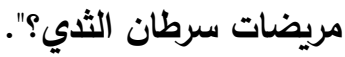

أظهرت نتائج الدراسة أن مستوى الدعم الاجتماعي لدى مريضات سرطان الثاي الثاي

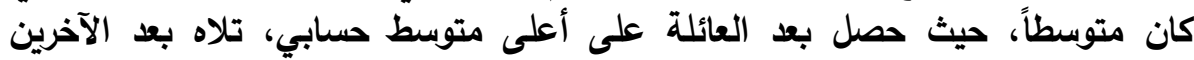

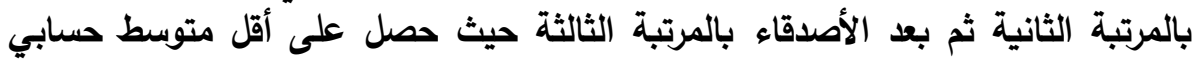

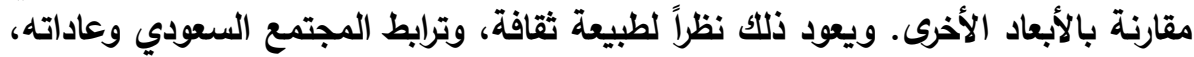

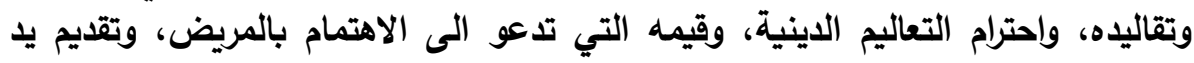

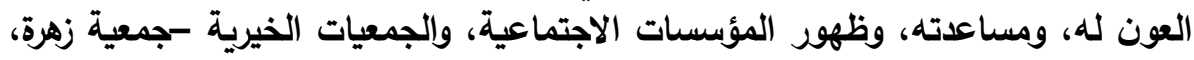

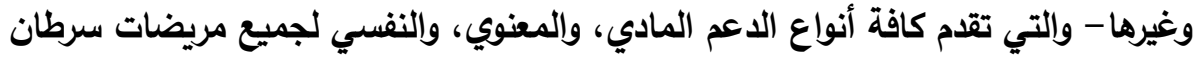

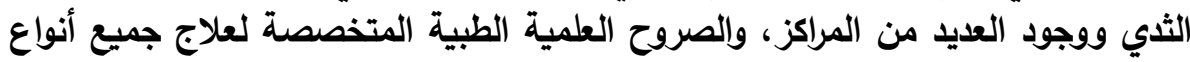

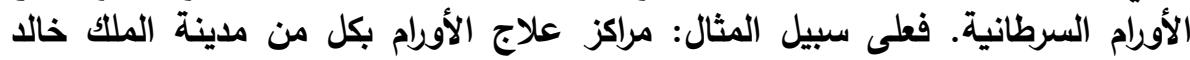

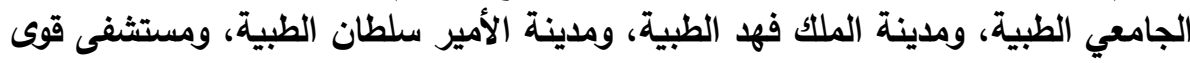

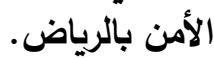

إضافة الى الدور البارز للإعلام، والتقدم التكنولوجي، والذي يقدم من خلاديه

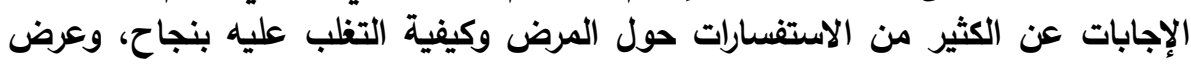

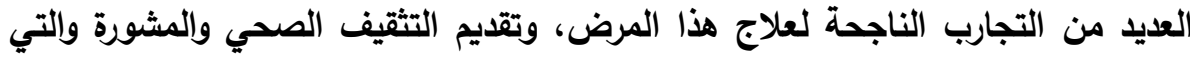

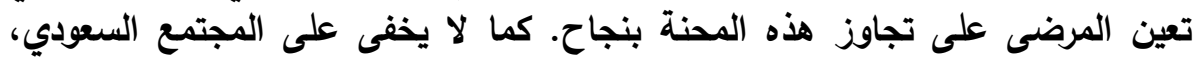

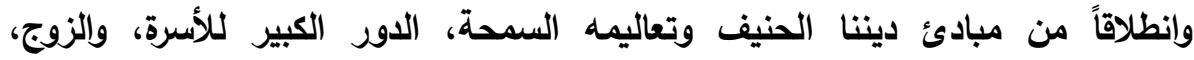

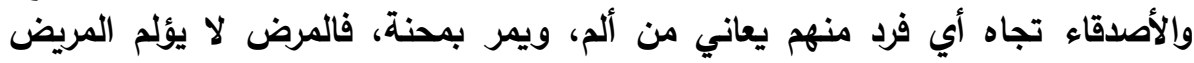

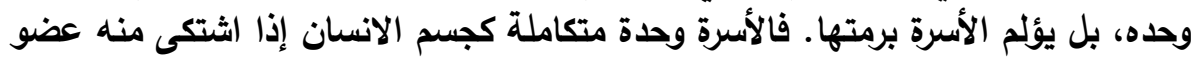




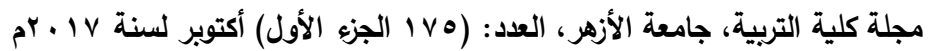

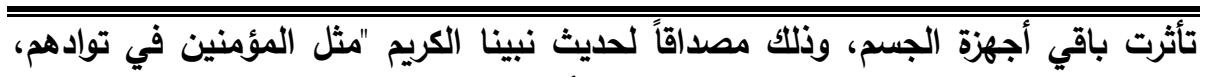

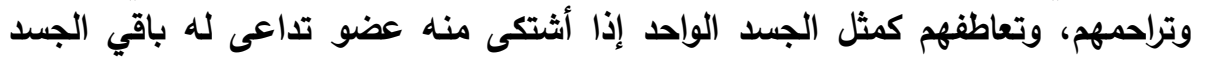

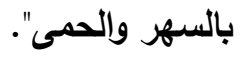

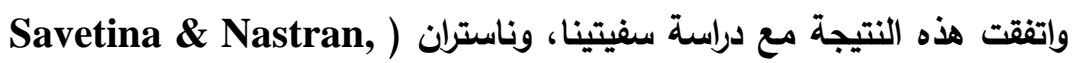

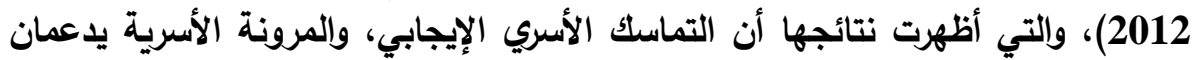

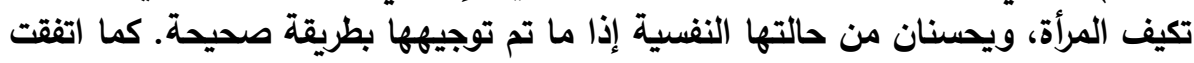

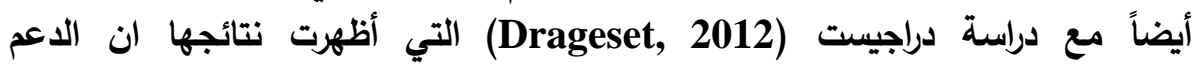

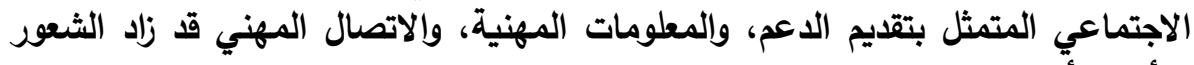

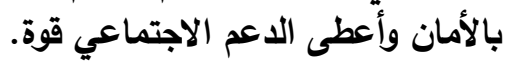

رابعاً - مناقشة النتائج المتعلقة بالسؤال الرابع الذي نصه:" هل توجد فروق دالة

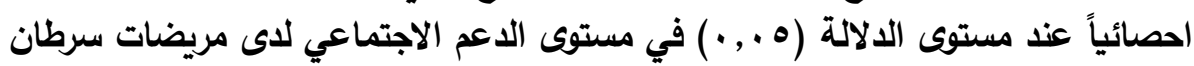

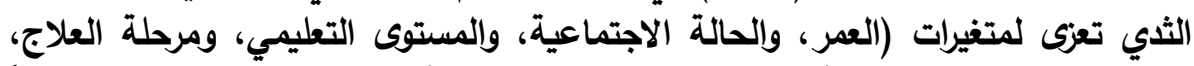

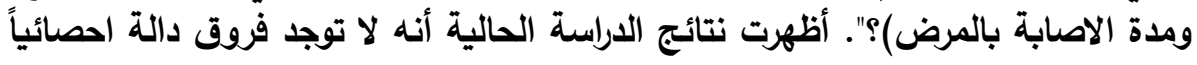

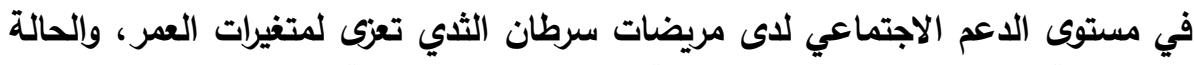

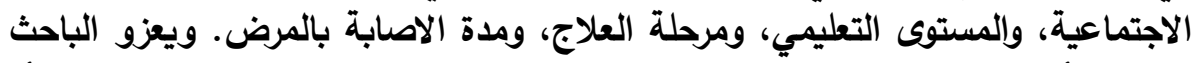

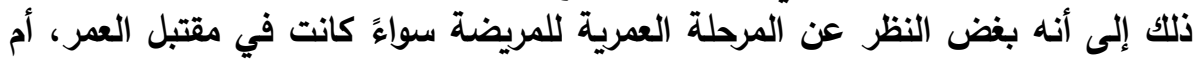

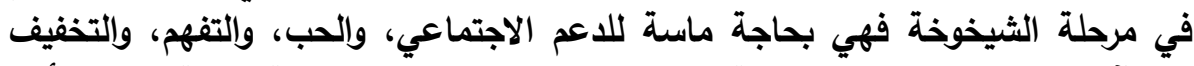

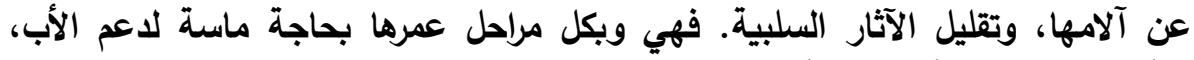

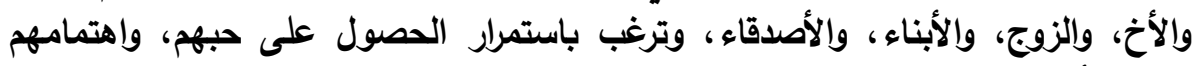

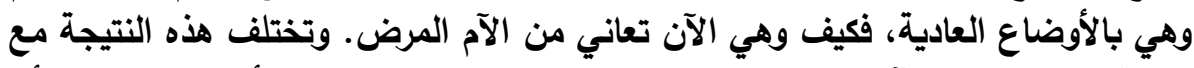

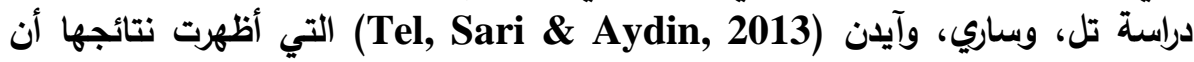

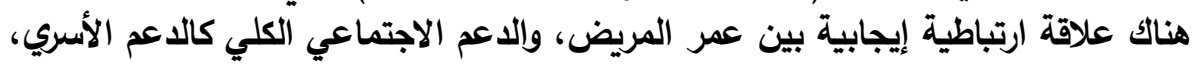

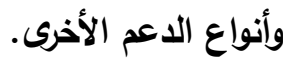

أما بخصوص المستوى التعليمي فالمجتمع السعودي المتعاطف مع الأبنة، الأبن،

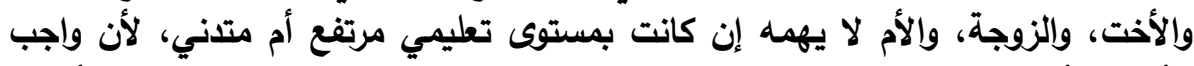

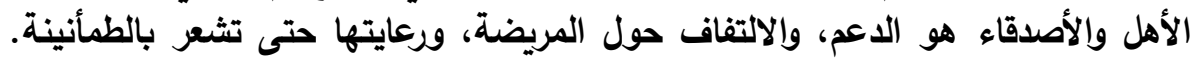

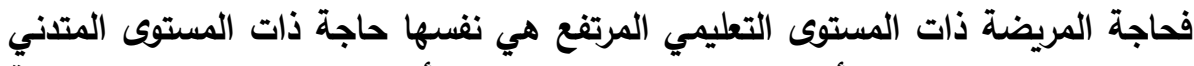

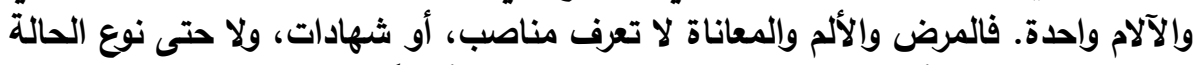

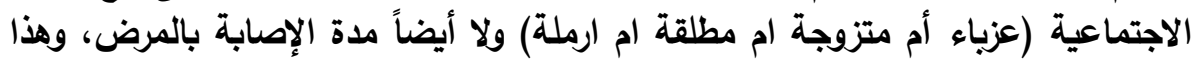




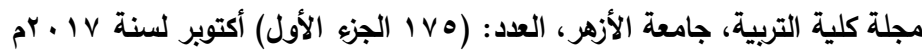

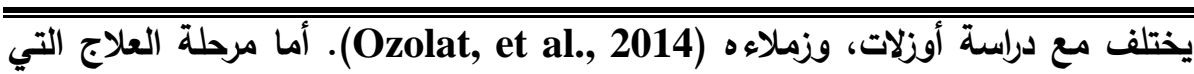

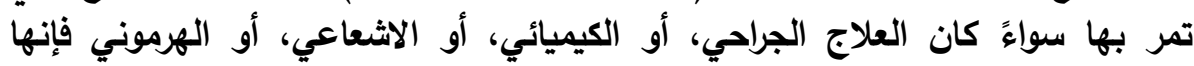

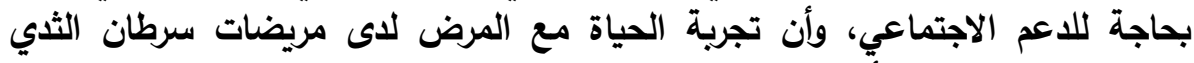

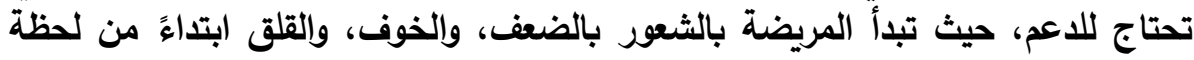

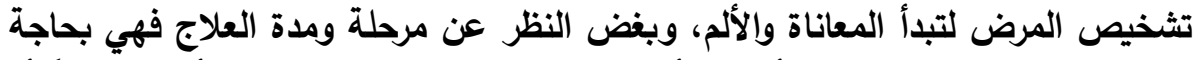

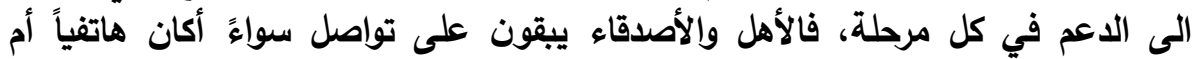

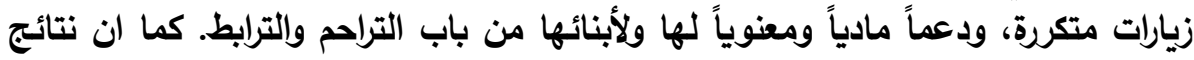

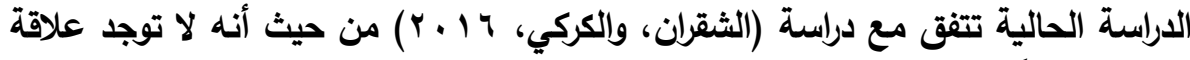
دالة احصائياً بين الدعم الاجتماعي وكل من متفير العمر، والثي، والمستوى التعليمي، ومرحلة

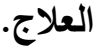

خامساً - مناقشة النتائج المتعلقة بالسؤال الخامس الذي نصه:" هل توجد علاقة

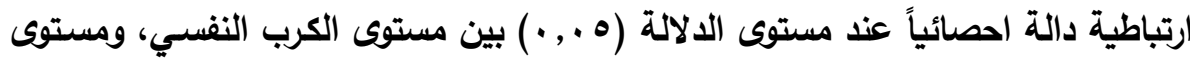

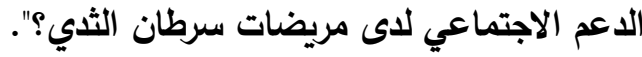

أظهرت نتائج الدراسة الحالية أنه توجد علاقة ارتباطية عكسية دالة احصائياً

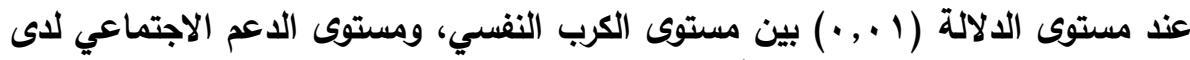

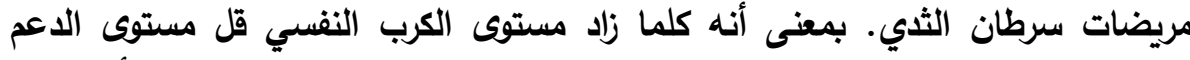

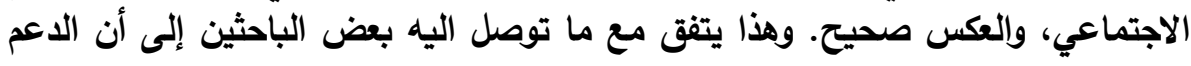

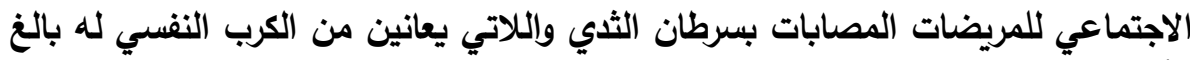
الأثر في تحسن حال حالتهن الصحية.

(Tel, Sari \& Aydin, 2013; Cutrona, Russel \& Rose, 1986; Helgeson قوي \& Cohens, 1996; Compas \& Luecken, 2002) قوية على أن الدعم المقدم من العلاقات الاجتماعية مع الآخرين خاصة من الألفئ الأسرة،

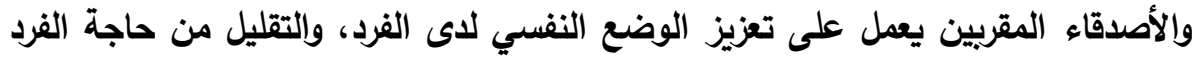

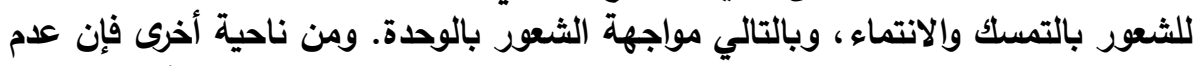

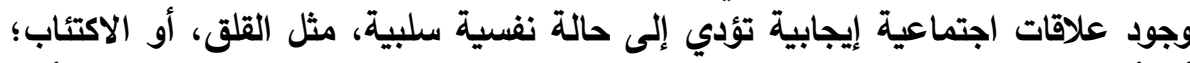

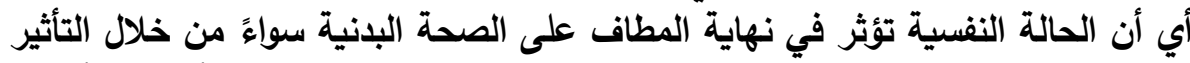

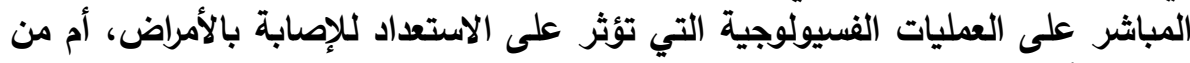

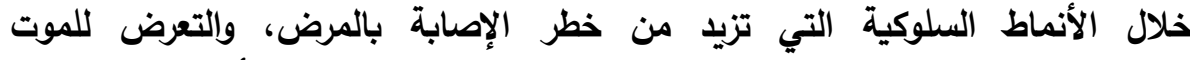
توقد أكدات النتائج التي (Bisschop, Kriegsman, Beekman \& Deeg, 2004).

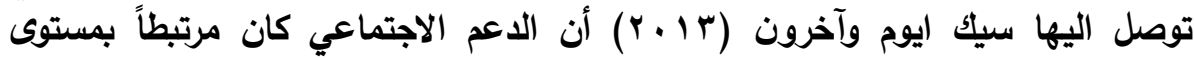

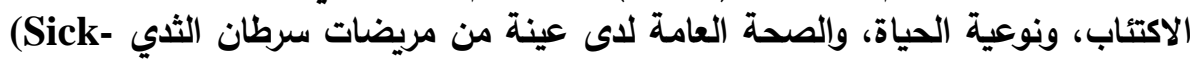

.Eom et al., 2013) 


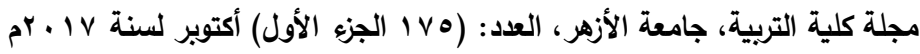

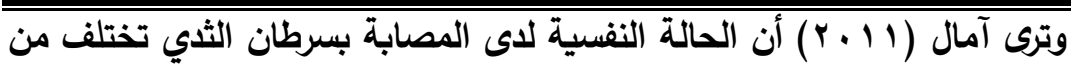

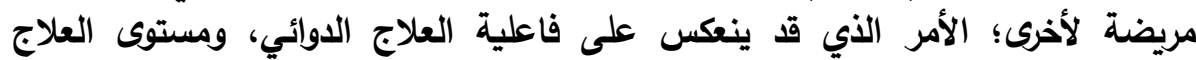

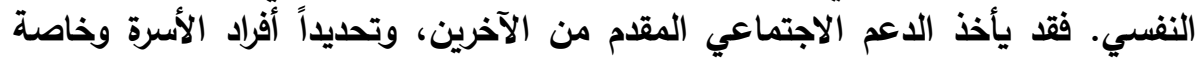

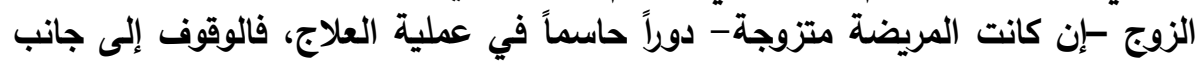

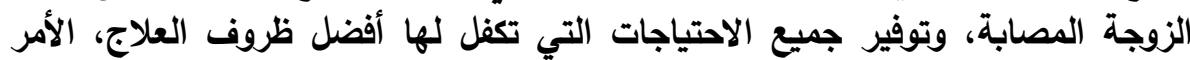

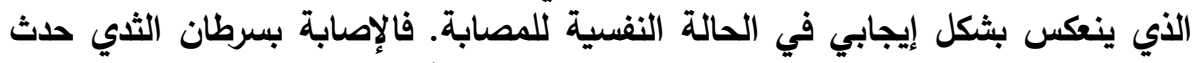

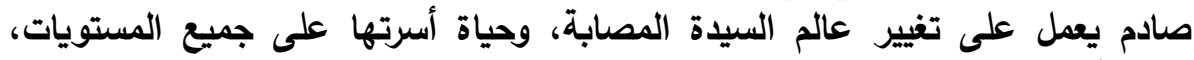

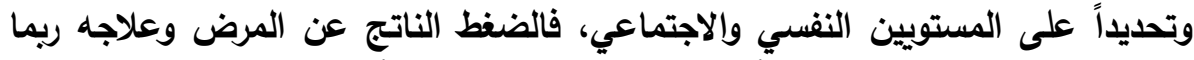

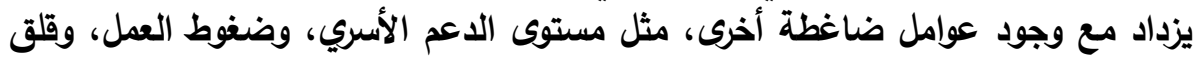
المستقبل، ونكوص الحالة النفسية، ورفض الذات، وعلم الرضا عن الحياة..

سادساً - مناقثة النتائج المتعلقة بالسؤال السادس الذي نصه:" هل يمكن التنبؤ

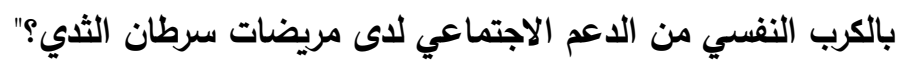

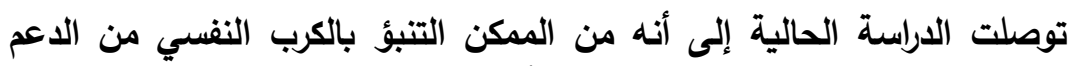

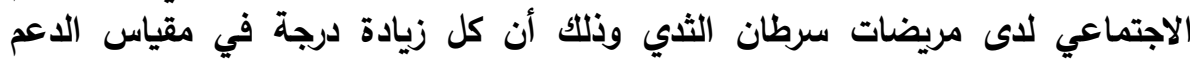

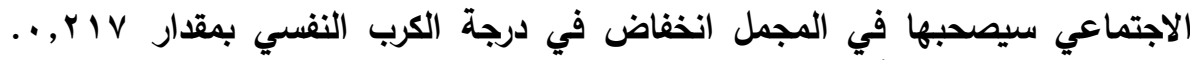

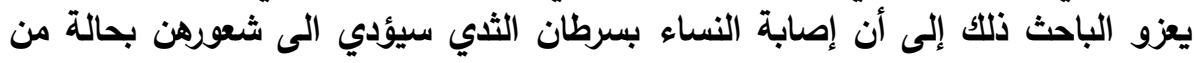

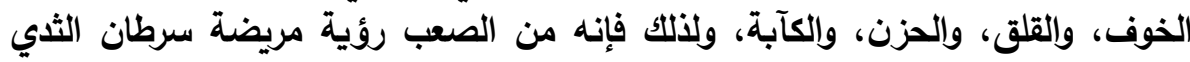

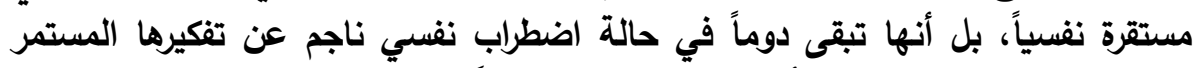

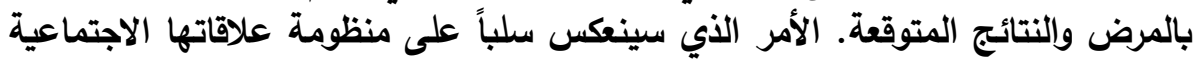

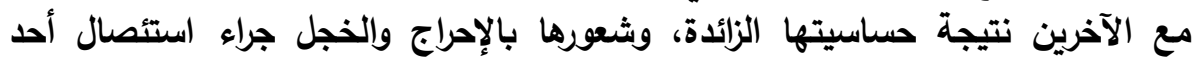

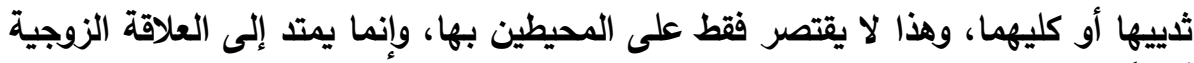

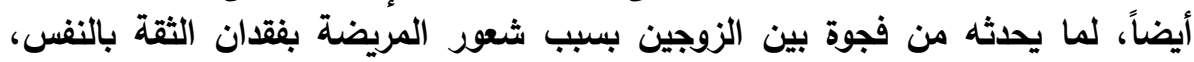

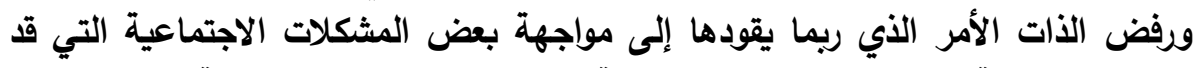

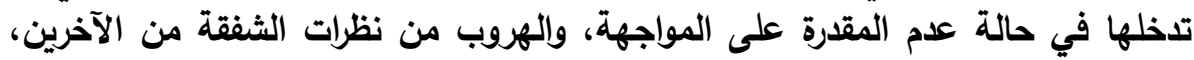

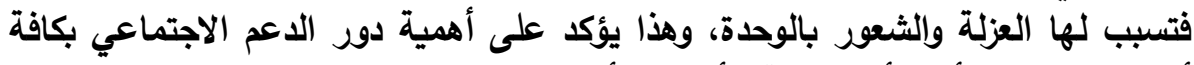

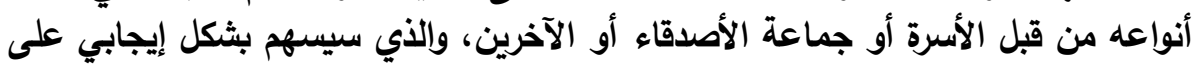

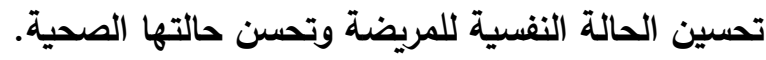

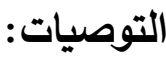
في ضوء ما توصلت اليها الاراسة من نتائج يوصي الباحث بما يلي: 


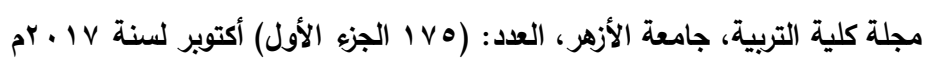

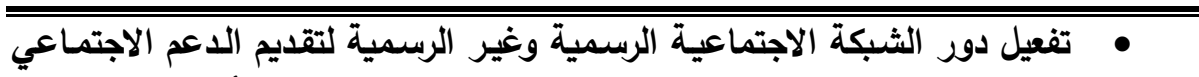

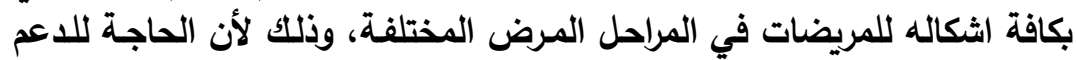

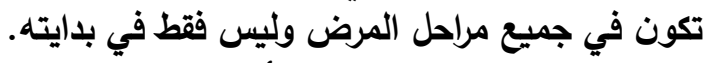

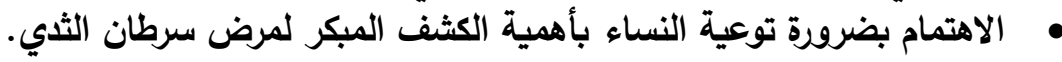

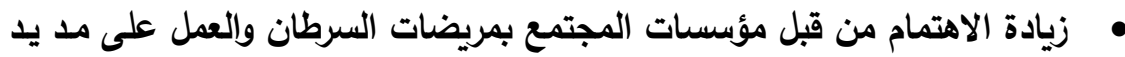

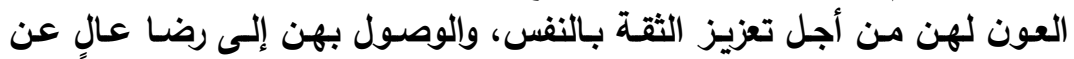

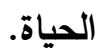

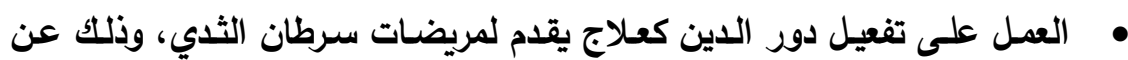

طريق تصميم برامج ارشاد ديني للمريضات.

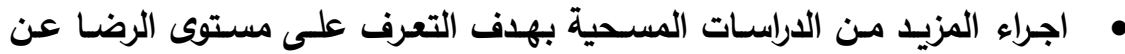

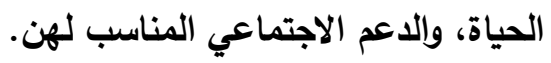

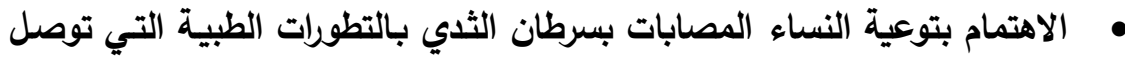

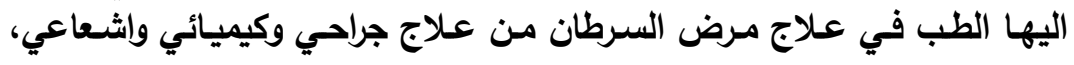

وهرموني.

• اجراء دراسات تبحث في المساندة الاجتماعية وعلاقتها بالضغوط النفسية والقلق

لأى مريضات سرطان الثدي.

• اجراء دراسـات تتــاول صسورة الجسم ومستوى القلق والاكتئساب للدى مريضـات

سرطان الثدي. 


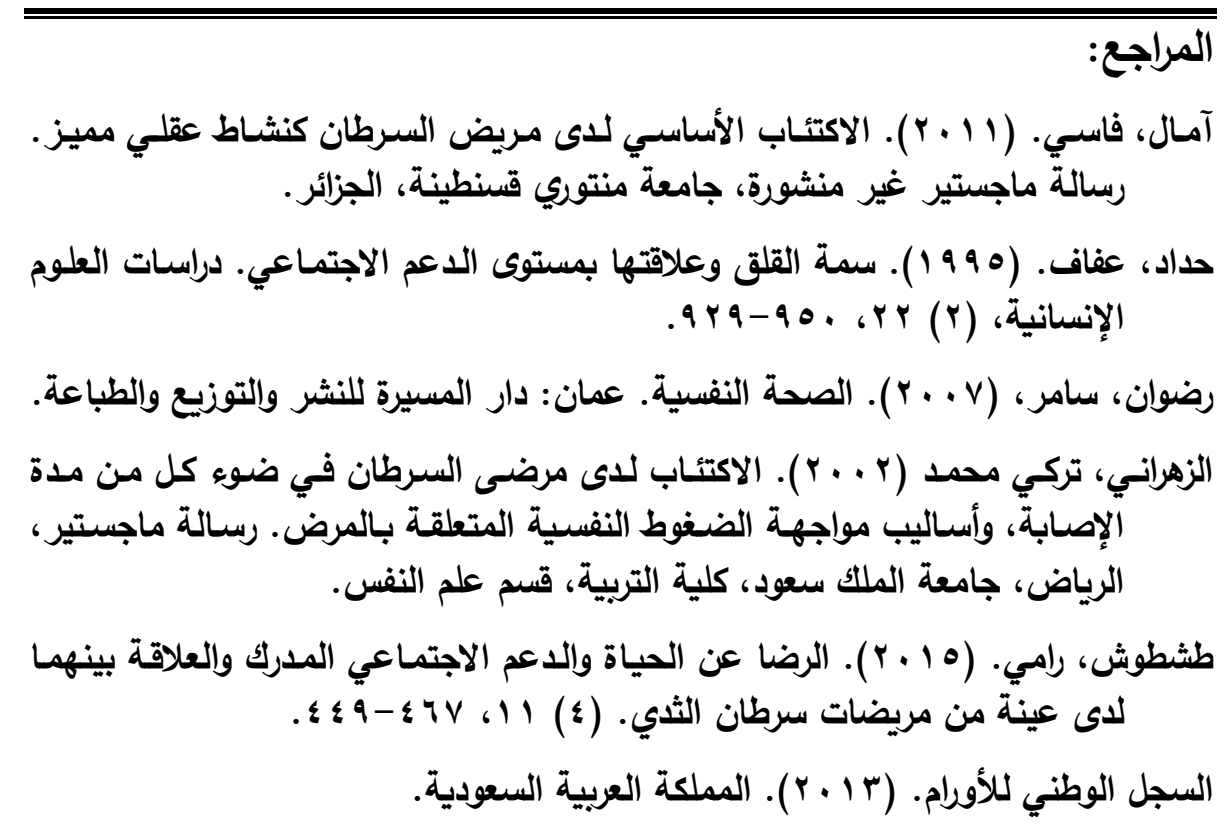

http://www.shc.gov.sa/Ar/HealthCenters/NCC/CancerRegistry/Pages/Ca ncerRegistryRecords.aspX

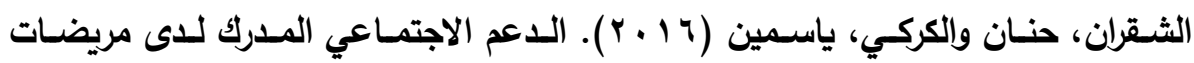

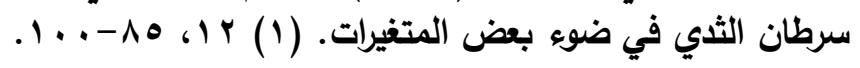

American Cancer Society. (2014). Breast cancer. U.S.A.

Breast Cancer Organization. (201 ). Breast cancer. U.S.A.

Bergbom, I. \& Lindwall, L. (2009). The altered body after breast cancer surgery. International Journal of Qualitative Studies on Health and Well-being, 4, 280-287.

Berhili, S., Kadiri, S., Bouziane, A., Aissa, A., Marnouche, E., et al. (2017). Associated factors with psychological distress in Moroccan breast cancer patients: A cross-sectional study. The Breast 31, 26-33.

Buunkm, B., Vanyperen, N., Taylor, S. \& Collins, H. (1991). Social Comparison and the drive upward revisited: affiliation as a response to marital stress. European Journal of social Psychology, 21 (6), 529-546.

Bisschop, M. I., Kriegsman, D. M., Beekman, A. T., \& Deeg, D. J. (2004). Chronic disease and depression the modifying role of psychological resources. Social science and Medicine, 59, 721-733. 


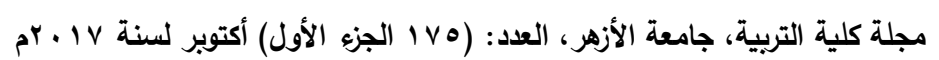

Boesen, E., H., Johansen, C. (2008). Impact of psychotherapy on cancer survival: time to move on?. Curr Opin Oncol, 20(4), 372-377.

Cohen, S., \& Will, T. A. (1985). Stress social support and the buffering hypothesis. Psychological Bulletin, 98 (2), 310-335.

Compas, B. E., \& Luecken, L. (2002). Psychological adjustment to breast cancer. American Psychological Society, 11 (3), 111114.

Cutrona, C., Russell, D., \& Rose, J. (1986). Social support and adaptation to stress by the elderly. Journal of Psychology and Aging, 1 (1), 47-54.

Coyne, J., C., Hanisch, L., J., Palmer, S., C. (2007). Psychotherapy does not promote survival (Kissane et al., 2007): now what? Psycho-Oncology ,16(11), 1050-1052.

Casellas- Grau, A., Vives, J., Font, A., Ochoa, C., (2016). Positive psychological functioning in breast cancer: An integrative review. The Breast, 27, 136-168.

Drageset, S. (2012). Psychological distress, coping and social support in the diagnostic and preoperative phase of breast cancer. Doctoral Dissertation, University of Bergen, Norway.

El-Rufaie, O., \& Absood, G. (19৭๑). Validity study of the Hospital Anxiety and Depression Scale among group of Saudi patients. British Journal of Psychiatry, 151, 687-688.

Hadeed, L., \& El-Bassel, N. (2006). Social support among AfroTrinidadian women experiencing intimate partner violence. Violence Against Women, 12 (8), 220-229.

Helgeson, V. S., \& Cohens, S. (1996). Social support and adjustment to cancer: Reconciling descriptive correlational and intervention research. Health Psychology, 15 (2), 135-148.

Hotopf, M., Chidgey, J., Addington-Hall, J., Lan Ly, K. (2002) Depression in advanced disease: a systematic review. Part 1. Prevalence and case finding. Palliat Med,16, 81-97.

International Agency for Research on Cancer, 2012. World Health Organization. Globocan. http://globocan.iarc.fr/Pages/fact_sheets_cancer.aspx (accessed 24.03.14.).

Jacobs, B., Bigdeli, M., Annear, P., L., Van Damme, W. (2012). Addressing access barriers to health services: an analytical framework for selecting appropriate interventions in lowincome Asian countries. Health Policy Plan, 27, 288-300. 


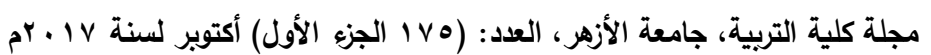

Kleponis, P. (2006). Communication in Marriage. Retrieve March, 2013, from http://www.maritahlhealing.com.

Ozolat, A., Ayaz, T., Konag, O., \& Ozkan, A. (2014). Attachment style and perceived social support as predictors of biopsychosocial adjustment to cancer. Turk J Med Sci, 44, 24-30.

Jorgensen, L., Garne, J., Sogaard, M., Laursen, B., (2015). The experience of distress in relation to surgical treatment and care for breast cancer: An interview study. European Journal of Oncology Nursing, 19, 612-618.

Leavy, R. (1983). Social support and psychological disorder: A review. Journal of Community Psychology, 11 (1), 3-21.

Liao, M., N., Chen, S., C., Chen, S., C., Lin, Y., C., Chen, M., F., Wang, C., H., Hsu, Y., Hung, H., C., Jane, S., W., (2015) Change and predictors of symptom distress in breast cancer patients following the first $\mathbf{4}$ months after diagnosis. Journal of the Formosan Medical Association, 114, 246-253.

Mphil, X., X. (2015). Serious Psychological Distress as a Barrier to Cancer Screening Among Women, Women's Health, 22 (1), 94-55.

NCCN Clinical Practice Guidelines in OncologyTM. (2015). Distress Management http://www.nccn.org/professionals/physician_gls/PDF/distres s.pdf. (Accessed 22 Feb 2016).

Nelson, D., Tyne, K., Naik, A., Bougatsos, C., Chan, B. \& Humphrey, L. (2010). Screening for Breast Cancer: Systematic Evidence Review Update for the U.S Preventive Services Task Force. Ann Intern Med, 17 (151), 727-742.

Pareson, R. E. (1990). Counseling and social support: perspective and practice. Sage publication, the international professional publishers. New burg, London, New Delhi.

Perry, N., Broeders, M., de Wolf, C., Tornberg, S., Holland, R. \& Karsa, R. (2006). European guidelines for quality assurance in breast cancer screening and diagnosis. European Health Communication Publications Belgium.

Sam Oh, Y., (2016). Communications with health professionals and psychological distress in

family caregivers to cancer patients: A model based on stresscoping theory. Applied Nursing Research, 33, 5-9.

Sarason, G., Levine, M., Basham, B., \& Sarason, R. (1983). Assessing social support: The social support questionnaire. Journal of Personality and Social Psychology, 44 (1), 127-139. 


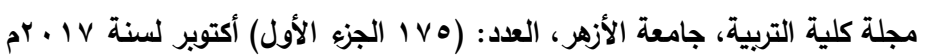

Savetina, M. \& Nastran, K. (2012). Family relationships and posttraumatic growth in breast cancer patients. Psychiatria Danubina, 24 (23), 298-306.

Sick-Eom, C., Shin, D., Kim, S., Yang, H., Sug Jo, H., Kweon, S., Kang, Y., Kim, J., Long Cho, B., \& Park, J. (2013). Impact of perceived social support on the mental health and healthrelated quality of life in cancer patients: Results from a nationwide multicenter survey in South Korea. PsychoOncology, 22, 1283-1290.

Smeltzer, S., Bare, B., Hinkle, J. \& Cheever, K. (2008). Brunner \& Suddarth's Texbook of Medical-Surgical Nursing. USA: Lippincott Williams \& Wilkins.

Snell, L., McCarthy, C., Klassen, A., Cano, S., Rubin, L., Hurley, K., et al. (2010). Clarifying the expectations of patients undergoing implant breast reconstruction: a qualitative study. Plast Reconstr Surg, 126(6), 1825-1830.

Tel, B., Sari, A., \& Aydin, H. (2013). Social support and depression among the cancer patients. Global Journal of Medical Research, 13 (3), 1-5.

Vaxus, A. (1988). Social support: theory, Research, and Intervention. New York: Prager.

Yang YL, Liu L, Wang Y, Wu H, Yang XS, Wang JN, et al. (2013). The prevalence of depression and anxiety among Chinese adults with cancer: a systematic review and metaanalysis. BMC Cancer, 3, 393.

Yildirim, M., \& Batmaz, M. (2013). The psychological status and the perceived social support of women who have undergone breast surgery. Yeni Symposium Journal, 51 (2), 91-100.

Zimet, G. Dahlem, N., Zimet, S. \& Farley, G. (1988). The Multidimensional Scale of Perceived Social Support. Journal of Personality Assessment, 52, 30-41.

Zigmond, A. S. Snaith, R. P. (1983). The Hospital Anxiety and Depression Scale. Acta Psychiatrica Scandinavica, 67(6), 361-370. 